Universidad de Lima

Facultad de Ciencias Empresariales y Económicas

Carrera de Economía

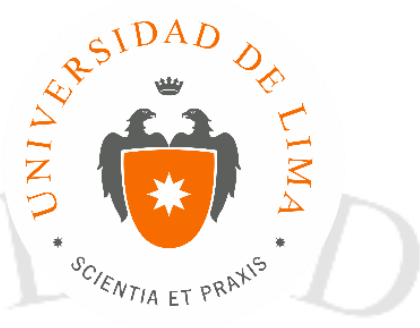

\title{
IRRACIONALIDAD FINANCIERA, EVIDENCIA PARA EL CASO PERUANO
} 2011-2015

Trabajo de investigación para optar el Título Profesional de Economista

\author{
Renzo Giovanni Milon Kahatt
}

Código 20111454

\section{Asesor}

Carlos Hugo Mendiburu Díaz

$$
\text { Lima - Perú }
$$

Diciembre de 2018 


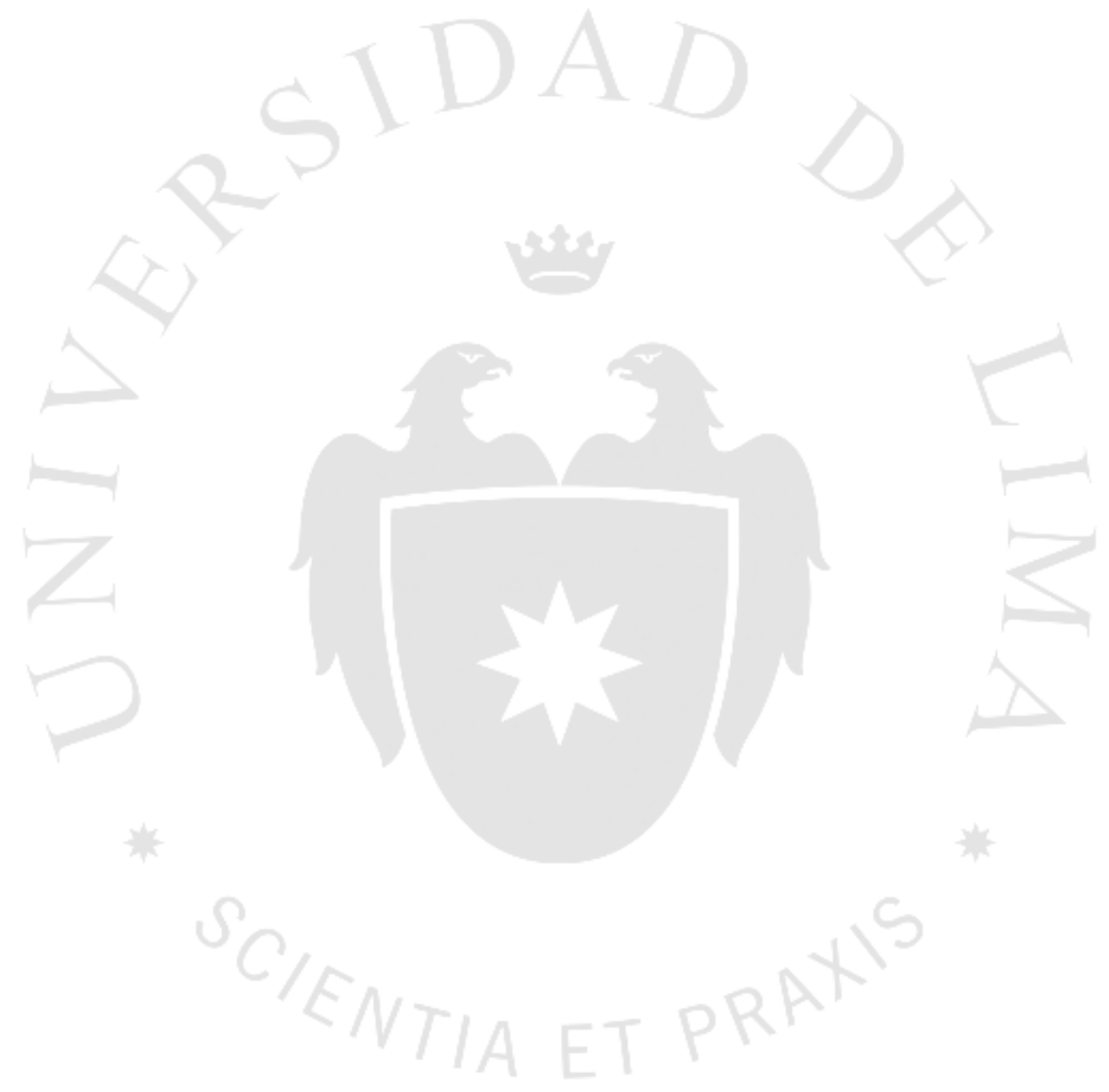




\section{IRRACIONALIDAD FINANCIERA,}

EVIDENCIA PARA EL CASO PERUANO

$$
\text { 2011-2015 }
$$




\section{TABLA DE CONTENIDO}

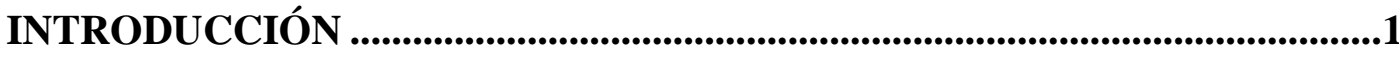

CAPÍTULO I: ESTADO DEL ARTE.................................................................7

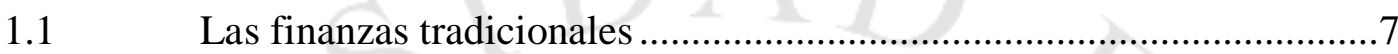

1.1.1 La hipótesis de eficiencia del mercado ........................................

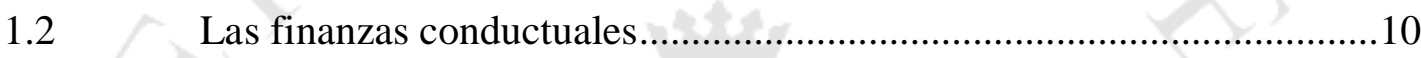

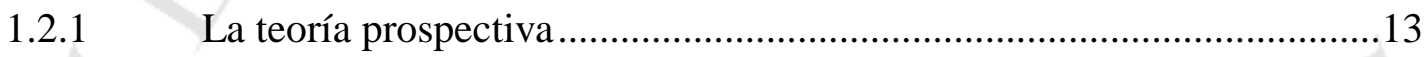

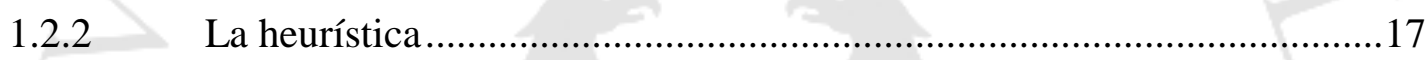

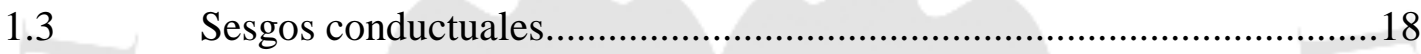

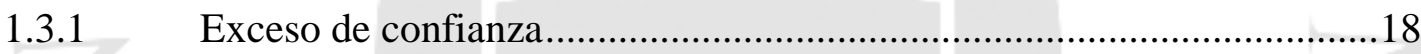

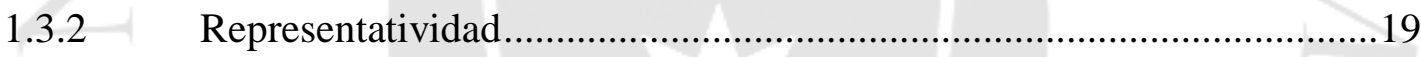

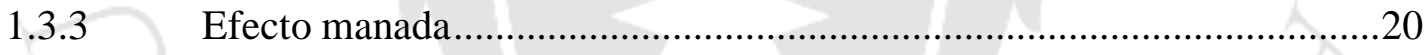

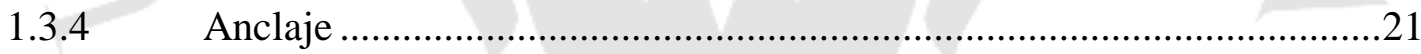

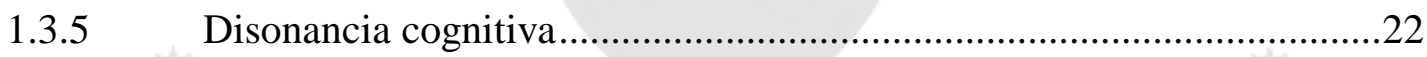

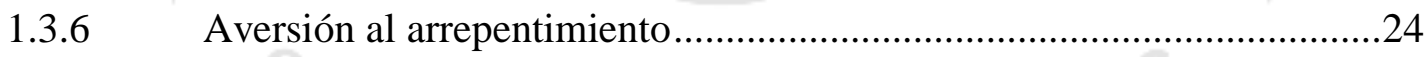

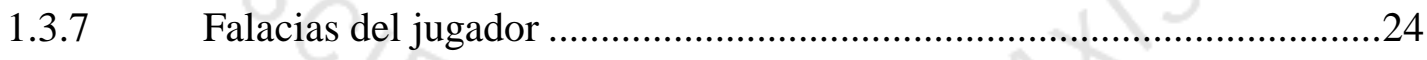

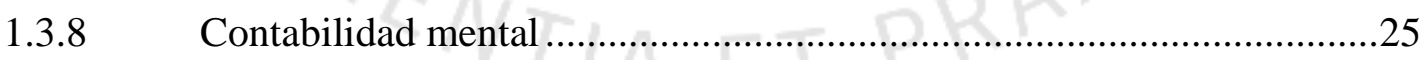

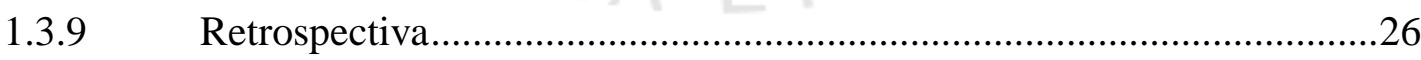

La teoría de "empujones": Nudge Theory ..........................................26

CAPÍTULO II: METODOLOGÍA DE ANÁLISIS .................................................30

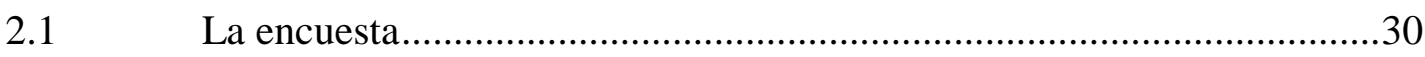

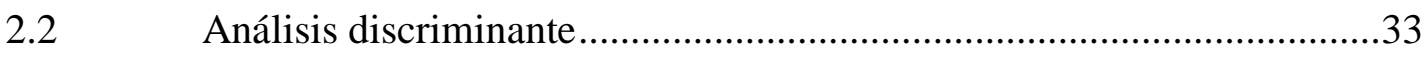




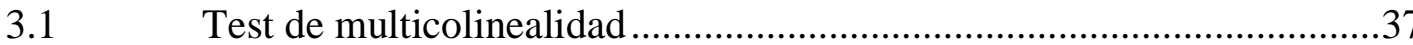

3.2 Efecto de la caída de la bolsa de valores de Lima en los portafolios......45

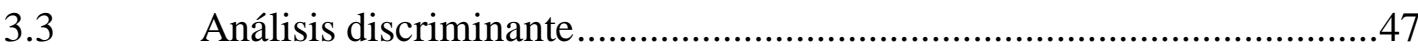

3.4 Impacto independiente de los sesgos conductuales ..............................54

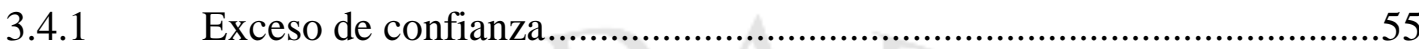

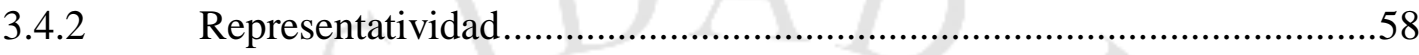

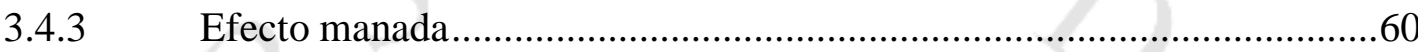

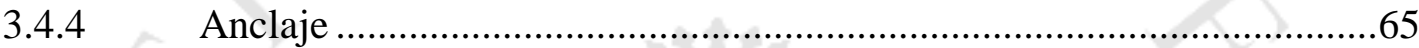

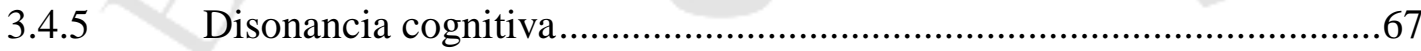

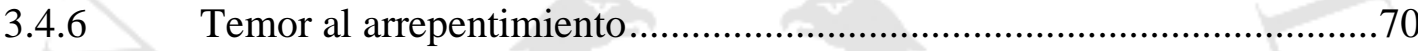

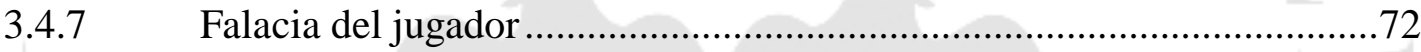

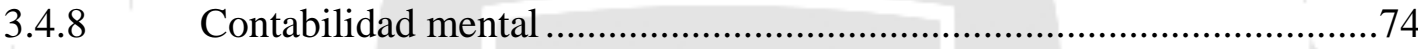

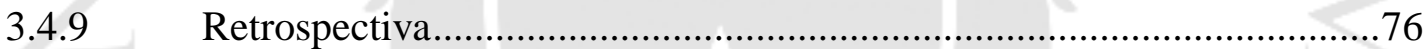

CAPÍTULO IV: RESUMEN DE RESULTADOS ...................................................79

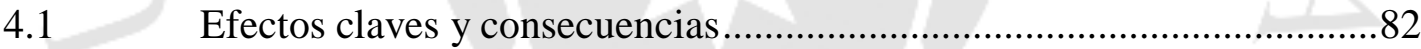

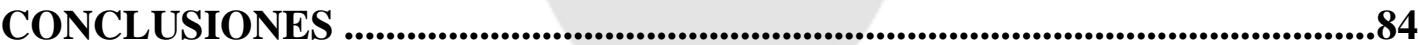

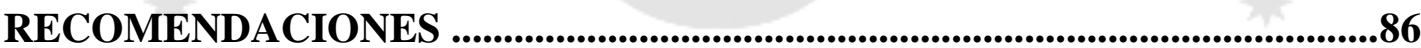

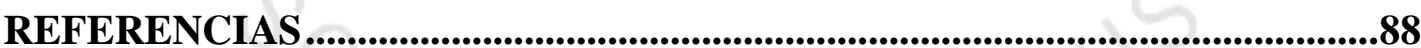

BIBLIOGRFÍA.................................................................94

ANEXOS 


\section{ÍNDICE DE TABLAS}

Tabla 3.1 Matriz de correlación de variables ......................................

Tabla $3.2 \quad$ Estadísticos de colinearidad (exceso de confianza) ...................41

Tabla 3.3 Estadísticos de colinearidad (representatividad)......................41

Tabla 3.4 Estadísticos de colinearidad (temor al arrepentimiento)................42

Tabla $3.5 \quad$ Estadísticos de colinearidad (efecto manada).........................42

Tabla 3.6 Estadísticos de colinearidad (anclaje)...........................43

Tabla $3.7 \quad$ Estadísticos de colinearidad (falacia del jugador) ......................43

Tabla 3.8 Estadísticos de colinearidad (contabilidad mental)..................44

Tabla 3.9 Pérdidas incurridas por grupos de inversionistas................... 45

Tabla 3.10 Test chi cuadrado (experiencia de los inversionistas y pérdidas del portafolio).......................................................46

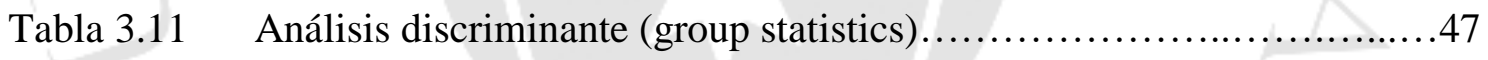

Tabla 3.12 Análisis discriminante (test de igualdad de medias) $\ldots \ldots \ldots \ldots \ldots \ldots \ldots . . .48$

Tabla 3.13 Análisis discriminante (prueba M de Box)..........................49

Tabla 3.14 Análisis discriminante (test de Wilk's Lambda)........................50

Tabla 3.15 Análisis discriminante (coeficientes estandarizados canónicos)..........51

Tabla 3.16 Análisis discriminante (matriz de estructura) .......................52

Tabla 3.17 Análisis discriminante (tabla de clasificación) ........................53

Tabla 3.18 Análisis discriminante (coeficientes canónicos no estandarizados) ......54

Tabla 3.19 Clasificación de las preguntas de la encuesta, según sesgo conductual..55

Tabla 3.20 Exceso de confianza - tabla de contingencia.........................56

Tabla $3.21 \quad$ Exceso de confianza - test chi-cuadrado I...........................56 
Tabla 3.22 Exceso de confianza - test chi-cuadrado II .57

Tabla 3.23 Exceso de confianza - puntajes ponderados..........................57

Tabla 3.24 Representatividad - tabla de contingencia.............................59

Tabla 3.25 Representatividad - puntajes ponderados..........................60

Tabla 3.26 Efecto manada preliminar - tabla de contingencia II..................61

Tabla 3.27 Efecto manada preliminar - tabla de contingencia II..................62

Tabla 3.28 Efecto manada preliminar - tabla de contingencia III..................63

Tabla 3.29 Efecto manada - tabla de contingencia.............................63

Tabla $3.30 \quad$ Efecto manada - puntajes ponderados..............................64

Tabla 3.31 Efecto manada - test chi-cuadrado................................65

Tabla 3.32 Anclaje - tabla de contingencia.................................66

Tabla 3.33 Anclaje - test chi-cuadrado.....................................67

Tabla 3.34 Anclaje - puntajes ponderados...................................67

Tabla 3.35 Disonancia cognitiva - tabla de contingencia.........................69

Tabla 3.36 Disonancia cognitiva - puntajes ponderados $\ldots \ldots \ldots \ldots \ldots \ldots \ldots \ldots \ldots . \ldots 6$

Tabla 3.37 Disonancia cognitiva - test chi-cuadrado.......................... 70

Tabla 3.38 Temor al arrepentimiento - tabla de contingencia.....................71

Tabla 3.39 Temor al arrepentimiento - test chi-cuadrado...........................71

Tabla $3.40 \quad$ Temor al arrepentimiento - puntajes ponderados.......................72

Tabla $3.41 \quad$ Falacia del jugador - tabla de contingencia I........................73

Tabla 3.42 Falacia del jugador - tabla de contingencia II........................ 73

Tabla $3.43 \quad$ Falacia del jugador - puntajes ponderados.......................... 74

Tabla 3.44 Contabilidad mental - tabla de contingencia ..........................75

Tabla 3.45 Contabilidad mental - test chi-cuadrado............................... 75

Tabla 3.46 Contabilidad mental - puntajes ponderados..........................76 
Tabla 3.47 Retrospectivo - tabla de contingencia I.

Tabla 3.48 Retrospectivo - tabla de contingencia II..........................77

Tabla 3.49 Retrospectivo - puntajes ponderados............................. 78

Tabla 4.1 Análisis discriminante - resumen de resultados........................80

Tabla 4.2 Método de puntajes ponderados - resumen de resultados...............81

Tabla 4.3 Pruebas chi-cuadrado - resumen tablas de contingencia...............81

Tabla $4.4 \quad$ Efectos y consecuencias - resumen............................. 82

Tabla 4.5 Conocimiento de las finanzas conductuales........................83 


\section{ÍNDICE DE FIGURAS}

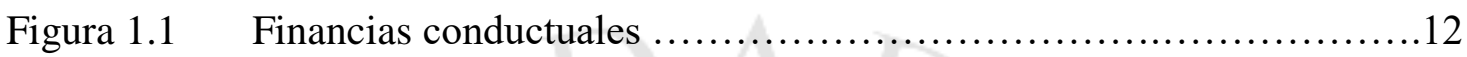

Figura 1.2 Función de utilidad de la teoría prospectiva......................... 16

Figura 3.1 Rango de edades de los inversionistas............................ 36

Figura 3.2 Separación de dato en dos sub muestras ............................... 


\section{ÍNDICE DE ANEXOS}

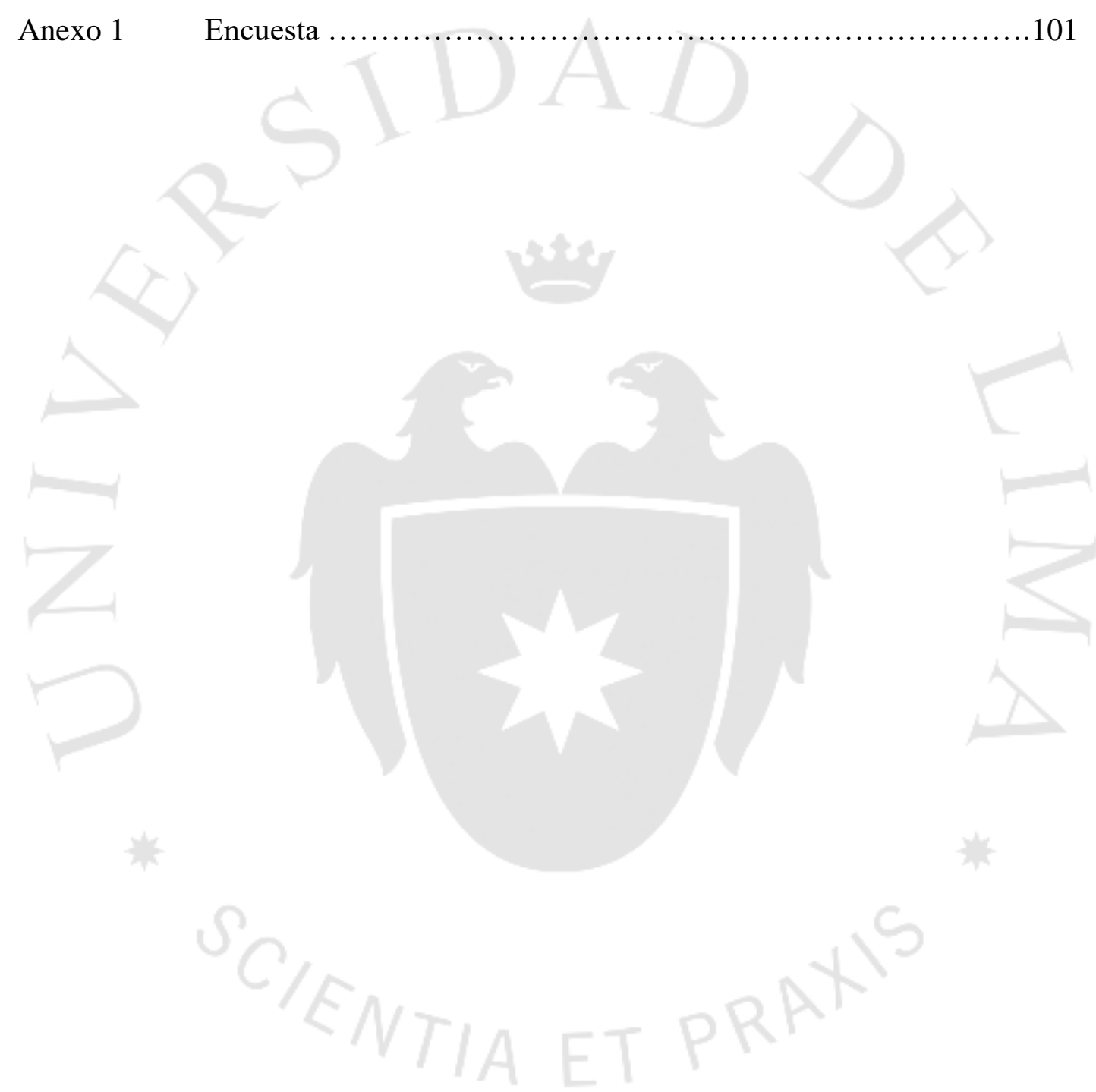




\section{INTRODUCCIÓN}

“The investor's chief problem - and even his worst enemy - is likely to be himself." - (Graham, 1949)

Desde la Crisis Mundial del 2008 los mercados financieros se han visto plagados por escenarios de alta volatilidad, miedo e incertidumbre.

Hoy en día muchos expertos y analistas tratan de entender estos mismos mercados utilizando distintos modelos de diversos grados de complejidad, pero siempre basados en una misma premisa central: Los inversionistas son personas "racionales".

De acuerdo a Nofsinger (2002) el campo de las finanzas ha evolucionado en las últimas décadas basado en la suposición de que las personas toman decisiones racionales y sus predicciones del futuro no están sesgadas. Se asume por lo tanto que los inversionistas toman decisiones meticulosas, económicamente calculadas y viables siempre. Sin embargo, esta suposición de racionalidad e imparcialidad en las personas ha sido cuestionada por psicólogos por mucho tiempo.

De acuerdo a $\operatorname{Thaler}^{1}$ (2005) un inversionista racional es alguien que:

- Al recibir nueva información, actualiza sus creencias de manera puntual y apropiada.

- Toma decisiones normativamente correctas.

Pero la realidad es otra, "La evidencia revela continuos patrones de irracionalidad, inconsistencia e incompetencia en la manera en que los seres humanos toman decisiones al ser sujetos a la incerteza" (Bernstein, 1998).

\footnotetext{
${ }^{1}$ Premiado con el premio Nobel de economía en 2017.
} 
En el periodo 1920-2015 se han presentado en el mundo más de 120 crisis financieras y 45 bancarias particularmente en los países emergentes, lo cual ha generado volatilidad, incertidumbre e inestabilidad en todo el mundo.

El ejemplo más grande, conocido y documentado de esto sucedió el 15 de septiembre del 2008 cuando una "anomalía de mercado" sacudió los cimientos de la economía mundial y provocó la Crisis Financiera más grande de la historia de la humanidad; ésta se originó en Estados Unidos y se expandió rápidamente causando estragos por todo el mundo.

Las finanzas conductuales nacen como una alternativa al paradigma vigente actual. Éstas argumentan que sin la suposición de "racionalidad" varios fenómenos financieros serían más comprensibles. La propuesta de esta nueva rama de la economía es simple: complementar y combinar los modelos de finanzas tradicionales con la psicología cognitiva con el objetivo de crear un modelo más completo del comportamiento humano en el proceso de toma de decisiones (Thaler, 2005).

Desde un punto de vista práctico, las finanzas conductuales permiten identificar ciertos conceptos que impulsan a los seres humanos a comportarse de manera irracional y esto los lleva a tomar decisiones sub óptimas.

Es claro por lo tanto que los seres humanos son susceptibles a diferentes sesgos conductuales; un ejemplo de esto es la anomalía llamada "Anchoring” o Anclaje que ocurre cuando un individuo confía demasiado en cierta información específica (llamada ancla) al tomar decisiones.

El inversionista peruano no debería ser la excepción y la alta volatilidad en el Índice General de la Bolsa de Valores de Lima (IGBVL) en el periodo entre 2005-2015 lo sugiere.

La presente tesis tiene como objetivo analizar la existencia y el impacto de factores conductuales en los procesos de toma de decisión de inversionistas peruanos; evaluando concretamente la presencia de sesgos conductuales y sus consecuencias en las decisiones de inversión. Todo esto con el fin de concientizar a los inversionistas, optimizar sus decisiones y limitar la proliferación de anomalías de mercado. 
Se buscó en primer lugar describir y analizar la evolución y las limitaciones de la teoría de finanzas conductuales en la identificación y cuantificación de 9 sesgos conductuales en inversionistas peruanos.

En total la presente tesis analiza los efectos de nueve sesgos conductuales: Exceso de confianza, representatividad, efecto manada, anclaje, disonancia cognitiva, aversión a las pérdidas, falacia del jugador, contabilidad mental y sesgo de disponibilidad.

El primer objetivo específico es identificar los sesgos que tengan mayor frecuencia e incidencia para reconocerlos y posiblemente establecer una estrategia para mitigar o controlar sus efectos.

El segundo objetivo específico es comparar los resultados obtenidos con el comportamiento del mercado financiero peruano.

La hipótesis principal de la tesis estipula que existen ciertos sesgos conductuales que afectan las decisiones de inversionistas peruanos y la generalización de éstos puede ocasionar anomalías de comportamiento en la Bolsa de Valores de Lima (BVL).

La primera hipótesis específica es que el número de años de experiencia de los inversionistas considerados no reduce la frecuencia y la incidencia de los sesgos conductuales en la toma de decisiones.

La segunda hipótesis específica considera que los sesgos conductuales que se presentan con mayor frecuencia son "efecto manada", "exceso de confianza" y anclaje" sesgos que pueden generar burbujas y caídas de precios en el mercado de valores peruano.

La fuente primaria de información ha sido obtenida utilizando un cuestionario que fue repartido virtualmente de manera individual a cada uno de los inversionistas a analizar. Para lograr los objetivos previamente identificados se analizó el periodo 20002015.

Esta investigación ha tomado como referencia e inspiración la investigación realizada por Rahul Subash "Role of Behavioral Finance in Portfolio Investment Decisions: Evidence from India” entre 2011-2012 y publicada por la Charles University de Praga. 
La metodología de análisis y la elaboración de las encuestas han sido tomadas del estudio mencionado anteriormente, que buscaba analizar la presencia de 9 sesgos conductuales en una muestra de inversionistas indios.

El perfil de la muestra son inversionistas individuales, brokers, agentes o representantes de bancos de inversión y/o fondos mutuos y estudiantes universitarios que tengan un historial real de transacciones en la BVL y conocimientos de mercado de capitales.

Se utilizaron las encuestas para obtener ideas y percepciones de la experiencia de los participantes en función a su conducta y decisiones de inversión. Estas preguntas han sido adaptadas del cuestionario realizado por Subash (2012).

Se eligió este método para recopilar data primaria por tres razones principales:

i. Es una manera práctica de acercarse a inversionistas reales y permite obtener ideas en base a sus experiencias pasadas.

ii. Es más factible que los inversionistas provean información confiable ya que la naturaleza de la encuesta es anónima.

iii. No existe en Perú ninguna base de datos o fuente de información académica o privada de donde se pueda tomar datos relacionados a finanzas conductuales.

En esta investigación se realizó un estudio comparativo para categorizar inversionistas entre jóvenes y experimentados, para determinar analíticamente factores que puedan identificar similitudes o diferencias entre patrones específicos de comportamiento.

El cuestionario realizado mediante una encuesta simplifica la logística de la recopilación de información. Esto también ha permitido no comprometer el tiempo de los inversionistas y darles la libertad para que contesten las preguntas cuando puedan darse el tiempo, lo que ha permitido una mejor disposición para responder las preguntas realizadas.

El perfil de la muestra ha sido creado en base a un criterio, el número de años de experiencia en la bolsa de valores, debido a que se considera que estos influyen en la manera en que los sesgos conductuales afectan a los inversionistas. La muestra ha sido 
partida en dos grupos de inversionistas para obtener inversionistas jóvenes e inversionistas experimentados.

El periodo 2000-2015 es apropiado para el análisis ya que ha sido para Perú un periodo de crecimiento pero con importantes fluctuaciones, debido a cambios en el entorno internacional y a factores internos.

Si bien el entorno ha sido relativamente estable económicamente para el Perú, nos ha provisto de información que cuenta con decisiones de inversionistas durante periodos de crecimiento y bonanza económica general pero también de crisis internacional en los mercados financieros y desaceleración económica.

La data recolectada ha sido procesada utilizando herramientas como promedios ponderados, porcentajes, técnicas de escalamiento en $\operatorname{SPSS}^{2}$ y el análisis discriminante.

Se han codificado 10 variables en SPSS, una de ellas dicotómica que representa el grupo al que pertenece el inversionista, las 9 restantes corresponden cada una a un sesgo conductual, estas han sido creadas mediante técnicas de escalamiento como 3-point y 5-point Likert y también mediante media aritmética. Se ha realizado un análisis que permite eliminar la posibilidad de multicolinealidad, y un análisis discriminante para comprobar si los sesgos conductuales afectan de manera diferenciada a los inversionistas jóvenes frente a los inversionistas experimentados.

\section{Descripción de capítulos:}

En el primer capítulo se tocarán aspectos relevantes acerca de la teoría clásica económica, la hipótesis de eficiencia de mercado e introducción a las Finanzas Conductuales, específicamente se tratan los temas de anomalías de mercado, los procesos de toma de decisiones y la teoría de "empujones”; en el segundo capítulo se explicará la metodología de análisis donde se incluye el diseño de la investigación, el perfil de la muestra, la recolección de datos y los métodos empleados; en el tercer capítulo se presentará un análisis empírico de los datos y el procesamiento de los mismos; en el cuarto capítulo se presentará el impacto de los sesgos conductuales y sus consecuencias en los

\footnotetext{
${ }^{2}$ IBM SPSS Statistics.
} 
inversionistas analizados; finalmente en el último capítulo se presentará un resumen de los resultados, las conclusiones y las recomendaciones.

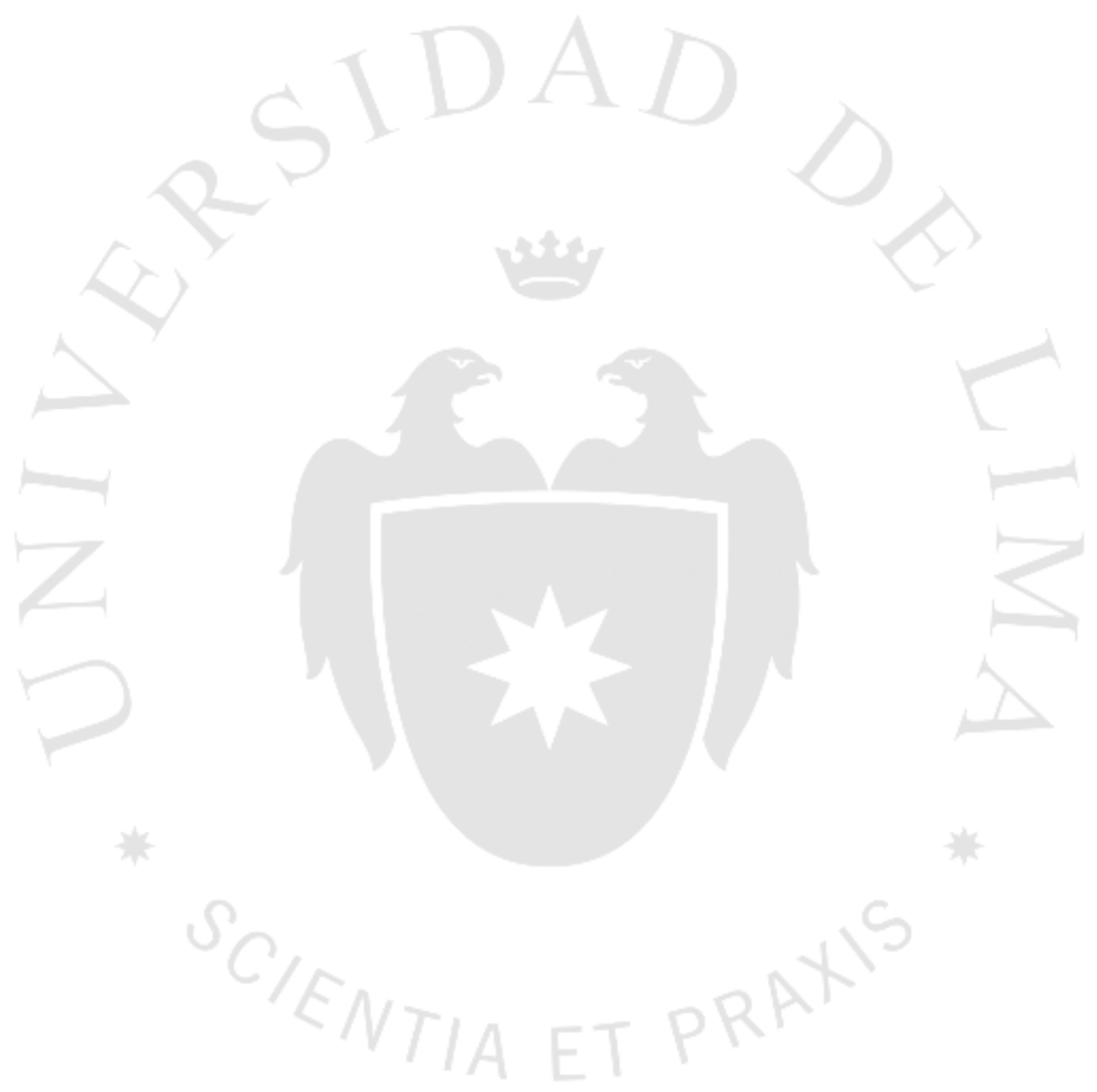




\section{CAPÍTULO I: ESTADO DEL ARTE}

\subsection{Las finanzas tradicionales}

Según Rahul Subash (2012) hay dos paradigmas clave dentro de la teoría tradicional de las finanzas:

i. Los agentes son perfectamente racionales: esto implica que toda nueva información disponible es interpretada correcta y uniformemente por todos los agentes al actualizar sus creencias.

ii. Los mercados son eficientes: La hipótesis de eficiencia de mercado estipula que toda información relevante será reflejada en los precios de mercado de manera instantánea y completa (Fama, 1965). Si esta hipótesis se cumpliera no existiría ninguna decisión de inversión o estrategia que logre obtener consistentemente rentabilidades por sobre el promedio de mercado.

A pesar de esto en los mercados de valores de todo el mundo existen y se presentan anomalías y comportamientos que no pueden ser explicados bajo las finanzas tradicionales.

Algunos ejemplos de estas anomalías son:

i. El Efecto Enero, durante los últimos días del mes de diciembre las cotizaciones de ciertas empresas en la bolsa tienden a bajar. Esto produce en los primeros días del mes de enero rentabilidades anormalmente elevadas. Por lo tanto, en este caso los precios de una acción se incrementan sin fundamentos económicos. Esta anomalía fue observada por primera vez en 1942 por el banquero Sidney B. Wachtel.

ii. La Maldición del Ganador, cuando el ganador de una subasta termina habiendo pagado un precio mayor al valor intrínseco de un bien principalmente debido a información incompleta y la sobreestimación del valor del bien por su parte y de sus competidores (Thaler R. , 1988).

iii.Efecto Tamaño: Este se da cuando los rendimientos de empresas de menor tamaño superan los rendimientos de empresas de mayor tamaño incluso luego 
de ajustar el rendimiento al riesgo relativo. Esto podría ocurrir si el modelo $\mathrm{CAPM}^{3}$ no refleja correctamente el mayor riesgo correspondiente a invertir en empresas de menor tamaño.

iv. Efecto cambio del mes: Las acciones suelen brindar rendimientos positivos los últimos días de un mes y las primeras dos semanas del siguiente.

v. Efecto PER: El Ratio Precio-Beneficio (PER), es el ratio obtenido de la división del precio de una acción entre la utilidad por acción que genera dicha acción. Este ratio mide la relación entre el precio de una acción y el beneficio que ofrece al accionista, es decir cuántas veces se paga el beneficio neto anual con el precio unitario de una acción. La anomalía se refiere a que acciones con un ratio PER bajo proporcionan rentabilidades superiores al promedio.

\subsubsection{La hipótesis de eficiencia del mercado}

An 'efficient' market is defined as a market where there are large numbers of rational, profit-maximizers actively competing, with each trying to predict future market values of individual securities, and where important current information is almost freely available to all participants. In an efficient market, competition among the many intelligent participants leads to a situation where, at any point in time, actual prices of individual securities already reflect the effects of information based both on events that have already occurred and on events which, as of now, the market expects to take place in the future. In other words, in an efficient market at any point in time the actual price of a security will be a good estimate of its intrinsic value." (Fama, 1965)

La hipótesis de eficiencia de mercado es uno de los principales fundamentos de las finanzas tradicionales, esta hipótesis fue desarrollada en "Random Walks in Stock Market Prices" en 1965 por el profesor Eugene Fama y finalmente publicada en "Efficient Capital Markets" en 1970.

\footnotetext{
${ }^{3}$ El Modelo de Capital Asset Pricing Model o (CAPM), creado por William Sharpe y publicado en 1970 en el libro "Portfolio Theory and Capital Markets" es un modelo que ayuda a los inversionistas a calcular el riesgo de una inversión y cuál debería ser el retorno esperado por esa inversión.
} 
Con Random Walks in Stock Market Prices (1965) Fama apoya el modelo de "Caminatas Aleatorias" como una mejor alternativa ante los modelos de predicción de precios en el mercado de valores. Estos modelos previos eran el análisis técnico y el análisis fundamental. El análisis técnico y el análisis fundamental son dos técnicas de predicción de los precios futuros de las acciones mediante dos métodos diferentes: El análisis técnico parte de la premisa de que la historia tiende a repetirse y por lo tanto existen patrones identificables en el comportamiento del precio de las acciones que permitirían "predecir" en cierta medida el comportamiento futuro de una acción mediante su comportamiento pasado. Por otro lado, el análisis fundamental parte de la suposición de que toda acción tiene un valor intrínseco en un momento del tiempo, este valor depende de las ganancias potenciales que esta acción puede generar y ya que el precio de la acción depende de factores como la gestión de la empresa, la industria, la economía, etc, es posible analizar estos factores para determinar si el valor de la acción en el mercado es mayor o menor a este valor intrínseco para predecir si el precio de la acción en el futuro aumentará o caerá.

El modelo de "Caminatas Aleatorias" explicado por Fama (1965) propone que en un mercado eficiente existe un gran número de actores racionales tratando de maximizar su utilidad al predecir los valores futuros de acciones en el mercado, en un ambiente donde la información es gratis y disponible para todos. La competencia entre los participantes crea una situación en la cual en todo momento el precio de una acción refleja su valor intrínseco ya que se basan en la información disponible y en las expectativas futuras. En el caso de que ciertos inversionistas sean irracionales el arbitraje racional del resto eliminaría la influencia de los inversionistas irracionales sobre el precio. Por otro lado, si los inversionistas racionales trataran de tomar ventaja sobre estos conocimientos sus acciones terminarían por neutralizarse unas a otras sin afectar los precios (Fama, 1965).

La teoría de caminatas aleatorias propone que los cambios sucesivos de precios son independientes y por lo tanto el pasado no puede predecir el futuro ya que los precios históricos, los retornos y otra información son incorporados completamente en los precios, lo que haría imposible la posibilidad de obtener retornos basados en el análisis técnico. Por otro lado, el análisis fundamental sería completamente innecesario en un mercado de caminatas aleatorias debido a que sería imposible para un inversionista 
obtener retornos superiores a la media mediante el uso de información disponible al público ya que esta se incorpora inmediatamente en los precios. En el caso hipotético de que los analistas fueran capaces de predecir la ocurrencia de ciertos eventos que afecten el valor intrínseco de una acción esto no correspondería a individuos aislados y en conjunto estos individuos beneficiarían conjuntamente al resto de inversionistas incorporando la información rápidamente. En un mercado de caminatas aleatorias por lo tanto un inversionista mediocre produciría el mismo retorno que un analista altamente calificado.

Esta hipótesis guarda una estrecha relación con la idea de caminatas aleatorias en la definición de precios de mercado. Luego de casi 46 años la hipótesis de eficiencia de mercado continúa siendo uno de los paradigmas financieros centrales de las finanzas tradicionales.

\subsection{Las finanzas conductuales}

Las finanzas conductuales son una nueva rama de la economía que integra las finanzas, la psicología y la sociología para estudiar ciertos elementos, patrones y anomalías que las finanzas tradicionales no han logrado explicar satisfactoriamente. Las finanzas conductuales rompen con los paradigmas tradicionales de las finanzas ya que incorporan conceptos y modelos significativamente diferentes. Uno de los factores clave que las diferencian es que las finanzas conductuales presentan un enfoque donde se pone en tela de juicio la supuesta "racionalidad" de los individuos en el momento de tomar decisiones de inversión. A los seres humanos les preocupan y afectan muchos elementos además de la utilidad esperada y el riesgo inherente. Existe una infinidad de otros factores que afectan directamente los procesos cognitivos ya que todo tipo de decisión humana incluye un proceso emocional y las decisiones de inversión no son la excepción. Se cree que esta nueva visión del comportamiento humano es capaz de explicar anomalías de mercado, detectar sesgos conductuales en las decisiones de inversión de los inversionistas y de cierta manera ayudar a mitigarlos.

De acuerdo a la propuesta realizada por Schindler (2007 citado en Cano \& Cardoso, 2015) hay tres pilares sobre los que se basan las finanzas conductuales: 
1. Límites al arbitraje $^{4}$ : En un ambiente donde individuos racionales e irracionales interactúan el efecto del comportamiento irracional tiene un impacto substancial en los precios. Por lo tanto, en las finanzas conductuales se busca explicar oportunidades de arbitraje que no desaparecen rápidamente.

2. Psicología: Para explicar la irracionalidad de los inversores y su proceso de toma de decisiones las finanzas conductuales se basan en la evidencia recopilada por la psicología cognitiva y en los sesgos que nacen cuando las personas forman sus creencias y preferencias, y en la forma en que toman decisiones de inversión a partir de éstas, ver Barberis \& Thaler (2003 citado en Cano \& Cardoso, 2015).

3. Sociología: A pesar de que en teoría cada inversionista toma decisiones individuales sin influencia externa, en la práctica esto no se aplica. Se ha comprobado que las transacciones financieras y los movimientos de los mercados son fenómenos fundamentalmente sociales, en la medida de que las personas actúan y transan en los mercados financieros de manera colectiva e influenciados por el comportamiento de otros actores, la sociología cobra importancia como disciplina dentro de las finanzas conductuales.

Las finanzas conductuales por lo tanto son una integración multidisciplinaria de la psicología, la sociología y la teoría financiera con el objetivo de comprender cómo los factores conductuales y sociales afectan los procesos de toma de decisiones financieras de los agentes económicos, y de esta manera, se puede llegar a desarrollar una comprensión más profunda y rica de los mercados financieros.

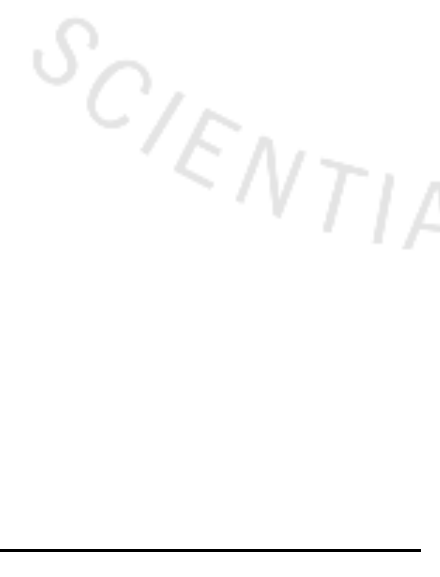

${ }^{4}$ El arbitraje en economía y finanzas es la práctica que permite obtener una utilidad instantánea y libre de riesgo debido a un desequilibrio de precios entre dos o más mercados. 


\section{Figura 1.1}

Finanzas conductuales

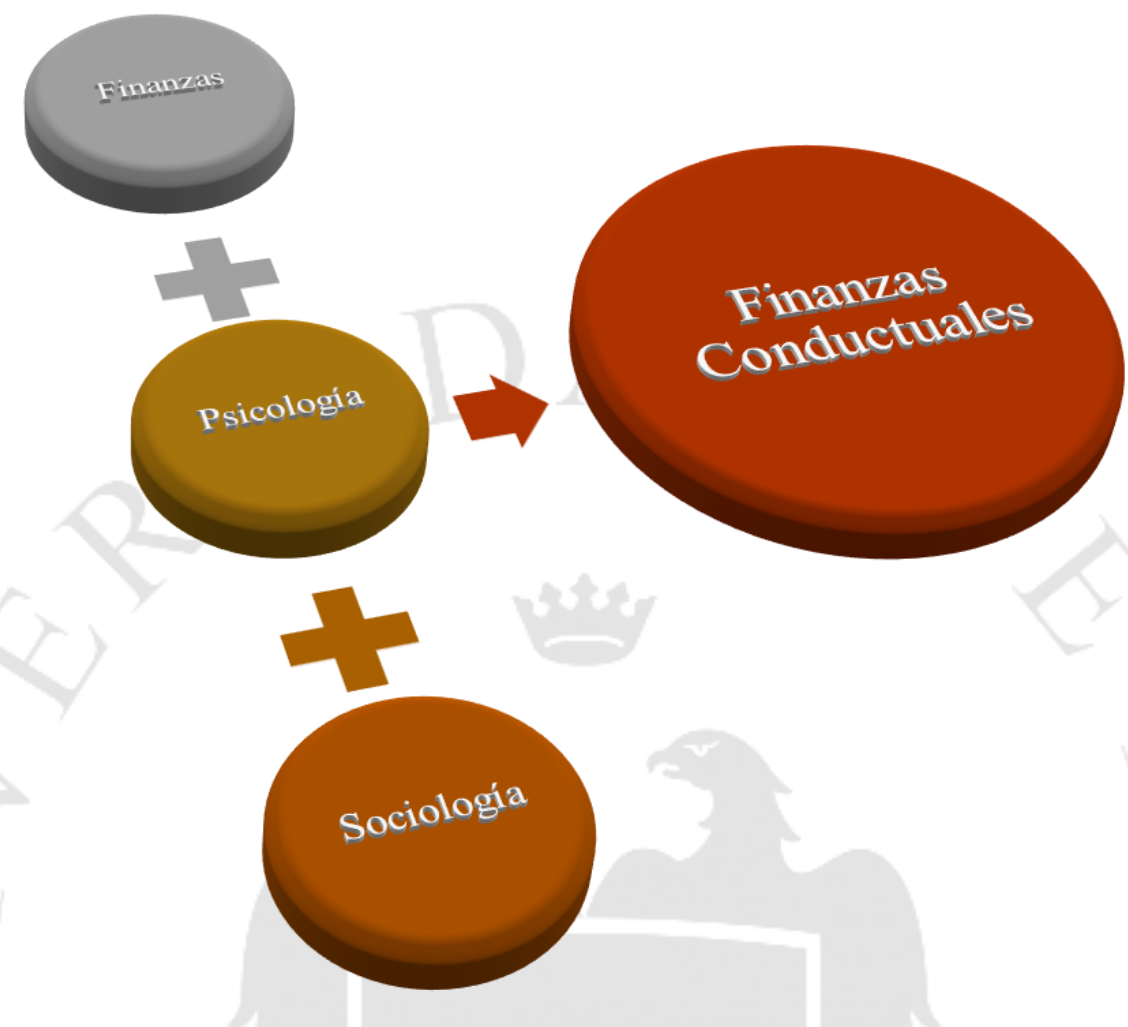

Fuente: Schindler (Rumors in Financial Markets: Insights into Behavioral Finance, 2007) elaboración propia. Revisado en abril 2016.

De acuerdo a Cano \& Cardoso (2015) existen tres puntos claves que diferencian las finanzas conductuales de las finanzas tradicionales:

i. Racionalidad del Inversor: La hipótesis de eficiencia de mercado asume que los agentes económicos buscan maximizar su utilidad y toman decisiones óptimas basándose en un análisis de costo y beneficio. Las finanzas conductuales por su parte han documentado una significativa serie de desviaciones acerca de la racionalidad de mercado, estas desviaciones son los sesgos conductuales que se presentan cuando el proceso de toma de decisiones se realiza bajo incertidumbre y conducen normalmente a resultados no deseados.

ii. Eficiencia Informativa: En la realidad los precios no reflejan toda la información relevante, existe información pública y privada que no logra reflejarse correctamente muchas veces. 
iii. El rol de la información en el proceso de toma de decisiones: Para la hipótesis de eficiencia de mercado la información es el único factor que influencia la toma de decisiones, sin embargo, las finanzas conductuales incorporan otros factores (psicológicos, cognitivos y conductuales) los cuales también afectan el proceso de toma de decisiones de los agentes.

\subsubsection{La teoría prospectiva}

Esta teoría fue concebida originalmente por Kahneman y Tversky en 1979, posteriormente en el 2002 Daniel Kahneman fue premiado con el premio Nobel en economía por sus descubrimientos.

La teoría es desarrollada para prospectos simples con resultados monetarios y probabilidades definidas.

Esta teoría identifica dos fases diferentes en el proceso de toma de decisiones, una fase de edición o también conocida como framing o "encuadre" y la segunda consiste en una fase de evaluación.

En el ámbito de la teoría social se denomina encuadre (en inglés, frame) a un esquema de interpretación o una colección de anécdotas y estereotipos, sobre los cuales se basan los individuos para entender y responder ante eventos o determinadas situaciones (Goffman, 1974). En la fase de edición o encuadre el individuo realiza una fase preliminar de análisis de los prospectos ofrecidos, en ésta normalmente el agente simplifica mentalmente cada posible decisión, lo cual lo ayuda a decidir. En la segunda fase los modelos creados por el individuo son evaluados y se elige el prospecto que permite obtener la máxima utilidad. De esta manera la fase de edición sirve para organizar y reformular las opciones "encuadrándolas", de manera que se cree un método que permita simplificar decisiones posteriores.

La teoría prospectiva evidencia mediante experimentos empíricos que las personas subestiman los resultados probables en comparación a los que son seguros. Esto se debe a que tienden a darle mayor importancia o "peso" a los resultados percibidos con mayor certeza respecto a los que se consideran solo probables. Esto explica la aversión al riesgo en el caso de que las ganancias sean seguras y una interesante atracción hacia el 
riesgo en alternativas que presentan pérdidas probables y no certeras, esto es llamado por los autores "efecto reflejo" (Kahneman \& Tversky, 1979).

Esta teoría demuestra irregularidades en el comportamiento humano cuando existe la necesidad de tomar decisiones concernientes a riesgos bajo condiciones de incertidumbre. Las personas terminan dándole mayor peso a los resultados que son percibidos como "ciertos" con respecto a los que se consideran solo probables. Esto es conocido como "efecto certeza" (Kahneman \& Tversky, 1979).

La teoría también presenta evidencia de que los agentes muchas veces no analizan la posición final de beneficio en la que se encuentran, sino que consideran ganancias y pérdidas en función a algún punto de referencia subjetivo. Este punto de referencia debería corresponder a la situación actual de un activo, pero en muchos casos no lo es ya que este punto es afectado por las expectativas del agente o por la formulación de los prospectos creados.

La función de maximización de utilidad por lo tanto es diferente. En la teoría moderna de portafolio la maximización de utilidad se basa en la posición final de bienestar mientras que en la teoría prospectiva las continuas ganancias y pérdidas importan. Esto implica que las personas toman decisiones diferentes para situaciones que aportan niveles de bienestar final idénticos. Las ganancias y pérdidas terminan siendo medidas en base a un punto de referencia neutro y los cambios son medidos en términos relativos en vez de absolutos Kahneman \& Tversky (1979).

Odean (1998) explica que una de las implicaciones de la teoría prospectiva es que cuando los agentes se encuentran frente una decisión que involucra dos o tres resultados potenciales simples, estos se comportan como si maximizaran una función de utilidad en forma de S. Esta función se define bajo un enfoque de ganancias y pérdidas y no bajo niveles de utilidad, es cóncava en el cuadrante de las ganancias (lo que implica aversión al riesgo) y convexa en el de pérdidas (lo que implica que se es amante al riesgo). Además de esto la función es más empinada para las pérdidas que para las ganancias lo cual refleja que la mayor cantidad de agentes son adversos al riesgo.

Un interesante ejemplo que permite una mejor comprensión de este comportamiento es el experimento conducido por Kahneman y Tversky (1981): 
En este experimento se presenta el siguiente problema bajo dos formas o encuadres: Se espera que una enfermedad contagiosa mate a 600 personas, se crean dos programas para combatirla, pero solo se puede implementar uno. En el primero (A) 200 personas serán salvadas, en el programa (B) existe $1 / 3$ de probabilidad de salvar a 600 personas y $2 / 3$ de que ninguna sea salvada. El 72\% de los participantes en el estudio eligieron la opción A lo que demuestra que son adversos al riesgo aún ante la opción de B que da la misma utilidad esperada 1/3 de salvar a 600. En teoría los individuos racionales no deberían cambiar sus decisiones ante cambios en la formulación de un problema si los resultados son los mismos, pero en el segundo experimento brindó respuestas completamente opuestas al primero. Para el mismo problema, si se aplica el programa (C) 400 personas morirán y si se aplica el programa (D) existe 1/3 de probabilidad de que nadie muera y 2/3 de probabilidad de que los 600 mueran. El 78\% de los participantes eligió la opción D ya que la certeza de la muerte de 400 es menos aceptable que la probabilidad de que 600 mueran. Por lo tanto, los participantes ante este problema se convirtieron en buscadores de riesgo solo con el cambio de la formulación del problema. Si nos damos cuenta los problemas (A) y (C) así como (B) y (D) son idénticos solo cambiando la formulación. En (A) y (B) se habla de personas salvadas (ganancia) y en (B) y (D) se habla de personas muertas (pérdida). 
Figura 1.2

Función de utilidad de la teoría prospectiva

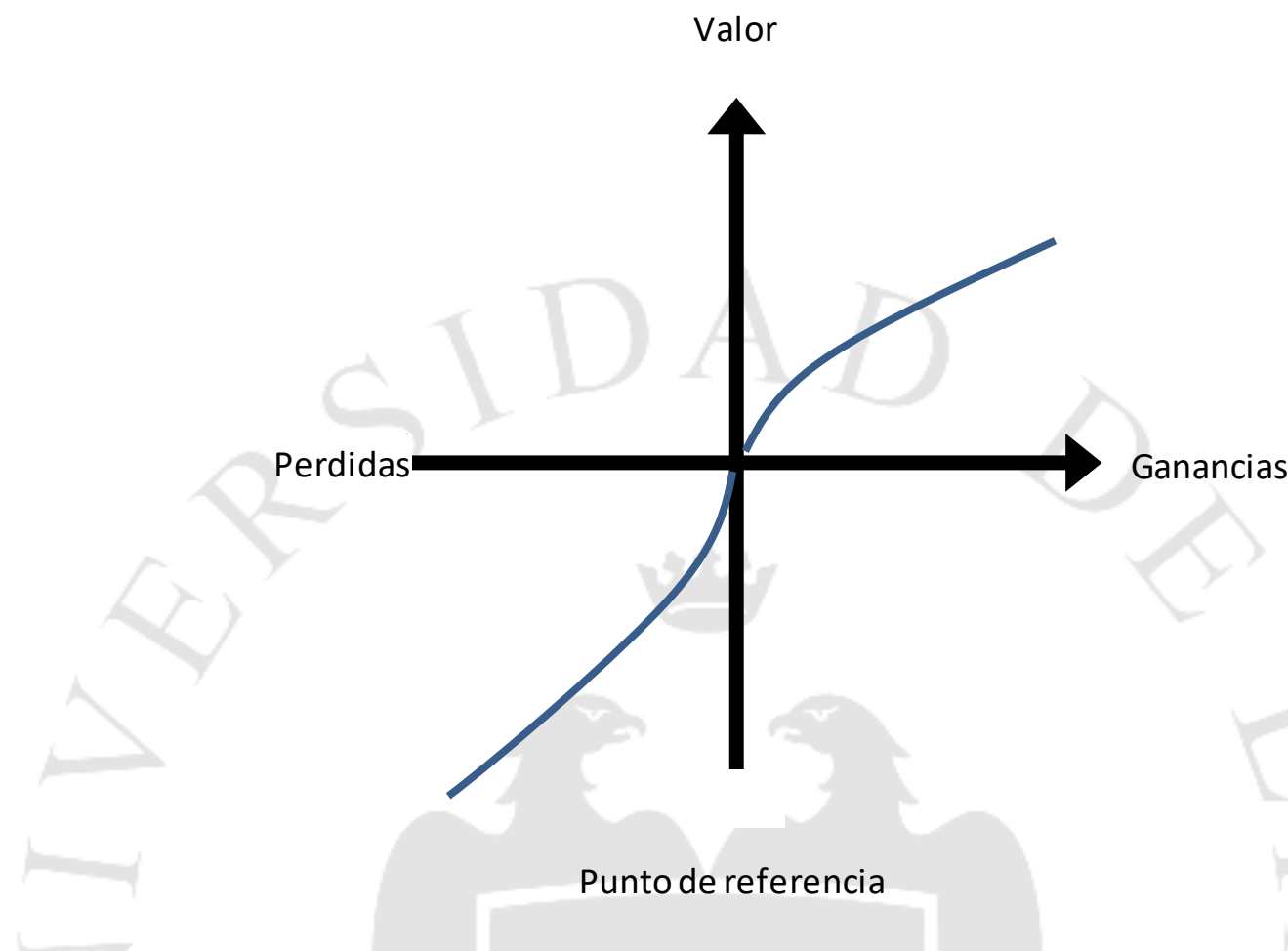

Fuente: Kahneman \&Tversky 1979, elaboración propia, abril 2016.

La forma de la función implica que un cambio determinado en ganancias o pérdidas tiene menor efecto en el valor experimentado por el inversionista cuando la distancia del punto de referencia es grande. Por ejemplo, si una persona ha sufrido grandes pérdidas en operaciones recientes presenta una mayor probabilidad de asumir niveles de riesgo que serían impensables en otro momento, todo con el objetivo de recuperar su capital (Odean T. , 1998).

Otro elemento interesante de la teoría prospectiva de Kahneman y Tversky es que considera que los individuos reemplazan las probabilidades por decisiones ponderadas. Es decir, si a un agente se le presentan dos decisiones diferentes, cada una con una probabilidad de suceso, estas probabilidades no serán utilizadas concretamente por el individuo ya que a partir del punto de referencia que este utilice cada probabilidad se transforma en una decisión ponderada creada por el agente. Estas decisiones ponderadas son generalmente menores a sus probabilidades correspondientes, con excepción a cuando las probabilidades se encuentran en un rango muy bajo. En la teoría prospectiva 
el valor de cada resultado es multiplicado por la decisión ponderada (el peso otorgado a dicha decisión), estos pesos son creados por los agentes de manera subjetiva, pero cabe resaltar que no son probabilidades propiamente dichas y no deberían ser interpretadas como medidas de rango o confianza (Kahneman \& Tversky, 1979).

\subsubsection{La heurística}

La heurística en resolución de problemas consiste en un procedimiento mediante el cual las personas resuelven problemas particulares. Este proceso mental ha sido reconocido y estudiado en psicología debido a que está presente en muchas de nuestras decisiones cotidianas y también en ciertas decisiones particulares.

Algunos autores como Daniel Kahneman y Amos Tversky definen la heurística como "reglas" simples y eficientes que las personas establecen para resolver problemas complejos o sobre los cuales no existe información completa. Por lo tanto, en sí la heurística puede ser descrita como una estrategia o "atajos" que ayudan a los agentes a tomar decisiones sin involucrar muchos recursos mentales. Un ejemplo de "atajos heurísticos" son los estereotipos, estos son modelos pre establecidos por los agentes que les permiten agilizar la toma de decisiones sin realizar extensos análisis.

Shefrin en su libro Beyond Greed and Fear (2000) presenta un concepto interesante de Heurística: El ser humano, muchas veces no es capaz de procesar toda la información que se le presenta diariamente. Al acumular experiencia, esta da la impresión de saber cómo funciona algo. Por lo tanto, se piensa o asume mediante la creación de una "regla de oro" que la solución puede ser similar a la ya encontrada anteriormente por lo tanto al presentarse una situación similar, la regla se aplica. Este fenómeno se llama Heurística y es especialmente relevante en los procesos de compra y venta actuales, cuando el número de instrumentos y la cantidad de información son extenuantes. El atractivo de esta técnica es el ahorro de tiempo que puede permitir y el principal problema es la dependencia de experiencia previa. Los modelos tradicionales de finanzas excluyen la heurística y asumen que todas las decisiones se realizan en base a herramientas estadísticas racionales como citado por Rahul Subash en (2012).

Shefrin (2000) explica que las simplificaciones heurísticas producen que los precios de mercado se desvíen de sus valores fundamentales. Por lo tanto, la heurística 
en finanzas conductuales es otra teoría que se complementa con la Teoría Prospectiva para estudiar el comportamiento del ser humano.

\subsection{Sesgos conductuales}

Como se ha explicado anteriormente, los individuos no siempre actúan de forma "racional" cuando deben tomar decisiones inciertas, la psicología y las finanzas conductuales identifican ciertos patrones que impulsan errores cognitivos en los agentes, es decir decisiones "irracionales".

Si bien hasta el momento no se ha logrado presentar una teoría general que explique concretamente porque las personas operan bajo ciertos sesgos, hay muchos estudios que los identifican y caracterizan (Cano \& Cardoso, 2015).

A continuación, se procederá a describir y explicar nueve sesgos conductuales considerados como los más representativos e importantes para el presente estudio.

\subsubsection{Exceso de confianza}

"En su forma más básica, el exceso de confianza puede ser resumido como una fe injustificable en el razonamiento intuitivo propio, nuestro propio juicio y nuestras habilidades cognitivas" (Pompian, 2006). Psicólogos como Daniel Kahneman han determinado que este sesgo causa que las personas sobre estimen sus propios conocimientos, subestimen riesgos y exageren sus habilidades para controlar eventos. Este concepto de exceso de confianza proviene de una gran cantidad de experimentos psicológicos cognitivos y mediciones en las cuales los sujetos sobre estiman tanto sus propias habilidades de predicción como la precisión de la información que se les fue brindada. Los resultados muestran que las personas se desempeñan pobremente en la determinación y calibración de estimados probabilísticos, ocurre muchas veces que dan por ciertos eventos cuya probabilidad de ocurrencia es mucho menor al $100 \%$. En 
resumen, las personas piensan que son más inteligentes y que tienen mejor información de la que realmente poseen (Pompian, 2006).

Para Shefrin (2000), el exceso de confianza "Atañe a que tan bien las personas entienden sus propias habilidades y los límites de su conocimiento". Individuos que presentan este sesgo piensan, muchas veces, que tienen más conocimientos de los que en realidad tienen. Esto no significa que los individuos sean ignorantes o incompetentes, simplemente postula que su visión de sí mismos es mejor de la realidad. Este rasgo se observa más comúnmente cuando los inversionistas eligen stocks o deciden las posiciones de entrada y salida. Estas tendencias fueron estudiadas por Odean (1998) quien encuentra que uno de los mayores efectos del exceso de confianza es que producía que los agentes realicen un número excesivo de intercambios que tendían a tener resultados significativamente menores a los rendimientos del mercado.

Es interesante observar que Barber y Odean (2001) realizaron un estudio para inversionistas basado en género y obtuvieron resultados en los cuales se documentaba que el exceso de confianza aumentaba excesivamente la cantidad de intercambios, los hombres en promedio realizaban $45 \%$ más de intercambios y además sus resultados netos eran $-2,5 \%$ mientras que para las mujeres alcanzaba niveles de $1,72 \%$ para data de 1991 hasta 1997.

\subsubsection{Representatividad}

Pompian (2006) explica el concepto de representatividad de la siguiente manera: Las personas han desarrollado una propensión innata (derivada de experiencias pasadas) para clasificar objetos y pensamientos. Aún al encontrarse frente a nuevos eventos que no califican entre los modelos previos los agentes tratan de calificar el nuevo fenómeno dentro de la clasificación más parecida y solo luego de realizar esto se inicia un proceso 
de reconocimiento de las nuevas características. Esto permite a los individuos desarrollar respuestas rápidas que los ayudan a sobrevivir diariamente. El sesgo de representatividad nace cuando algún fenómeno o elemento es clasificado de manera errónea porque resulta similar a otros previos, este error puede persistir en todas las futuras interacciones con este elemento.

Por lo tanto, la representatividad es un juicio basado en exceso de dependencia o confianza en estereotipos.

El sesgo de representatividad puede ser interpretado de dos formas diferentes en inversionistas individuales (Pompian, 2006):

- Falacia de tasa básica: Sucede cuando por ejemplo se compara la compañía A con una compañía B (digamos de la misma industria) al tratar de determinar el éxito potencial de A. En lugar de una investigación concienzuda y detallada se recurre a estereotipos al tomar decisiones de inversión.

Falacia de tamaño de muestra: Al juzgar la probabilidad de un resultado particular de inversión, muchas veces los agentes fallan al considerar el tamaño de la muestra de la data en la cual basan su decisión. Por lo tanto, asumen incorrectamente que el tamaño de la muestra es representativo para el total de la población. Por ejemplo, en el caso de juzgar un fenómeno del cual se desconoce, muchas veces se considera como evidencia representativa solo pocos eventos relacionados conocidos.

\subsubsection{Efecto manada}

A diferencia del resto de sesgos conductuales el efecto manada es un fenómeno que puede ser fácilmente reconocido y observado en la vida cotidiana, aunque casi siempre es detectado a posteriori de la resolución del evento en el que se observa. Este atributo, como en muchos animales, se encuentra presente también en el ser humano (de allí el nombre), este consiste en imitar consciente o inconscientemente las acciones de un grupo mayor cuando individualmente no se tomaría la misma decisión.

Entre los diferentes motivos por los cuales nace el efecto manada se puede diferenciar la presión social, el ser humano es un animal sociable y tiene un deseo natural por encajar y ser aceptado por el grupo, por lo tanto, seguir el grupo es muchas veces un 
comportamiento alentado y recompensado por el resto. Otro de los motivos es de una índole más racional e involucra el sentido común, este nos dice que es menos probable que un grupo grande de personas pueda estar equivocada. Muchas veces aun cuando un individuo no esté de acuerdo con cierta decisión este tiende a realizarla de todas maneras ya que piensa que el resto del grupo sabe o comprende algo que escapa a su propia comprensión. Esto ocurre principalmente debido a la falta de experiencia.

El efecto manada puede afectar incluso a profesionales en finanzas e inversiones, este sucede normalmente cuando los inversionistas tienden a seguir las inversiones tomadas por la mayoría. En los mercados financieros los agentes presentan fuertes presiones psicológicas cuando se acerca el mejor momento para comprar o vender acciones ya que nadie más lo está haciendo. La razón principal para esta presión es la influencia derivada de colegas y compañeros. Gerentes, por ejemplo, adoptan el efecto manada porque están preocupados acerca de lo que otros piensan acerca de sus decisiones de inversión (1990)

El efecto manada por lo tanto, es la tendencia de que individuos tiendan a emular acciones de un gran grupo sin tomar en cuenta si ellos tomarían o no esa decisión individualmente. Una razón es que las personas son sociables y generalmente tienden a buscar la aceptación de un grupo en vez de permanecer solos. Otra razón es porque los inversionistas tienden a pensar que es poco probable que un gran grupo pueda estar equivocado. Esto los haría seguir al "rebaño" bajo la ilusión de que este pueda conocer algo que el inversionista desconoce.

\subsubsection{Anclaje}

Cuando las personas tratan de estimar valores de una magnitud desconocida o sobre los cuales no se tiene conocimiento las personas generalmente recurren a una heurística psicológica llamada "anclaje", esto consiste básicamente en utilizar un dato o idea inicial elegido de manera arbitraria como "ancla" la cual posteriormente se va poco a poco ajustando de acuerdo a la información obtenida y a los análisis mentales realizados hasta llegar a obtener un resultado final satisfactorio para el agente. 
Pompian (2006) afirma que las personas en general son mejores realizando estimaciones comparativas (es decir a partir de un punto de referencia) frente a estimaciones o figuras absolutas.

El problema del anclaje radica en que distintos estudios realizados han demostrado que, sin importar el punto de partida, las personas normalmente no tienen buenos resultados ya que los ajustes al ancla son insuficientes (Pompian, 2006).

"En muchas situaciones, las personas tienden a realizar estimaciones partiendo de un valor inicial que es ajustado posteriormente hasta obtener una respuesta final. Este valor inicial, o punto de partida, puede ser sugerido por la formulación del problema." (Tversky \& Kahneman, 1974).

El Anclaje es una heurística psicológica simple y general para la mayor parte de las personas, en el caso de las finanzas este se da cuando los inversionistas dan importancia innecesaria a "anclas" arbitrariamente asignadas que en muchos casos son estadísticamente aleatorias y psicológicamente determinadas. Estas anclas crean un sesgo en los inversionistas y los pueden llevar a tomar decisiones de inversión que no son del todo "racionales". Un ejemplo en finanzas podría ser el siguiente:

Cuando se requiere estimar un buen precio para una acción que no conoce es probable que un inversionista empiece usando una variable inicial, por ejemplo, el precio más bajo del stock en 52 semanas. Luego esta ancla es ajustada hacia arriba o abajo para reflejar la información o el propio análisis, pero estudios han demostrado que estos ajustes son insuficientes y tienden a producir resultados sesgados. Inversionistas que tienen este sesgo son posiblemente influenciados por estas anclas al responder preguntas como ‘¿Es este es un buen momento para comprar o vender stock?’ o ‘El stock tiene un precio justo?' El concepto de Anclaje por lo tanto puede ser explicado por la tendencia de los inversionistas a "anclarse" a sus pensamientos generando lógicamente puntos de referencia irrelevantes al tomar decisiones de inversión” (Pompian, 2006).

\subsubsection{Disonancia cognitiva}

La disonancia cognitiva es un elemento común y recurrente en la vida cotidiana del ser humano, esta se presenta cuando al adquirir nueva información esta entra en conflicto o contradice ideas, pensamientos o concepciones previas del individuo. Este conflicto entre 
nueva información (evidencia) y antiguas creencias o conceptos crea involuntaria y automáticamente cierta disconformidad o malestar mental.

El termino de disonancia cognitiva corresponde al estado de imbalance que ocurre cuando nuestras actitudes, emociones, creencias o valores (todas estas son cogniciones) entran en contradicción con nueva información o evidencia (Pompian, 2006). Al presentarse la disonancia cognitiva los agentes tratan de armonizar sus cogniciones para eliminar la disconformidad mental.

Cuando un inversionista enfrenta una situación en la cual tiene que seleccionar entre dos alternativas, es probable que se cree algún conflicto luego de haberla tomado. Los aspectos negativos de la alternativa elegida se vuelven más visibles mientras que los afectos positivos de la alternativa no seleccionada se suman al conflicto. Esto puede terminar minando la confianza en la decisión recientemente tomada (Pompian, 2006).

“Los psicólogos concluyen que las personas muchas veces realizan racionalizaciones extensivas para poder sincronizar sus procesos cognitivos y mantener estabilidad psicológica" (Pompian, 2006). Esto quiere decir que los agentes muchas veces tratarán inconscientemente de convencerse a sí mismos de que su primera decisión ha sido acertada solo para evitar el proceso de malestar psicológico provocado por el conflicto, esto puede producir que los inversionistas ignoren o eviten información que afecte negativamente sus inversiones o decisiones.

De acuerdo a Pompian, (2006), existen dos aspectos identificables de disonancia cognitiva en el proceso de toma de decisiones.

1. Percepción Selectiva: Cuando inversionistas solo registran información que afirma sus creencias y de esta manera crean un punto de vista incompleto de la situación real.

2. Toma de decisiones selectiva: Los inversionistas tienden a reforzar compromisos o situaciones previamente realizadas incluso ante evidencia de la posibilidad de que esta no sea la decisión correcta. Esto ocurre por el compromiso con la decisión original que fuerza al inversionista a racionalizar sus acciones de tal forma que se mantenga su decisión inicial, incluso ante evidencia de que esas mismas acciones producen resultados sub óptimos. 


\subsubsection{Aversión al arrepentimiento}

La aversión al arrepentimiento es un sesgo conductual que se presenta cuando las personas evitan tomar decisiones decisivas ya que temen "a priori" tomar decisiones sub óptimas (Pompian, 2006). Este comportamiento es común entre las personas y los inversionistas no son la excepción.

Los seres humanos evitan el "dolor emocional" o malestar causado al arrepentimiento por haber tomado una mala decisión, este fenómeno puede ocasionar en finanzas que inversionistas terminen manteniendo posiciones negativas (en acciones) por demasiado tiempo en vez de admitir el error y cortar las pérdidas. La aversión a las perdidas produce que los inversionistas teman ingresar a mercados que han generado pérdidas recientemente, aun cuando estas condiciones presentan grandes oportunidades para revaluaciones. Cuando se presentan pérdidas por instinto los agentes sienten que deben ser conservadores y se retiran a "lamerse sus heridas" (Pompian, 2006).

La causa principal de este tipo de error es la tendencia en los individuos de odiar admitir sus propios errores. Al padecer este sesgo, muchos inversionistas podrán evitar tomar acciones decisivas por miedo a fallar.

Según Pompian, (2006) Las personas con aversión al arrepentimiento tienden a evitar el estrés creado por dos tipos de errores.

1. Errores de comisión: Que ocurren como resultado de una acción equivocada, en esta el inversionista reflexiona en la decisión tomada y lamenta el hecho de haberla tomado, por lo tanto, cuestiona sus propios conocimientos.

2. Errores de omisión: Ocurren como resultado de perder oportunidades existentes.

\subsubsection{Falacias del jugador}

La falacia del jugador o apostador es una falacia lógica, es decir un argumento que parece ser válido, pero no lo es, en la cual se cree de manera errónea que el pasado (específicamente sucesos pasados), afectan los sucesos futuros en lo relativo a eventos aleatorios. Esta falacia es muy conocida en los "juegos de azar" y ha sido bastante 
estudiada ya que es un elemento de la psicología humana muy recurrente, como el dicho que dice "los dados no tienen memoria".

Kahneman y Tversky (1974) describen la falacia del jugador como el concepto erróneo de la justicia en las reglas del azar o probabilidad y comentan que en los mercados financieros los inversionistas que padecen de este sesgo son más propensos a realizar predicciones inversas en los precios de las acciones. La falacia del jugador nace cuando los inversionistas predicen inapropiadamente que la tendencia se revertirá y se acercan a pensamientos contrarios. Se dice que la Falacia del jugador ocurre cuando un inversionista opera bajo la percepción de que errores en eventos aleatorios se autocorrigen. Por ejemplo, si una moneda es lanzada diez veces y en cada una de ellas cae cara, se puede decir que el inversionista que piensa que el siguiente lanzamiento será sello estaría presentando este sesgo.

\subsubsection{Contabilidad mental}

El termino Contabilidad Mental fue descrito por Richard Thaler en 1980 y es definido por Thaler (1999) como un "Conjunto de operaciones cognitivas usadas por individuos y familias para organizar, evaluar y dar seguimiento a actividades financieras".

Thaler explica que el fenómeno consiste en la tendencia de las personas de codificar, categorizar y evaluar resultados económicos mediante una agrupación de los activos en un número determinado de cuentas mentales no intercambiables.

Esto quiere decir el agente que presente el sesgo trataría de manera diferente diferentes sumas de dinero basadas en cómo estos montos han sido obtenidos (salario, herencia, apuestas, bonos, etc.) pero también el destino del dinero (necesidades, ocio, ahorros, etc.) El concepto de encuadre, framing en inglés, es importante en el análisis de este sesgo ya que las personas alteran sus perspectivas en inversiones y dinero de acuerdo a las circunstancias que enfrentan (Pompian, 2006).

Pompian, (2006) concluye que los individuos crean diferentes tipos de contabilidades mentales para justificar decisiones que bajo otras condiciones no serían "racionales". Es importante resaltar que, si bien ciertas contabilidades mentales son negativas porque permiten a los individuos tomar decisiones peligrosas, en otros casos puede ser altamente beneficiosa como ahorros para la jubilación. 


\subsubsection{Retrospectiva}

El sesgo de retrospectiva es ese impulso que nos dice: “¡Lo sabía desde un principio!” una vez que un evento ya ha sucedido (Pompian, 2006).

En muchas ocasiones las personas afectadas por este sesgo tienden a pensar que un evento era en realidad predecible aun cuando no lo era.

Este comportamiento del ser humano existe ya que mentalmente los resultados realizados son mucho más comprensibles, es decir imaginables, que la infinidad de resultados posibles que no sucedieron (Pompian, 2006).

Esto no implica que las personas no puedan realizar predicciones, sino que explica que en muchas ocasiones los agentes piensan que realizaron predicciones acertadas en retrospectiva. El sesgo se manifiesta cuando el agente se convence a si mismo que sabía el resultado desde un inicio aun cuando era imposible saberlo.

En muchos casos el agente asume que el resultado que observa es el único resultado que siempre fue posible y por lo tanto subestima la incertidumbre del evento y desconoce los resultados que fueron muy posibles, pero no se materializaron.

El sesgo retrospectivo en mercados financieros puedo ocasionar graves daños a las carteras de los inversionistas ya que da la sensación de que ciertos resultados adversos fueran evitables si se hubieran tomado en cuenta ciertas señales o también ocasiona que resultados positivos sean vistos como el resultado de estrategias brillantes que pueden ser posteriormente replicadas. Por lo tanto, este sesgo podría ocasionar que los agentes no aprendan de sus errores.

\subsection{La teoría de "empujones": Nudge Theory}

"One lesson from my stories is that some things that economic theory says should not matter actually do matter"- (Thaler R. H., 2017)

En diciembre del 2017 Richard H. Thaler, profesor estadounidense de la universidad de Chicago, recibió el premio Nobel en Economía, en virtud de sus contribuciones a la Economía del comportamiento. Desde 1970 el profesor Thaler ha realizado experimentos y estudios relacionados a la economía conductual, los resultados 
de sus pruebas le permitieron comprender que la teoría económica tradicional está equivocada o incompleta, en los temas relacionados a las características que se le atribuyen al Homo Economicus" o "Econs" al tomar decisiones (Thaler \& Sunstein, 2008). La investigación de Thaler lo llevó a identificar, catalogar y cuantificar una serie de sesgos conductuales que afectan los procesos de toma de decisiones de los seres humanos.

Thaler encuentra en la teoría económica tradicional una serie de elementos que deberían ser irrelevantes y sin embargo en la práctica son relevantes, él llama estos factores "supposedly irrelevant factors" o SIF (Thaler R. H., 2017). El hallazgo de estos elementos es de gran importancia ya que permite complementar los modelos vigentes y explicar situaciones y fenómenos que bajo la teoría económica clásica eran inexplicables. Thaler postula que el gobierno y las empresas privadas pueden utilizar la Economía Conductual, considerando los efectos de los SIF, para ayudar a las personas a tomar mejores decisiones económicas en ciertos aspectos en los que tradicionalmente se equivocan. Los seres humanos viven en una realidad compleja donde usualmente no es posible pensar detenidamente en cada pequeña decisión que se toma, debido a esto, las personas toman una serie de atajos heurísticos que pueden ocasionar errores sistemáticos.

La teoría de empujones o "nudge theory" consiste en que existen ciertos factores en el ambiente (SIF) que influencian el comportamiento de los seres humanos, pero no influencian al "homo economicus". Por lo tanto, la definición de "nudge" es cualquier factor que altere significativamente el comportamiento de un ser humano siendo el mismo factor ignorado por un Econ (Thaler \& Sunstein, 2008).

En el Libro Nudge: Improving Decisions about health, wealth and Happiness (Thaler \& Sunstein, 2008) los autores explican el concepto de "Arquitectura de Decisiones" y demuestran, mediante una serie de experimentos prácticos, que la manera en la que se presentan las decisiones tiene un impacto significativo en los resultados finales. Debido a que en el mundo real existe una gran cantidad de situaciones donde inevitablemente se tienen arquitectos de decisión, se debería implementar un sistema donde se "empuje" o influencie a los individuos para que tomen decisiones que les permitan estar mejor bajo su propia perspectiva.

La ideología de "empujar" a los individuos influenciando sus decisiones, sin obligarlos a tomar una decisión y permitiéndoles sin mucho esfuerzo cambiar dicha 
decisión es llamada "Libertarian Paternalism" (Thaler \& Sunstein, 2008), libertarian porque las personas son en todo momento libres de elegir lo que ellos decidan y paternalism porque los autores consideran legítimo que los arquitectos de decisión traten de influenciar a los individuos en que tomen decisiones que hagan sus vidas más largas, más sanas y mejores. La necesidad de aplicar esta ideología nace debido a que los autores consideran que hay suficientes pruebas de que en muchos casos los individuos toman malas decisiones en temas fundamentales (debido a falta de atención, falta de información, falta de capacidades cognitivas ilimitadas y completo autocontrol), de esta manera los arquitectos de decisión estarían brindando una contribución positiva en el correcto desarrollo de las vidas de muchos individuos.

Para Thaler y Sunstein las personas que rechazan la visión de paternalismo principalmente por una suposición falsa y por dos conceptos errados (Thaler \& Sunstein, 2008):

1) Suposición Falsa: La suposición es que casi todas las personas, casi todo el tiempo toman decisiones que les convienen o generan valor, o al menos toman mejores decisiones de las que tomaría alguien más en su lugar. Esta suposición es falsa debido a que usualmente las personas solo toman buenas decisiones en contextos donde tienen experiencia, buena información y un nivel de retroalimentación rápido.

2) Primer concepto errado: Es posible evitar influenciar las decisiones de las personas, este concepto está errado debido a que en muchos casos los agentes (el gobierno o entidades privadas) deben tomar decisiones que afectaran el comportamiento por el simple hecho de que son arquitectos de decisión. En este caso existen "empujones" que a pesar de que no sean intencionados igual son empujones. De manera que una política "anti-empujones" no puede ser aplicada ya que la presencia de estos es inevitable.

3) Segundo concepto errado: El paternalismo necesariamente genera coerción, este concepto esta errado ya que, bajo la propuesta de los autores, las decisiones son finalmente tomadas por los individuos sin mayores complicaciones y sin perjuicio alguno.

En su libro y en base a los principios previamente mencionados (Thaler \& Sunstein, 2008) buscan aplicar la teoría de los empujones en diferentes maneras para 
mostrar como la teoría podría ser aplicada en 3 áreas en particular: El dinero (ahorro, inversiones, mercados y sistemas de seguros), La Salud (prescripción de medicamentos, donación de órganos, el planeta), La Libertad (educación, compra de boletos de lotería, matrimonio) con el fin de mejorar la vida de los individuos y aun así preservar la libertad de decisión.

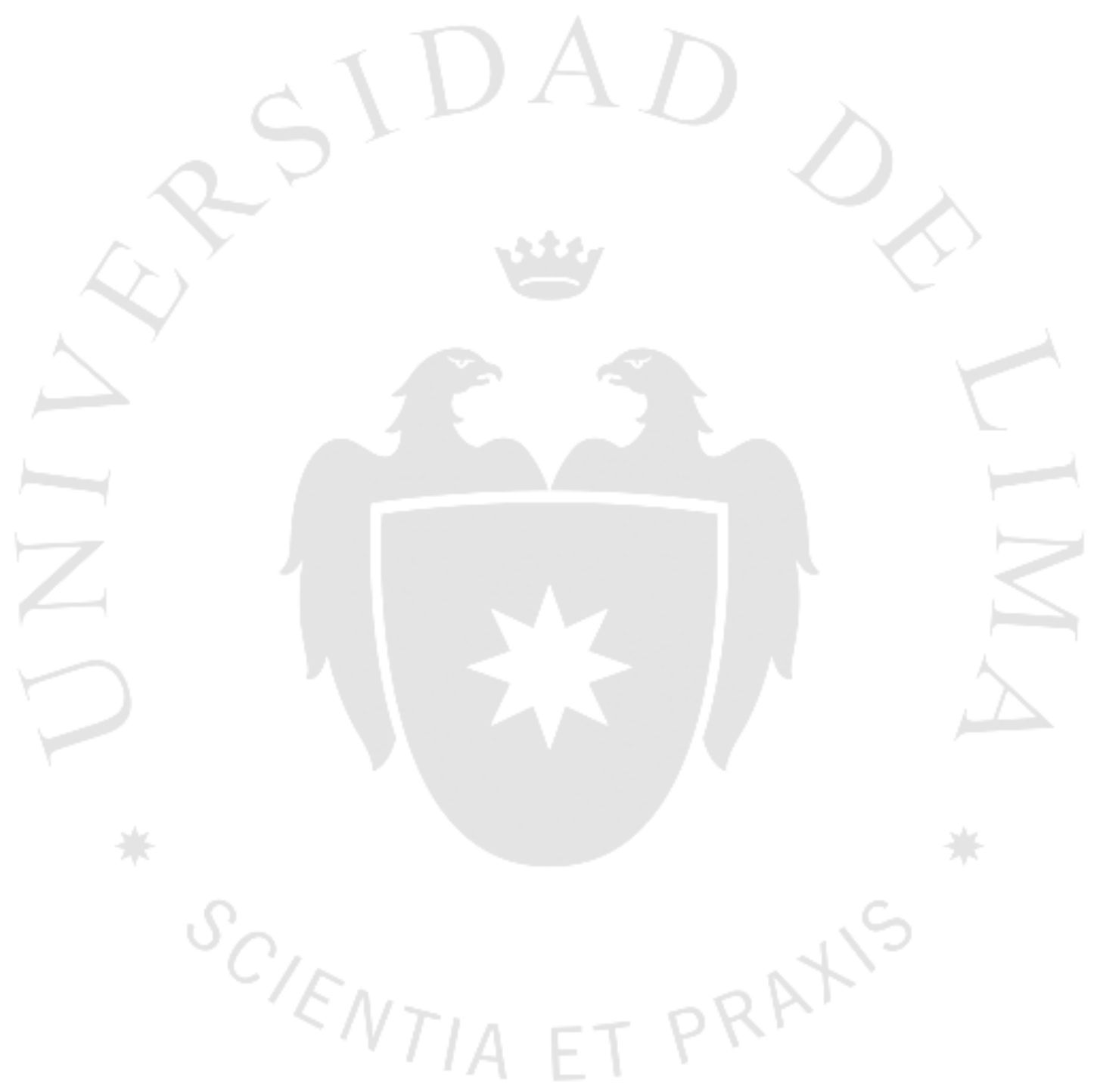




\section{CAPÍTULO II: METODOLOGÍA DE ANÁLISIS}

A continuación, se explicarán brevemente los métodos mediante los cuales se procederá a analizar la evidencia empírica recolectada, se comentará en qué consisten los métodos y pruebas a ser utilizadas, por qué han sido elegidas, cuáles son sus requisitos, qué buscan revelar y la manera como se interpretan los resultados obtenidos.

\subsection{La encuesta}

El cuestionario consiste en 30 preguntas, 22 de las cuales serán utilizadas para capturar información cuantitativa y el resto tienen como objetivo observar las actitudes de los inversionistas. Las preguntas se detallan a continuación:

1) ¿Cuál es su edad?

2) ¿Cuánto tiempo viene realizando operaciones en la bolsa de valores de Lima?

3) ¿En cuánta pérdida incurrió su portafolio en el periodo 2013-2014?

4) $\mathrm{Al}$ realizar inversiones, ¿a qué juicio o criterio de análisis usted otorga mayor confianza?

5) ¿Usted considera el comportamiento histórico de una acción antes de invertir en ella?

6) ¿El volumen de transacciones de una acción afecta su decisión de inversión?

7) Sus colegas y competidores inician inesperadamente la compra de acciones de una empresa de la que usted tiene poco conocimiento ¿Cómo afectaría esta actitud hacia su evaluación de las acciones de dicha compañía?

8) ¿Usted cree que es posible encontrar el valor futuro de una acción a través de un análisis detallado de su evolución histórica?

9) ¿Usted considera que fue posible predecir el colapso de la bolsa de WallStreet en el inicio de la crisis financiera global del año 2007-2008?

10) ¿Cómo considera usted que será el desempeño de sus inversiones en comparación al índice de la BVL? 
11) ¿Usted considera que es capaz de predecir los precios futuros de las acciones mejor que otros?

12) En una escala de 1 a 7 (1, bajo riesgo y 7 alto riesgo), ¿Cuál es el nivel de riesgo que usted asume?

13) ¿Usted invertiría en una acción si la evaluación que usted atribuye es diferente a la de algún experto muy conocido cuya evaluación se publicó en una revista de finanzas o en un medio reconocido?

14) ¿Con que frecuencia sus decisiones de inversión son acertadas?

15) ¿Usted realiza órdenes de compra/venta con un precio objetivo antes de que abra la bolsa?

A) En caso de haber elegido sí en la pregunta anterior, ¿cuál de los siguientes criterios usted consideraría para fijar el precio objetivo?

16) ¿Usted utiliza "stop loss" en sus intercambios?

17) Entre el PER y el valor intrínseco de una acción, ¿cuál de los dos tiene mayor peso en su decisión de inversión?

18) ¿Cómo reaccionó al periodo de caída de la bolsa peruana entre 2013 y 2015 ?

19) Considere la siguiente situación: El precio de una acción Blue Chip es S/ 500. Este cae a S/ 100 como resultado de una crisis. Los analistas son neutrales y dan señales para mantener la acción. ¿Usted compraría la acción a su nuevo precio (S/100), considerando el alto precio en su pasado cercano?

20) ¿Usted considera que su subconsciente trata de justificar errores cometidos al realizar decisiones de inversión?

21) Si escuchara la opinión de un famoso analista y esta entra en contradicción con su opinión acerca de una acción, ¿cambiaría su opinión inmediatamente?

22) ¿Qué haría usted si es criticado por invertir en una acción que esta "a la baja" o por vender una acción que se encuentra "en alza"?

23) ¿Usted ha mantenido una acción "a la baja" por mucho tiempo esperando un repunte, o ha vendido una acción "en alza" y luego ha sentido que pudo haber esperado un mayor aumento?

24) ¿En algún momento usted no realizó una decisión de inversión debido a que se encontraba esperando nueva información (favorable) concerniente a dicha acción? 
25) ¿Usted es capaz de anticipar el cambio entre buenos y malos retornos de mercado?

26) Suponga que se lanza una moneda tres veces, y cada vez cae en "Sello". ¿Qué pensaría usted del resultado del siguiente lanzamiento de la moneda?

27) ¿Usted ahorra parte de sus ingresos personales para invertir en la bolsa de valores?

28) Si usted gana una lotería de S/ 10.000.000 (10 Millones), ¿en qué tipo de acciones consideraría invertir?

29) Si usted estuviera entre el 2006 y el 2007, y alguien le dijera que una crisis financiera estaba a punto de explotar en los siguientes años, ¿Usted quedaría convencido? ¿En qué rango?

30) En una escala del 1 al 5, ¿con cuánto calificaría su conocimiento relativo al nuevo campo de estudios relativo a la toma de decisiones financieras llamado "Behavioral Finance" o "Finanzas Conductuales"?

Las preguntas con objetivo cuantitativo fueron construidas mediante una escala Likert (escala simétrica unidimensional donde todos los elementos miden lo mismo, pero con diferentes grados de aprobación o desaprobación).

Para la mayoría de preguntas se utilizará una escala de Likert de 3 puntos, los puntos de la escala tienen la siguiente forma:

i. Sí, siempre $=$ Positivo

ii. Algunas veces, Tal vez $=$ Neutral

iii. No, Nunca $=$ Negativo

Estos puntos son cuantificados mediante la asignación de puntajes, en este caso se utilizará el Método de puntajes ponderados, se asignará un peso de tres a los resultados positivos, dos a los neutros y uno a los negativos.

Perfil de la muestra: El objetivo del estudio es observar el comportamiento de inversionistas reales, es probable que muchos de ellos tengan poco o ningún conocimiento acerca de las finanzas conductuales. Para el estudio se ha utilizado una muestra representativa de los inversionistas de la BVL con un total de 84 inversionistas, más adelante se detallará brevemente algunas de las instituciones donde laboran dichos inversionistas. 
La muestra se separó en base a un criterio:

i. Años de experiencia en el mercado de valores.

En base a los resultados se seleccionarán dos grupos de inversionistas.

Se buscó tener el mismo número de observaciones en ambos grupos y filtrar las encuestas con muchas respuestas en blanco.

Una gran limitación del estudio corresponde a que se plantea estudiar el comportamiento de los inversionistas mediante un cuestionario. La toma de decisiones de inversión es un proceso complejo y exhaustivo, por lo tanto, es posible que durante el cuestionario el inversionista se encuentre relajado y con la mente fresca, por lo tanto, podría elegir respuestas que lo hagan quedar bien, especialmente en contextos en que se presentan situaciones hipotéticas. Para evitar esto ciertas preguntas hacen referencia a eventos pasados del inversionista.

Los 84 encuestados han sido en su mayoría seleccionados mediante conexiones directas o por referencias directas, han sido encuestados profesores de la Universidad de Lima con experiencia en la BVL, los cuales en muchos casos han ofrecido su apoyo derivando la encuesta a colegas, compañeros y conocidos que cumplan con los requisitos. Por otro lado, un gran aporte de los encuestados ha sido llevado a cabo mediante compañeros del trabajo en el Banco Santander Perú que invertían activamente en la BVL, de igual manera se les solicitó compartir la encuesta mediante el link electrónico a otros contactos, colegas y compañeros que compartieran los requisitos. Por último, un número inferior y más limitado de encuestas fue llenada por personas directamente conocidas por el investigador que invierten en la BVL, a este grupo de personas también se les exhortó a compartir el link de la encuesta entre colegas y conocidos que estuvieran en grado de participar. Debido al anonimato que implica la investigación no se puede saber con exactitud la proporción o el número de encuestados obtenido por cada uno de los grupos previamente mencionados.

\subsection{Análisis discriminante}

El análisis discriminante es un tipo de técnica funcional y su uso principal corresponde a la realización de pronósticos. Esta herramienta utiliza un número "N" de variables 
independientes cuantitativas y una sola variable dependiente cualitativa o nominal (De la Garza, Blanca, \& Beatriz, 2013).

La función discriminante actualmente utilizada es la ecuación discriminante de Fisher propuesta en 1930. El objetivo de este análisis es encontrar una combinación lineal de variables independientes que permitan al investigador diferenciar de la mejor manera posible diferentes grupos o niveles que la variable dependiente posee (en este caso inversionistas jóvenes y experimentados). Una vez que se obtiene la función, esta puede ser utilizada para clasificar nuevos elementos u observaciones (pronosticar) (De la Garza, Blanca, \& Beatriz, 2013).

El análisis discriminante es una herramienta muy utilizada, en medicina sirve para diagnosticar enfermedades en pacientes según sus síntomas, en psicología ayuda a evaluar si una persona sufre trastornos según su perfil mental, en recursos humanos sirve como filtro previo a una entrevista y en finanzas permite decidir si se otorga o no un crédito a una persona, etc. (De la Garza, Blanca, \& Beatriz, 2013).

Un ejemplo práctico que permite captar correctamente el propósito de esta técnica es el siguiente:

El análisis de la muestra obtenida por esta investigación permitirá dividir a los individuos en dos grupos: los que puedan ser catalogados como inversionistas jóvenes (con 8 o menos años de experiencia tranzando en la bolsa) y los inversionistas experimentados (con más de 9 años de experiencia tranzando en la bolsa); el análisis discriminante permitirá comprobar si efectivamente los entrevistados están correctamente clasificados en esos dos grupos y más importante permitirá identificar que variables son las que determinan la diferencia entre las personas de ambos grupos.

La asignación a cada grupo se realiza mediante una función lineal que combinara los nueve sesgos conductuales previamente explicados. De esta manera se podrá corroborar si ambos grupos son afectados de manera diferente por las variables propuestas y pronosticar el comportamiento de estas con relación al grupo al que pertenecen.

En el presente estudio se realizará el análisis discriminante descriptivo y no el predictivo, ya que el objetivo es verificar la existencia de diferencias en el comportamiento de los dos grupos con respecto a las variables utilizadas. 
El análisis discriminante es bastante similar al análisis de regresión múltiple, la diferencia radica en que en el presente análisis se utiliza una variable dependiente categórica. (De la Garza, Blanca, \& Beatriz, 2013).

$$
\begin{aligned}
& \text { La ecuación } \quad \text { a } \quad \text { utilizar } \quad \text { será } \\
& D=v 1 X 1+v 2 X 2+v 3 X 3+v 4 X 4+v 5 X 5+v 6 X 6+v 7 X 7+v 8 X 8+v 9 X 9+a
\end{aligned}
$$

Dónde:

- D es la función discriminante

- " "v" es el peso de la variable

- X1-X9 corresponden a los diferentes sesgos

- “a" es la constante, el residuo.

Debido a que el análisis discriminante utiliza variables significativas en la diferenciación de los grupos debe encontrar pesos para las variables independientes. Para el cálculo de estos coeficientes se utiliza la máxima diferencia entre los datos.

La muestra mínima es de 5 observaciones por variable dependiente, aunque se recomienda 20 observaciones por cada una de ellas (en este caso se recomiendan 40 como mínimo para resultados analizables).

La composición de la muestra deberá de preferencia ser similar a la composición de la población. Si los grupos son nítidos u homogéneos no es necesario que la muestra sea grande, pero si son heterogéneos es importante que esta sea de un tamaño considerable. Si es posible obtener la composición de la población se espera que esta se refleje en la composición de la muestra (De la Garza, Blanca, \& Beatriz, 2013). 


\section{CAPÍTULO III: ANÁLISIS DE EVIDENCIA EMPÍRICA}

La investigación tuvo una muestra de 84 inversionistas la cual se ha dividido en dos grupos de acuerdo al grado de experiencia de los inversionistas.

El primer grupo está conformado por inversionistas con poca experiencia, este grupo está conformado por 40 personas, con 8 o menos años de experiencia.

El segundo grupo es de inversionistas experimentados y está compuesto por 44 personas todas con 9 o más años de experiencia en la bolsa de valores de Lima.

Se creó una variable dicotómica creada en función a los años de experiencia de los inversionistas mientras que las preguntas de escala Likert de 3 o más puntos fueron aritméticamente combinadas mediante SPSS para formar 9 variables, cada una representando un sesgo conductual que ha sido analizado en la presente investigación.

Los resultados de la investigación son los siguientes de la muestra considerada de 84 inversionistas el 33.33\% (28) se encontraban en un rango de edad entre 20 a 29 años, el $15.48 \%$ (13) se encontraban entre 30 y 39 años, el 17.86\% (15) tenían entre 40 y 49 años y el $29.75 \%$ (25) se encontraban entre 50 y 59 años, adicionalmente se obtuvieron dos respuestas de inversionistas mayores a 60 años y un inversionista no brindó su edad. Figura 3.1

Rango de edades de los inversionistas

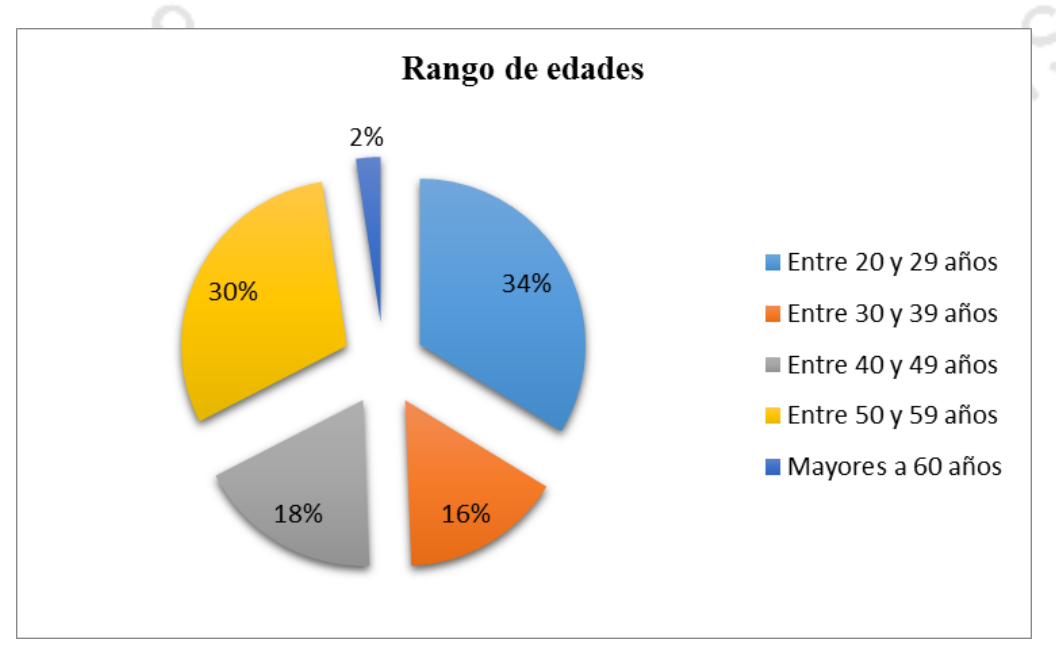

Fuente: Data recopilada y procesada, elaboración propia. 
La edad promedio de los encuestados es 40 años y la moda es 57 años.

Con respecto a la edad, la variable dicotómica, 40 encuestados (47.6\%) tienen 9 o menos años de experiencia y los 44 restantes (52.4\%) tienen más de 9 años de experiencia. Los años de experiencia promedio corresponden a 11 años y medio.

Figura 3.2

Separación de data en dos sub muestras

\section{División de las submuestras}

๑ 9 o menos años de experiencia $\square$ más de 9 años de experiencia

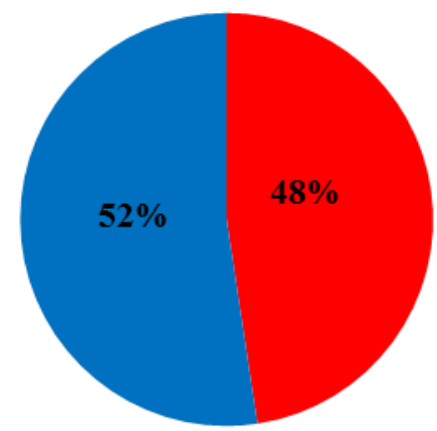

Fuente: Data recopilada y procesada, elaboración propia

\subsection{Test de multicolinealidad}

En primer lugar, se ha analizado si existe un problema de multicolinealidad entre las nueve variables creadas. La tabla 3.1 presenta la matriz de correlación entre las variables, esta matriz está dividida en dos partes, en la primera se observa los coeficientes de Pearson y la segunda parte muestra la significancia de los coeficientes.

Altos coeficientes de correlación fueron encontrados para tres variables: Exceso de confianza, Representatividad y Temor al arrepentimiento, sin embargo, el determinante de la matriz de correlación sugiere que en conjunto no existe problema de multicolinealidad entre las variables. 
Para comprobar si existen efectivamente problemas de multicolinealidad entre las variables se utilizaron los Factores de Inflación de la Varianza o por sus siglas en ingles VIF (Variance Inflation Factors).

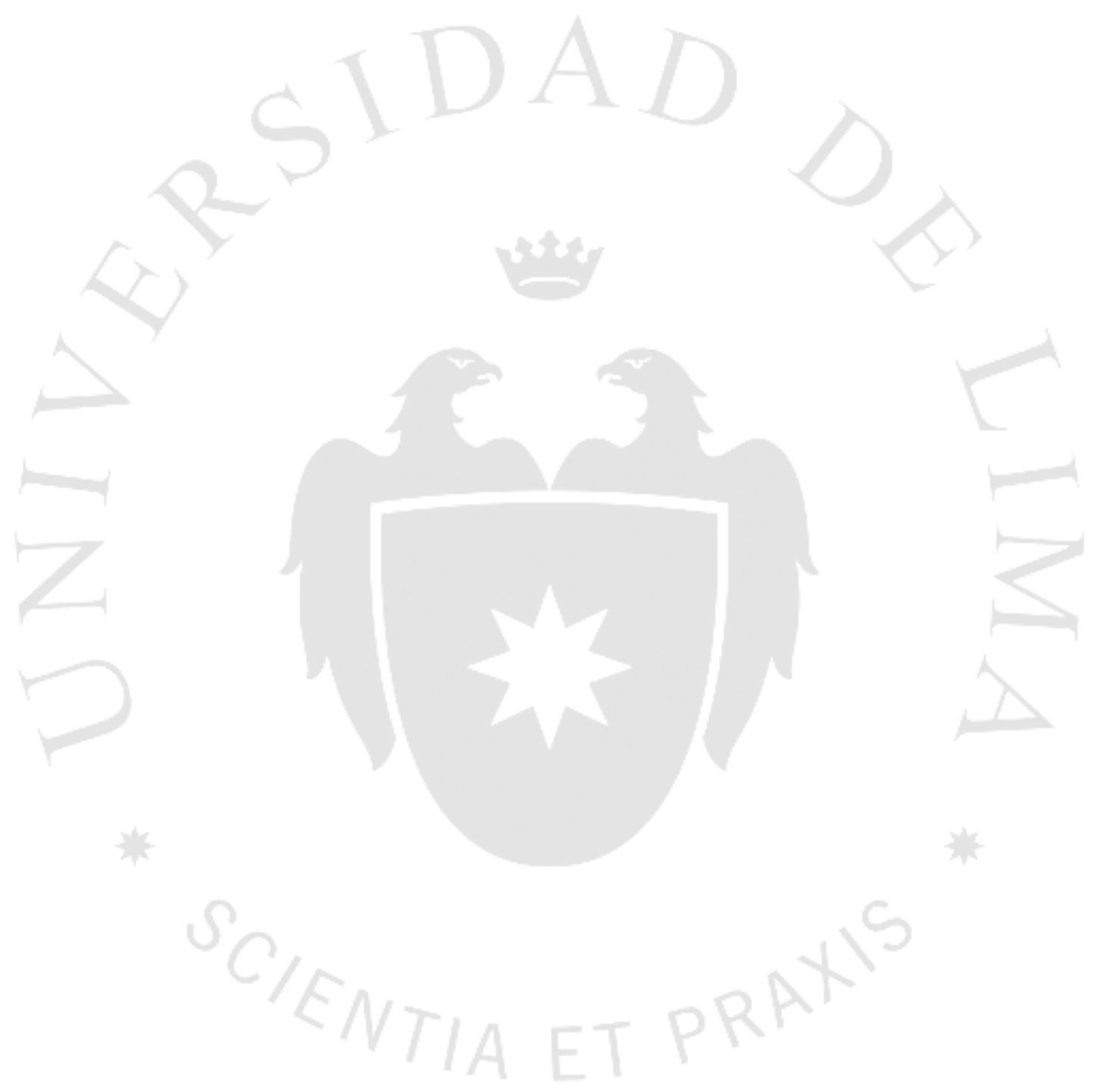


Tabla 3.1

Matriz de correlación de variables

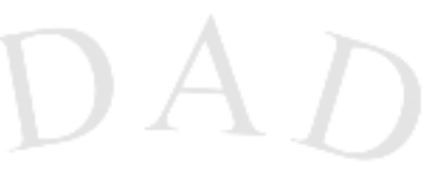

Pearson Correlation

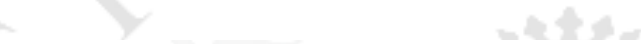

\begin{tabular}{|c|c|c|c|c|c|c|c|c|c|}
\hline & $\begin{array}{l}\text { Exceso de } \\
\text { Confianza }\end{array}$ & Represent. & $\begin{array}{l}\text { Efecto } \\
\text { Manada }\end{array}$ & Anclaje & $\begin{array}{l}\text { Disonancia } \\
\text { Cognitiva }\end{array}$ & $\begin{array}{l}\text { Temor al } \\
\text { arrepentimiento }\end{array}$ & $\begin{array}{l}\text { Falacia del } \\
\text { Jugador }\end{array}$ & $\begin{array}{l}\text { Contabilidad } \\
\text { Mental }\end{array}$ & Retrospectivo \\
\hline Exceso de Confianza & 1 & $.396^{* *}$ & 0.104 & $.477^{* *}$ & -0.012 & -0.020 & $.393 * *$ & $.327 * *$ & $.338 * *$ \\
\hline Representatividad & $.396 * *$ & 1 & $.476^{* *}$ & 0.122 & -0.080 & $.208 *$ & 0.112 & 0.144 & $.193 *$ \\
\hline Efecto Manada & 0.104 & $.476^{* *}$ & 1 & 0.129 & 0.053 & $.239 *$ & 0.093 & 0.043 & 0.117 \\
\hline Anclaje & $.477 * *$ & 0.122 & 0.129 & 1 & 0.119 & 0.111 & $.533 * *$ & $.376^{* *}$ & 0.164 \\
\hline Disonancia Cognitiva & -0.012 & -0.080 & 0.053 & 0.119 & 1 & 0.095 & $.221 *$ & 0.101 & 0.032 \\
\hline Temor al arrepentimiento & -0.020 & $.208 *$ & $.239 *$ & 0.111 & 0.095 & 1 & 0.013 & $.343 * *$ & $.206^{*}$ \\
\hline Falacia del Jugador & $.393 * *$ & 0.112 & 0.093 & $.533 * *$ & $.221 *$ & 0.013 & 1 & $.249 *$ & $.349 * *$ \\
\hline Contabilidad Mental & $.327 * *$ & 0.144 & 0.043 & $.376^{* *}$ & 0.101 & $.343 * *$ & $.249 *$ & 1 & 0.032 \\
\hline Retrospectivo & $.338 * *$ & $.193 *$ & 0.117 & 0.164 & 0.032 & $.206^{*}$ & $.349 * *$ & 0.032 & 1 \\
\hline
\end{tabular}

**. Correlation is significant at the 0.01 level (1-tailed).

*. Correlation is significant at the 0.05 level (1-tailed). 
(continuación)

\begin{tabular}{|c|c|c|c|c|c|c|c|c|c|}
\hline & $\begin{array}{l}\text { Exceso de } \\
\text { Confianza }\end{array}$ & Represent. & $\begin{array}{l}\text { Efecto } \\
\text { Manada }\end{array}$ & Anclaje & $\begin{array}{l}\text { Disonancia } \\
\text { Cognitiva }\end{array}$ & $\begin{array}{l}\text { Temor al } \\
\text { arrepentimiento }\end{array}$ & $\begin{array}{l}\text { Falacia del } \\
\text { Jugador }\end{array}$ & $\begin{array}{l}\text { Contabilidad } \\
\text { Mental }\end{array}$ & Retrospectivo \\
\hline Exceso de Confianza & & 0.000 & 0.172 & 0.000 & 0.458 & 0.427 & 0.000 & 0.001 & 0.001 \\
\hline Representatividad & 0.000 & & 0.000 & 0.135 & 0.234 & 0.029 & 0.155 & 0.096 & 0.040 \\
\hline Efecto Manada & 0.172 & 0.000 & & 0.122 & 0.315 & 0.014 & 0.199 & 0.350 & 0.145 \\
\hline Anclaje & 0.000 & 0.135 & 0.122 & & 0.140 & 0.158 & 0.000 & 0.000 & 0.068 \\
\hline Disonancia Cognitiva & 0.458 & 0.234 & 0.315 & 0.140 & & 0.194 & 0.022 & 0.180 & 0.387 \\
\hline Temor al arrepentimiento & 0.427 & 0.029 & 0.014 & 0.158 & 0.194 & & 0.454 & 0.001 & 0.030 \\
\hline Falacia del Jugador & 0.000 & 0.155 & 0.199 & 0.000 & 0.022 & 0.454 & & 0.011 & 0.001 \\
\hline Contabilidad Mental & 0.001 & 0.096 & 0.350 & 0.000 & 0.180 & 0.001 & 0.011 & & 0.388 \\
\hline Retrospectivo & 0.001 & 0.040 & 0.145 & 0.068 & 0.387 & 0.030 & 0.001 & 0.388 & \\
\hline
\end{tabular}

Fuente: Data recopilada y procesada en SPSS
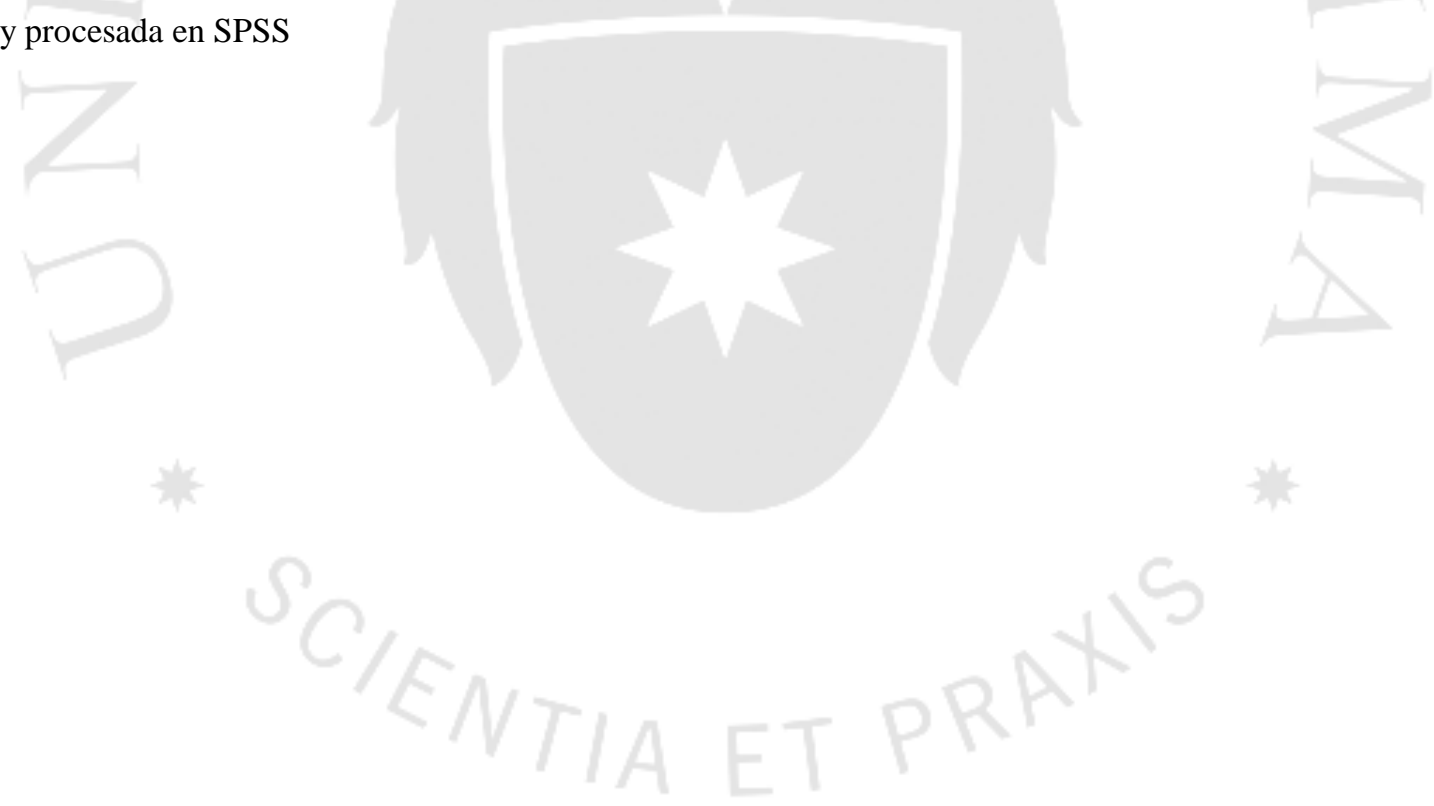
Tabla 3.2

Estadísticos de colinearidad (exceso de confianza)

Coefficients $^{a}$

\begin{tabular}{lll}
\hline Model & \multicolumn{2}{l}{ Collinearity Statistics } \\
\hline & Tolerance & VIF \\
\hline Representatividad & 0.723 & 1.383 \\
\hline Efecto Manada & 0.733 & 1.365 \\
\hline Disonancia Cognitiva & 0.917 & 1.090 \\
\hline Temor al arrepentimiento & 0.767 & 1.303 \\
\hline Contabilidad Mental & 0.731 & 1.367 \\
\hline Falacia del Jugador & 0.599 & 1.670 \\
\hline Retrospectivo & 0.801 & 1.249 \\
\hline Anclaje & 0.647 & 1.546 \\
\hline a. Dependent Variable:Exceso de Confianza & \\
\hline
\end{tabular}

Fuente: Data recopilada y procesada en SPSS.

Tabla 3.3

Estadísticos de colinearidad (representatividad)

Coefficients $^{a}$

\begin{tabular}{lll}
\hline Model & \multicolumn{2}{l}{ Collinearity Statistics } \\
\hline & Tolerance & VIF \\
\hline Disonancia Cognitiva & 0.927 & 1.078 \\
Temor al arrepentimiento & 0.729 & 1.373 \\
Contabilidad Mental & 0.686 & 1.458 \\
Falacia del Jugador & 0.596 & 1.677 \\
Retrospectivo & 0.733 & 1.365 \\
Anclaje & 0.586 & 1.708 \\
Exceso de Confianza & 0.624 & 1.603 \\
Efecto Manada & 0.915 & 1.092 \\
\hline a. Dependent Variable: Representatividad & & \\
\hline
\end{tabular}

Fuente: Data recopilada y procesada en SPSS. 
Tabla 3.4

Estadísticos de colinearidad (temor al arrepentimiento)

Coefficients $^{a}$

\begin{tabular}{lll}
\hline Model & \multicolumn{2}{l}{ Collinearity Statistics } \\
\hline & Tolerance & VIF \\
\hline Disonancia Cognitiva & 0.921 & 1.086 \\
\hline Contabilidad Mental & 0.812 & 1.231 \\
\hline Falacia del Jugador & 0.611 & 1.637 \\
\hline Retrospectivo & 0.802 & 1.247 \\
\hline Anclaje & 0.580 & 1.723 \\
\hline Exceso de Confianza & 0.570 & 1.754 \\
\hline Efecto Manada & 0.739 & 1.354 \\
\hline Representatividad & 0.627 & 1.594 \\
\hline
\end{tabular}

a. Dependent Variable: Temor al arrepentimiento

Fuente: Data recopilada y procesada en SPSS.

Tabla 3.5

Estadísticos de colinearidad (efecto manada)

Coefficients $^{a}$

\begin{tabular}{lll}
\hline Model & \multicolumn{2}{l}{ Collinearity Statistics } \\
\hline & Tolerance & VIF \\
\hline Disonancia Cognitiva & 0.920 & 1.087 \\
\hline Contabilidad Mental & 0.692 & 1.445 \\
\hline Falacia del Jugador & 0.596 & 1.676 \\
\hline Retrospectivo & 0.733 & 1.365 \\
\hline Anclaje & 0.583 & 1.716 \\
\hline Exceso de Confianza & 0.536 & 1.867 \\
\hline Representatividad & 0.776 & 1.289 \\
\hline Temor al arrepentimiento & 0.727 & 1.376 \\
\hline a. Dependent Variable: Efecto Manada & & \\
\hline
\end{tabular}

Fuente: Data recopilada y procesada en SPSS. 
Tabla 3.6

Estadísticos de colinearidad (anclaje)

Coefficients $^{a}$

\begin{tabular}{lll}
\hline Model & \multicolumn{2}{l}{ Collinearity Statistics } \\
\hline & Tolerance & VIF \\
\hline Disonancia Cognitiva & 0.915 & 1.093 \\
\hline Contabilidad Mental & 0.705 & 1.418 \\
\hline Falacia del Jugador & 0.713 & 1.402 \\
\hline Retrospectivo & 0.742 & 1.347 \\
\hline Exceso de Confianza & 0.595 & 1.681 \\
\hline Representatividad & 0.624 & 1.603 \\
\hline Temor al arrepentimiento & 0.718 & 1.392 \\
\hline Efecto Manada & 0.733 & 1.364 \\
\hline
\end{tabular}

a. Dependent Variable: Anclaje

Fuente: Data recopilada y procesada en SPSS.

Tabla 3.7

Estadísticos de colinearidad (falacia del jugador)

Coefficients $^{a}$

\begin{tabular}{lll}
\hline Model & \multicolumn{2}{l}{ Collinearity Statistics } \\
\hline & Tolerance & VIF \\
\hline Disonancia Cognitiva & 0.956 & 1.047 \\
\hline Contabilidad Mental & 0.693 & 1.444 \\
\hline Retrospectivo & 0.809 & 1.237 \\
\hline Exceso de Confianza & 0.531 & 1.882 \\
\hline Representatividad & 0.613 & 1.631 \\
\hline Temor al arrepentimiento & 0.729 & 1.371 \\
\hline Efecto Manada & 0.724 & 1.381 \\
\hline Anclaje & 0.688 & 1.453 \\
\hline
\end{tabular}

a. Dependent Variable: Falacia del Jugador

Fuente: Data recopilada y procesada en SPSS. 
Tabla 3.8

Estadísticos de colinearidad (contabilidad mental)

Coefficients $^{a}$

\begin{tabular}{lll}
\hline Model & \multicolumn{2}{l}{ Collinearity Statistics } \\
\hline & Tolerance & VIF \\
\hline Disonancia Cognitiva & 0.916 & 1.091 \\
Retrospectivo & 0.766 & 1.306 \\
Exceso de Confianza & 0.564 & 1.772 \\
Representatividad & 0.613 & 1.631 \\
Temor al arrepentimiento & 0.843 & 1.186 \\
Efecto Manada & 0.730 & 1.370 \\
Anclaje & 0.592 & 1.691 \\
Falacia del Jugador & 0.602 & 1.661 \\
\hline a. Dependent Variable: Contabilidad Mental & \\
\hline Fuent: Data recopilada y procesada en SPSS.
\end{tabular}

Fuente: Data recopilada y procesada en SPSS.

De acuerdo a Liao \& Valliant (2012) los VIF son un indicador que mide cuanto se incrementa la varianza de los coeficientes estimados si no existe correlación entre las variables independientes en un modelo de regresión. Los VIF son calculados dividiendo 1 entre el nivel de tolerancia, se considera que existen problemas de multicolinealidad cuando los valores de los VIF son cercanos, iguales o mayores a 4.

Para comprobar que no se tuvieran problemas de multicolinealidad se estimaron regresiones lineales para las variables que presentaron posibles problemas de alta correlación utilizando estas como variables dependientes y el resto como variables independientes.

Luego de las pruebas se puede descartar efecto de la multicolinealidad entre las variables ya que en ningún caso los indicadores VIF son lo suficientemente elevados por lo tanto se mantienen todas las variables para el resto de la investigación. 


\subsection{Efecto de la caída de la bolsa de valores de Lima en los portafolios}

Tabla 3.9

Pérdidas incurridas por grupos de inversionistas

\begin{tabular}{|c|c|c|c|c|c|c|c|}
\hline \multicolumn{3}{|l|}{$\begin{array}{ll}\text { Tipo } & \text { de } \\
\text { Inversionista } & \end{array}$} & \multicolumn{5}{|c|}{ Pérdida incurrida en el periodo 2013-2014 } \\
\hline & & & $>50 \%$ & $\begin{array}{l}30- \\
50 \%\end{array}$ & $\begin{array}{l}10- \\
30 \%\end{array}$ & $<10 \%$ & $\begin{array}{l}\text { Sin } \\
\text { pérdidas }\end{array}$ \\
\hline Inversionistas & Conteo & 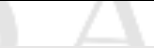 & 5 & 4 & 13 & 11 & 7 \\
\hline \multirow[t]{2}{*}{ Jovenes } & $\begin{array}{lc}\% & \text { dentro } \\
\text { inversionista } & \text { del }\end{array}$ & tipo de & $13 \%$ & $10 \%$ & $33 \%$ & $28 \%$ & $18 \%$ \\
\hline & $\%$ dentro de pérdidas & & $42 \%$ & $67 \%$ & $50 \%$ & $50 \%$ & $39 \%$ \\
\hline Inversionistas & Conteo & & 7 & 2 & 13 & 11 & 11 \\
\hline \multirow[t]{4}{*}{ Experimentados } & $\begin{array}{lc}\% & \text { dentro } \\
\text { inversionista } & \text { del }\end{array}$ & tipo de & $16 \%$ & $5 \%$ & $30 \%$ & $25 \%$ & $25 \%$ \\
\hline & $\%$ dentro de pérdidas & & $58 \%$ & $33 \%$ & $50 \%$ & $50 \%$ & $61 \%$ \\
\hline & Conteo & & 12 & 6 & 26 & 22 & 18 \\
\hline & $\begin{array}{lc}\% & \text { dentro } \\
\text { inversionista } & \end{array}$ & tipo de & $14 \%$ & $7 \%$ & $31 \%$ & $26 \%$ & $21 \%$ \\
\hline 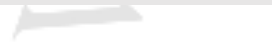 & $\%$ dentro de pérdidas & & $100 \%$ & $100 \%$ & $100 \%$ & $100 \%$ & $100 \%$ \\
\hline
\end{tabular}

Fuente: Data recopilada y procesada en SPSS.

El periodo de caída de la bolsa de lima peruana entre 2013 y 2014 ocasionó enormes pérdidas para los inversionistas de la BVL. El presente gráfico tiene como objetivo observar si en nuestra muestra los inversionistas sufrieron pérdidas significativas, el objetivo de esta pregunta en la encuesta era observar si existe alguna relación tangible entre las pérdidas incurridas y la experiencia de los inversionistas.

Se les preguntó a los inversionistas, para el periodo seleccionado en cuanta pérdida habían incurrido sus portafolios, los resultados pueden ser observados en la tabla 3.9 .

El 7\% de los inversionistas (4 jóvenes y 2 experimentados) admitieron haber incurrido en pérdidas en el rango de $30 \%$ a $50 \%$ en los años mencionados, mientras que el $31 \%$ de estos (13 jóvenes y 13 experimentados) incurrieron en niveles de pérdida entre $10 \%$ y $30 \%$.

Un $14 \%$ del total de inversionistas admitió haber incurrido en pérdidas mayores a $50 \%$ de estos 5 eran jóvenes y 7 eran experimentados. 
Los resultados pueden ser resumidos de la siguiente manera: El 83\% (33) de los inversionistas jóvenes admitió haber experimentado pérdidas, y un 55\% admite que estas pérdidas alcanzaron un nivel desde más de $50 \%$ hasta $10 \%$.

El 75\% (33) de los inversionistas experimentados admitió haber incurrido en pérdidas, y el $50 \%$ de estos admite que las pérdidas alcanzaron un nivel desde más de $10 \%$ hasta más de $50 \%$.

Siete inversionistas jóvenes marcaron la opción de no haber incurrido en pérdidas, pero revisando la data se encontró que debido al tiempo de experiencia en bolsa estos inversionistas no se encontraban transando en el periodo analizado por lo cual serán excluidos del siguiente análisis.

Se realizó un test Chi-cuadrado de independencia para comprobar si la hipótesis de menores pérdidas ligadas a años de experiencia de la siguiente manera:

Ho: No existe relación entre los años de experiencia y las pérdidas incurridas en el portafolio de los inversionistas en el periodo analizado.

H1: Existe relación entre los años de experiencia y las pérdidas incurridas en el portafolio de los inversionistas en el periodo analizado.

\section{Tabla 3.10}

Test chi cuadrado (experiencia de los inversionistas y pérdidas del portafolio)

\begin{tabular}{|l|l|l|l|l|}
\hline Chi-Square Tests & Value & df & Asymptotic Significance (2-sided) \\
\hline Pearson Chi-Square & 3.696 & 4 & 0.449 & \\
\hline Likelihood Ratio & 3.907 & 4 & 0.419 & \\
\hline N of Valid Cases & 77 & & & \\
\hline
\end{tabular}

Fuente: Data recopilada y procesada en SPSS.

Tanto el p-value de la Chi-cuadrado de Pearson como del Likelihood Ratio no nos permiten rechazar la hipótesis nula a un $95 \%$ de confianza, por lo cual no se puede considerar que exista una relación directa o significativa entre los años de experiencia de los inversionistas y las pérdidas incurridas en el periodo analizado. 


\subsection{Análisis discriminante}

Se utilizó la variable dicotómica (1-joven, 2-experimentado) como discriminante. El objetivo del análisis era encontrar si esta variable es un discriminador efectivo, es decir si se puede correctamente categorizar a los inversionistas entre jóvenes y experimentados de acuerdo al efecto de los sesgos conductuales en ellos.

Para este análisis se espera obtener diferencias entre los resultados de ambos grupos para ellos se analizó los resultados de las tablas 3.11 y 3.12 "Group Statistics” e Igualdad de las medias.

A continuación, se presentan resultados diferentes y en algunos casos contradictorios. Las variables Disonancia Cognitiva y Retrospectiva presentaban medias muy cercanas mientras que variables como Falacia del Jugador, Anclaje y Exceso de confianza también mostraban diferencias bastante pequeñas en las medias. Sin embargo sí se presentan diferencias en las medias de las variables Representatividad, Efecto Manada, Temor al arrepentimiento y especialmente Contabilidad Mental.

Tabla 3.11

Análisis discriminante (group statistics)

\begin{tabular}{|c|c|c|c|c|c|}
\hline \multicolumn{6}{|c|}{ Group Statistics } \\
\hline \multirow{2}{*}{\multicolumn{2}{|c|}{ YariableDicotomica }} & \multirow{3}{*}{$\begin{array}{l}\text { Mean } \\
3.3500\end{array}$} & \multirow{3}{*}{$\begin{array}{l}\text { Std. } \\
\text { Deviation } \\
0.5335\end{array}$} & \multicolumn{2}{|c|}{ Valid N (listwise) } \\
\hline & & & & Unweighted & Weighted \\
\hline \multirow[t]{9}{*}{ Joven } & Excess de Confianza & & & 40 & 40.000 \\
\hline & Representatividad & 2.2625 & 0.3200 & 40 & 40.000 \\
\hline & Efecte Manada & 2.5375 & 0.4986 & 40 & 40.000 \\
\hline & Disonancia Cognitiva & 2.0250 & 0.4797 & 40 & 40.000 \\
\hline & Temor al arrepentimiente & 2.0875 & 0.5417 & 40 & 40.000 \\
\hline & Contabilidad Mental & 2.4750 & 0.5986 & 40 & 40.000 \\
\hline & Falacia del Jugador & 1.9000 & 0.4414 & 40 & 40.000 \\
\hline & Retrospectivo & 2.0500 & 0.7494 & 40 & 40.000 \\
\hline & Anclaje & 2.0418 & 0.4960 & 40 & 40.000 \\
\hline \multirow[t]{9}{*}{ Experi. } & Excess de Confianza & 3.2955 & 0.9296 & 44 & 44.000 \\
\hline & Representatividad & 2.0795 & 0.4439 & 44 & 44.000 \\
\hline & Efecto Manada & 2.3523 & 0.5765 & 44 & 44.000 \\
\hline & Disonancia Cognitiva & 2.0000 & 0.4035 & 44 & 44.000 \\
\hline & Temor al arrepentimiente & 1.9659 & 0.4498 & 44 & 44.000 \\
\hline & Contabilidad Mental & 2.1136 & 0.8131 & 44 & 44.000 \\
\hline & Falacia del Jugador & 1.8636 & 0.4621 & 44 & 44.000 \\
\hline & Retrospective & 2.0682 & 0.8733 & 44 & 44.000 \\
\hline & Anclaje & 2.0833 & 0.4775 & 44 & 44.000 \\
\hline Total & Excess de Confianza. & 3.3214 & 0.7630 & 84 & 84.000 \\
\hline
\end{tabular}

(continúa) 
(continuación)

\begin{tabular}{|c|c|c|c|c|c|}
\hline & Anclaje & 2.0833 & 0.4775 & 44 & 44.000 \\
\hline \multirow[t]{9}{*}{ Total } & Excess de Confianza. & 3.3214 & 0.7630 & 84 & 84.000 \\
\hline & Representatividad & 2.1667 & 0.3983 & 84 & 84.000 \\
\hline & Efecte Manada & 2.4405 & 0.5455 & 84 & 84.000 \\
\hline & Disonancia Cognitixa & 2.0119 & 0.4389 & 84 & 84.000 \\
\hline & Temor al arrepentimiente & 2.0238 & 0.4964 & 84 & 84.000 \\
\hline & Contabilidad Mental & 2.2857 & 0.7375 & 84 & 84.000 \\
\hline & Falacia del Jugador & 1.8810 & 0.4500 & 84 & 84.000 \\
\hline & Retrospectivo & 2.0595 & 0.8118 & 84 & 84.000 \\
\hline & Anclaje. & 2.0635 & 0.4839 & 84 & 84.000 \\
\hline
\end{tabular}

Fuente: Data recopilada y procesada en SPSS.

La tabla 3.12 presenta evidencia estadística para observar sí existe efectivamente diferencias en las medias presentadas anteriormente, para ello se utilizó la prueba Wilks' Lambda $^{5}$ para la igualdad de las medias basadas en el análisis discriminante.

Pese a lo encontrado anteriormente esta prueba indica que solo las variables Representatividad, Temor al arrepentimiento y Contabilidad Mental poseen valores "F" elevados, sin embargo, utilizando el criterio del p-valor solo se podría rechazar la hipótesis nula para las variables Representatividad y Contabilidad mental, es decir existe una diferencia estadísticamente significativa entre las medias de ambos grupos para estas dos variables. Esto implica, bajo la óptica de nuestro análisis, que estos sesgos conductuales se manifiestan de manera diferente en los inversionistas de ambos grupos.

Para el resto de variables no fue posible comprobar la existencia de diferencias significativas entre las medias de los grupos.

Tabla 3.12

Análisis discriminante (test de igualdad de medias)

\begin{tabular}{|l|l|l|l|l|l|}
\hline Tests of Equality of Group Means & W(Wilks' Lambda & F & df1 & df2 & Sig. \\
\hline & & & & & \\
\hline Exceso de Confianza & 0.999 & 0.106 & 1 & 82 & 0.746 \\
\hline Representatividad & 0.947 & 4.613 & 1 & 82 & 0.035 \\
\hline Efecto Manada & 0.971 & 2.458 & 1 & 82 & 0.121 \\
\hline Disonancia Cognitiva & 0.999 & 0.067 & 1 & 82 & 0.796 \\
\hline
\end{tabular}

(continúa)

\footnotetext{
${ }^{5}$ El test Wilks' Lambda es utilizado en el análisis multivariado de la varianza para probar la hipótesis nula de que ambos grupos tienen medias idénticas basado en el discriminador. Los coeficientes que usa esta prueba son los valores "F", cuando estos son elevados tiende a indicar que las medias son idénticas.
} 
(continuación)

\begin{tabular}{|l|l|l|l|l|l|}
\hline $\begin{array}{l}\text { Temor } \\
\text { arrepentimiento }\end{array}$ & 0.985 & 1.261 & 1 & 82 & 0.265 \\
\hline Contabilidad Mental & 0.939 & 5.291 & 1 & 82 & 0.024 \\
\hline Falacia del Jugador & 0.998 & 0.135 & 1 & 82 & 0.714 \\
\hline & & & & & \\
\hline Retrospectivo & 1.000 & 0.010 & 1 & 82 & 0.919 \\
\hline Anclaje & 0.998 & 0.153 & 1 & 82 & 0.697 \\
\hline
\end{tabular}

Fuente: Data recopilada y procesada en SPSS.

Prosiguiendo con el análisis discriminante se comprobó que las matrices de varianza y covarianza sean idénticas para ambos grupos formados por el discriminador para ello se empleó la prueba M de Box que tiene como hipótesis nula la igualdad de las matrices de los grupos formados por el discriminador.

Tabla 3.13

Análisis discriminante (prueba M de Box)

\begin{tabular}{|c|c|c|c|}
\hline \multirow[t]{2}{*}{ tras } & \multicolumn{3}{|c|}{ Test Results } \\
\hline & \multicolumn{2}{|c|}{ Box's M } & 133.619 \\
\hline & \multirow{4}{*}{$\mathbf{F}$} & Approx. & 2.622 \\
\hline & & df1 & 45 \\
\hline & & df2 & 21668.486 \\
\hline & & Sig. & 0.000 \\
\hline & \multicolumn{3}{|c|}{$\begin{array}{l}\text { Tests null hypothesis of equal } \\
\text { population covariance matrices. }\end{array}$} \\
\hline
\end{tabular}

Fuente: Data recopilada y procesada en SPSS.

El resultado obtenido por el pvalue rechaza la hipótesis nula, lo que implica que se presenta heterocedasticidad entre los dos grupos creados por el análisis discriminante. La presencia de heterocedasticidad implica que los errores estándar asociados con el análisis discriminante no son lo suficientemente grandes y podrían estar sesgados.

De acuerdo a (Ramirez, 2007) la heterocedasticidad surge normalmente en datos de sección cruzada en muchos casos para datos microeconómicos, especialmente en encuestas ya que se trata de una población en un momento del tiempo y esto puede generar un patrón sistemático que afecta la constancia de la varianza.

En algunas muestras, sin embargo, es razonable suponer que la distribución potencial del término de disturbio es diferente en "diferentes" observaciones de la misma muestra (Ramirez, 2007) 
Para la investigación propuesta se piensa que este es un resultado posible y plausible debido al tamaño limitado de la muestra obtenida.

Por otro lado, según el departamento de estadística de la Universidad Carlos III de Madrid, la violación de este supuesto no tiene consecuencias tan graves debido a que, "En sentido estricto, la función discriminante minimiza la probabilidad de equivocarse al clasificar los individuos en cada grupo. Para esto, las variables originales deben tener una distribución normal multivariante y las matrices de covarianzas deben ser iguales en todos los grupos. Sin embargo, en la práctica esta es una técnica robusta y funciona bien aun cuando las dos restricciones anteriores no se cumplan" (Universidad Carlos III de Madrid, 2006).

Por otro lado, muchos investigadores consideran que el test $\mathrm{M}$ de Box, es muy sensible a la falta de normalidad multivariante y esto puede llevar a que matrices iguales pueden parecer como significativamente diferentes para dicho test (De la Fuente F., 2011).

Por lo tanto, se ha decidió por proseguir con el análisis sin embargo este resultado será discutido posteriormente.

Antes de pasar a mostrar la función discriminante obtenida por el análisis se utilizó la prueba de Wilk's Lambda para ver la proporción de la variabilidad total que no es explicada por la función.

Tabla 3.14

Análisis discriminante (test de Wilk's Lambda)

\begin{tabular}{|l|l|l|l|l|}
\hline $\begin{array}{l}\text { Wilks' Lambda } \\
\text { Test of Function(s) }\end{array}$ & $\begin{array}{l}\text { Chi- } \\
\text { square }\end{array}$ & df & \\
\hline $\mathbf{1}$ & 0.857 & 11.930 & 9.000 & 0.217 \\
\hline
\end{tabular}

Fuente: Data recopilada y procesada en SPSS.

El resultado muestra que el $85.7 \%$ de la variabilidad no es explicada por la función discriminante. Esto podría implicar que no existe una diferencia estadísticamente significativa entre el comportamiento presentado por ambos grupos estudiados al ser afectados por los sesgos conductuales. De esta manera contra el p-valor del Wilk's Lambda se prueban las siguientes hipótesis: 
- H0: Ambos grupos de inversionistas son igualmente afectados por los sesgos conductuales.

- H1: Existe un grupo de inversionistas más afectado que el otro por los sesgos.

En este caso la hipótesis nula no puede ser rechazada, lo que implica que ambos grupos de inversionistas están siendo efectivamente afectados de manera similar por los sesgos conductuales.

A pesar de estos resultados, es importante resaltar que la tabla 12 confirmó mediante evidencia estadísticamente representativa que Representatividad y Contabilidad Mental son dos sesgos conductuales que se manifiestan de manera diferente en ambos grupos de inversionistas.

Los coeficientes canónicos estandarizados de la función discriminante son el equivalente a los coeficientes que se obtienen en análisis de regresión múltiple. Entre más alto sea el valor de dichos coeficientes, mayor será la importancia de esas variables en la predicción de diferencias entre ambos grupos. Los signos de los coeficientes indican la dirección de la relación.

Tabla 3.15

Análisis discriminante (coeficientes estandarizados canónicos)

\begin{tabular}{|c|c|}
\hline $\begin{array}{lr}\text { Standardized } & \text { Canonical } \\
\text { Discriminant } & \text { Function } \\
\text { Coefficients } & \end{array}$ & Function \\
\hline Exceso de Confianza & -.225 \\
\hline Representatividad & .558 \\
\hline Efecto Manada & .270 \\
\hline Disonancia Cognitiva & .050 \\
\hline Temor al arrepentimiento & -.056 \\
\hline Contabilidad Mental & .824 \\
\hline Falacia del Jugador & .216 \\
\hline Retrospectivo & -.102 \\
\hline Anclaje & -.538 \\
\hline
\end{tabular}

Fuente: Data recopilada y procesada en SPSS.

Podemos observar que las variables Contabilidad Mental y Representatividad tienen coeficientes bastante elevados, esto comprueba ulteriormente los resultados obtenidos previamente en la tabla 3.14. Es interesante sin embargo observar que temor al arrepentimiento que parecía ser una variable significativa para la tabla 3.14 tiene un coeficiente canónico bastante bajo perdiendo de esta manera peso relativo como variable, 
por otro lado, la variable Anclaje a pesar de no parecer significativa en pruebas anteriores presenta un coeficiente bastante elevado lo que podría implicar que si brinda un aporte significativo para predecir las diferencias entre grupos.

Tabla 3.16

Análisis discriminante (matriz de estructura)

\begin{tabular}{|c|c|c|}
\hline & \multirow[t]{2}{*}{ Structure Matrix } & Function \\
\hline & & 1 \\
\hline & Contabilidad Mental & .623 \\
\hline & Representatividad & .581 \\
\hline & Efecto Manada & .424 \\
\hline & Temor al arrepentimiento & .304 \\
\hline & Anclaje & -.106 \\
\hline & Falacia del Jugador & .100 \\
\hline & Exceso de Confianza & .088 \\
\hline & Disonancia Cognitiva & .070 \\
\hline & Retrospectivo & -.028 \\
\hline & $\begin{array}{l}\text { Pooled within-groups correlations } \\
\text { between discriminating variables } \\
\text { and standardized canonical } \\
\text { discriminant functions } \\
\text { Variables ordered by absolute size } \\
\text { of correlation within function. }\end{array}$ & \\
\hline
\end{tabular}

Fuente: Data recopilada y procesada en SPSS

La matriz de estructura es otro método utilizado en el análisis discriminante para observar la importancia relativa de las variables independientes. Esta prueba se considera aún más exacta que los coeficientes canónicos estandarizados. En la tabla 3.16 podemos observar en orden de importancia las variables que más aporte brindan a la función discriminante, como ha sido reportado previamente, Contabilidad Mental, Representatividad y Temor al Arrepentimiento son tres de los sesgos con mayor aporte, pero es interesante observar que la variable Efecto Manada adquirió importancia como discriminador a pesar de no serlo en pruebas anteriores.

El análisis discriminante ofrece la opción de presentar los resultados en tablas de clasificación, estas tablas son una manera interesante de representar los patrones de comportamiento observados en ambos grupos de inversionistas.

En la tabla 3.17 se podrá observar en las filas las observaciones originales y en las columnas las predicciones del modelo. 
Tabla 3.17

Análisis discriminante (tabla de clasificación)

\begin{tabular}{|c|c|c|c|c|c|}
\hline \multicolumn{6}{|c|}{ Classification Results ${ }^{\mathrm{a}, \mathrm{c}}$} \\
\hline \multirow{2}{*}{\multicolumn{3}{|c|}{ VariableDicotomica }} & \multicolumn{2}{|c|}{ Predicted Group } & \multirow[b]{2}{*}{ Total } \\
\hline & & & $\mathrm{J}$ & $\mathrm{E}$ & \\
\hline \multirow{4}{*}{ Original } & \multirow{2}{*}{ Conteo } & Joven & 24 & 16 & 40 \\
\hline & & Experimentado & 11 & 33 & 44 \\
\hline & \multirow{2}{*}{$\%$} & Joven & 60.0 & 40.0 & 100.0 \\
\hline & & Experimentado & 25.0 & 75.0 & 100.0 \\
\hline \multirow{4}{*}{ Cross-validated $^{\mathrm{b}}$} & \multirow{2}{*}{ Conteo } & Joven & 19 & 21 & 40 \\
\hline & & Experimentado & 13 & 31 & 44 \\
\hline & \multirow{2}{*}{$\%$} & Joven & 47.5 & 52.5 & 100.0 \\
\hline & & Experimentado & 29.5 & 70.5 & 100.0 \\
\hline
\end{tabular}

a. $67.9 \%$ of original grouped cases correctly classified.

b. Cross validation is done only for those cases in the analysis. In cross validation, each case is classified by the functions derived from all cases other than that case.

c. $59.5 \%$ of cross-validated grouped cases correctly classified.

Fuente: Data recopilada y procesada en SPSS.

La tabla 3.19 muestra que el $67.9 \%$ de los casos originales fueron correctamente clasificados por el análisis discriminante, lo cual es un resultado bastante elevado. La tabla presenta dos tipos de resultados, los originales y los validados de forma cruzada. En la clasificación original 16 inversionistas jóvenes (40\%) presentaban un comportamiento frente a los sesgos atribuido por al análisis a inversionistas experimentados mientras que solo el $11(25 \%)$ de los inversionistas experimentados mostraron patrones de comportamiento atribuidos por el análisis a inversionistas jóvenes. En la segunda parte de la tabla se muestran resultados con un mayor nivel de precisión debido a que, bajo este método, una variable no es considerada y luego la función discriminante es desarrollada usando el resto de variables de manera que la variable omitida es categorizada usando este resultado. El proceso es repetido para todas las variables y de esa manera se obtienen los resultados cruzados.

$\mathrm{Al}$ obtenerse que un $67.9 \%$ de los casos han sido clasificados correctamente, la presente investigación postula que efectivamente existe diferencias entre inversionistas jóvenes y experimentados a pesar de que no se pueda decir que uno de los dos grupos sea afectado de manera diferente por los sesgos conductuales.

Mientras que los coeficientes canónicos estandarizados son utilizados para elaborar un ranking de la contribución de las variables a la diferenciación de los grupos 
los coeficientes no canónicos no estandarizados sirven para construir la función discriminante y establecer los verdaderos coeficientes de cada una de las variables.

Tabla 3.18

Análisis discriminante (coeficientes canónicos no estandarizados)

\begin{tabular}{|l|l|}
\hline \multicolumn{2}{|c|}{ Canonical Discriminant Function Coefficients } \\
\hline & Function \\
\cline { 2 - 2 } Exceso de Confianza & 1 \\
\hline Representatividad & -.294 \\
\hline Efecto Manada & 1.432 \\
\hline Disonancia Cognitiva & .498 \\
\hline Temor al arrepentimiento & .114 \\
\hline Contabilidad Mental & -.113 \\
\hline Falacia del Jugador & 1.146 \\
\hline Retrospectivo & .476 \\
\hline Anclaje & -.125 \\
\hline (Constant) & -1.106 \\
\hline Unstandardized coefficients & -4.319 \\
\hline
\end{tabular}

Fuente: Data recopilada y procesada en SPSS.

De manera que la función discriminante del análisis sería la siguiente:

$$
\mathrm{D}=-0.294 \mathrm{EC}+1.432 \mathrm{R}+0.498 \mathrm{EM}+0.114 \mathrm{DC}-0.113 \mathrm{TA}+
$$

\section{146CM + 0.476FJ $-0.125 R e t-1.106 A-4.319$}

Siendo, EC: Exceso de confianza, R: Representatividad, EM: Efecto Manda, DC: Disonancia Cognitiva, TA: Temor al arrepentimiento, CM: Contabilidad Mental, FJ: Falacia del Jugador, Ret: Retrospectivo, A: Anclaje y D la función discriminante. Cada coeficiente indica la contribución de dicha variable a la función, por ejemplo, la variable Contabilidad Mental con un coeficiente de 1.146 indica que este sesgo se presentó de manera diferente entre ambos grupos.

\subsection{Impacto independiente de los sesgos conductuales}

En la tabla 3.19 se puede observar la composición de preguntas que sirvieron para la construcción de las nueve variables, los resultados de estas preguntas se mostraran a 
continuación en el presente capitulo. Debido a la extensión de las preguntas estas estarán incluidas en el apéndice $\mathrm{I}^{6}$

Tabla 3.19

Clasificación de las preguntas de la encuesta, según sesgo conductual

\begin{tabular}{|lcll|}
\hline \multicolumn{1}{|c}{ Sesgo } & $\mathrm{N}^{\circ}$ de & \multicolumn{1}{c|}{ Numeros } & Formato \\
\hline Exceso de Confianza & 5 & $10,11,12,13$ y 14 & SPSS \\
Representatividad & 2 & 5 y 8 & SPSS \\
Efecto Manada & 3 & 4,6 y 7 & SPSS \\
Anclaje & 3 & 15,16 y 19 & SPSS \\
Disonancia Cognitiva & 2 & 20 y 21 & SPSS \\
Temor al arrepentimiento & 2 & 23 y 24 & SPSS \\
Falacia del Jugador & 2 & 25 y 26 & SPSS \\
Contabilidad Mental & 1 & 12 & SPSS \\
Retrospectiva & 2 & 9 y 29 & SPSS \\
\hline
\end{tabular}

Elaboración propia

\subsubsection{Exceso de confianza}

El exceso de confianza es uno de los sesgos conductuales más comunes, reconocidos y estudiados. Para la presente investigación se plantearon 5 preguntas relacionadas al exceso de confianza en la encuesta ${ }^{7}$. Todas las preguntas, excepto una, fueron diseñadas

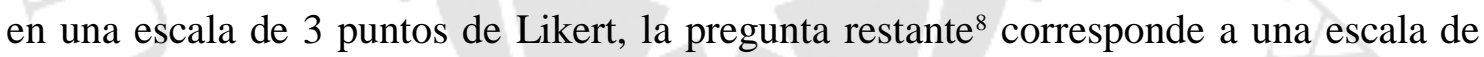
Likert de 7 puntos y fue recodificada para que responda a una Likert 3 puntos de la siguiente manera: 5-7 = alto riesgo, 3-4 = riesgo medio y 1-2 = bajo riesgo.

Posteriormente las 5 preguntas fueron puntuadas (con valores de 1-3 como ha sido explicado previamente), sumadas, promediadas y recodificadas para que representen una escala de 5 puntos de Likert que se puede observar en la tabla 3.20

\footnotetext{
${ }^{6}$ Preguntas del cuestionario, Anexo I.

${ }^{7}$ Preguntas 10-14, Anexo I.

${ }^{8}$ Pregunta 12 , Anexo I
} 
Tabla 3.20

Exceso de confianza - tabla de contingencia

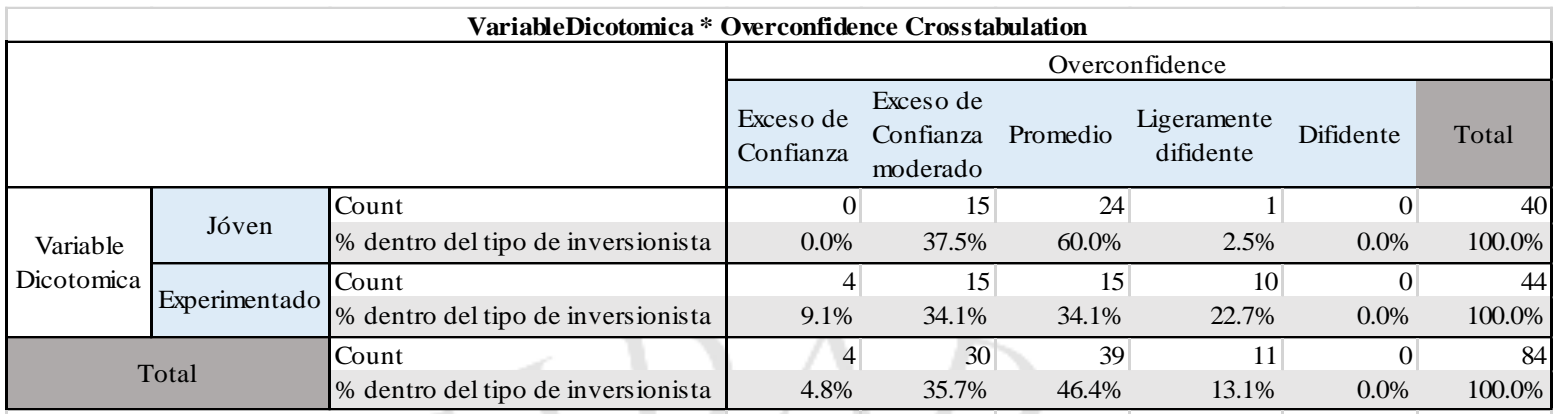

Fuente: Data recopilada y procesada en SPSS

De esta tabla es importante notar que el $37.5 \%$ de los inversionistas jóvenes y el 43.18\% de los inversionistas experimentados presentan al menos un nivel de exceso de confianza al menos moderado al tomar decisiones de inversión.

Los resultados del análisis discriminante sugieren que el Exceso de Confianza no es una variable que puede diferenciar a los inversionistas entre jóvenes y experimentados, para comprobar esto se realizó un test Chi-cuadrado.

Hipótesis a probar:

- H0: Los inversionistas jóvenes no presentan el sesgo de exceso de confianza más que los inversionistas experimentados.

- H1: Los inversionistas jóvenes presentan el sesgo de exceso de confianza en una proporción mayor o menor a los inversionistas experimentados.

Tabla 3.21

Exceso de confianza - test chi-cuadrado I

\begin{tabular}{|l|l|l|l|}
\hline Chi-Square Tests & Value & df & $\begin{array}{l}\text { Asymp. } \\
\text { Sig. (2- } \\
\text { sided) }\end{array}$ \\
\hline Pearson Chi-Square & $13.280^{\mathrm{a}}$ & 3 & .004 \\
\hline Likelihood Ratio & 15.998 & 3 & .001 \\
\hline Linear-by-Linear Association & .107 & 1 & .743 \\
\hline N of Valid Cases & 84 & & \\
\hline
\end{tabular}

a. 2 cells $(25.0 \%)$ have expected count less than 5 . The minimum expected count is 1.90 .

Fuente: Data recopilada y procesada en SPSS. 
Los resultados de la tabla 3.21 no pueden ser validados debido a que dos celdas contaban con el número mínimo de observaciones, por lo tanto, se repitió el análisis uniendo las categorías de Exceso de Confianza y Exceso de Confianza Moderado, así como Difidente con Ligeramente difidente.

Tabla 3.22

Exceso de confianza - test chi-cuadrado II

\begin{tabular}{|l|l|l|l|}
\hline Chi-Square Tests & \multicolumn{3}{l|}{} \\
\hline Pearson Chi-Square & Value & df & Asymp. Sig. (2-sided) \\
\hline Likelihood Ratio & $9.743^{\text {a }}$ & 2 & .008 \\
\hline Linear-by-Linear Association & 10.924 & 2 & .004 \\
\hline N of Valid Cases & .951 & 1 & .330 \\
\hline
\end{tabular}

a. 0 cells $(0.0 \%)$ have expected count less than 5 . The minimum expected count is 5.24 . Fuente: Data recopilada y procesada en SPSS.

El p-valor de la prueba Chi-cuadrado de Pearson rechaza la hipótesis nula, lo que implica que la experiencia de los inversionistas tiene influencia en el comportamiento derivado de la presencia del sesgo Exceso de Confianza. Este resultado entra en contradicción con los resultados obtenidos por el análisis discriminante anterior, lo cual se tuvo en cuenta para los resultados finales en el siguiente capítulo.

Para comprobar si los inversionistas en general tienden a presentar el sesgo de exceso de confianza se utilizó el método de puntajes ponderados, como puede ser observado en la tabla 3.23

Se asignaron pesos de 5 a 1 a las diferentes columnas (partiendo de 5 para el Exceso de Confianza hasta 1 para los Difidentes) el cálculo fue realizado en MS Excel.

Tabla 3.23

Exceso de confianza - Puntajes ponderados

\begin{tabular}{|l|l|l|l|l|}
\hline $\begin{array}{l}\text { Tipo de } \\
\text { Inversionista }\end{array}$ & $\begin{array}{l}\text { Puntaje } \\
\text { Ponderado }\end{array}$ & Promedio & $\begin{array}{l}\text { Puntaje } \\
\text { de } \\
\text { referencia }\end{array}$ & Resultado \\
\hline Jóven & 134 & 8.9 & 8 & Presencia del Sesgo \\
\hline Experimentado & 145 & 9.7 & 8.8 & Presencia del Sesgo \\
\hline
\end{tabular}

Fuente: Data recopilada y procesada en MS Excel.

El puntaje de referencia se calcula asumiendo una supuesta muestra donde el total de los participantes eligieron la opción neutral (en este caso promedio con un peso de 3 ). 
Tanto el grupo de inversionistas jóvenes como el grupo de inversionistas experimentados tienen puntajes ponderados promedio superiores al puntaje de referencia, lo que da indicios de que en general ambos grupos de inversionistas son afectados en mayor proporción por el sesgo efecto de confianza que una población neutral.

\subsubsection{Representatividad}

El sesgo de representatividad aparece cuando, en muchos casos, los inversionistas catalogan ciertos tipos de acciones solamente en base a eventos pasados de compañías "similares", ya sean estos del pasado inmediato o antiguo. Esto sucede debido a que es más fácil para el ser humano comparar información nueva en función de categorías previamente creadas (normalmente en función a la experiencia), de esta manera la mente evita realizar análisis “innecesarios” y "evita” una pérdida de tiempo.

El análisis de este sesgo tuvo resultados diversos en el análisis discriminante, las pruebas que se exponen a continuación tienen como objetivo analizar si ambos grupos de inversionistas pueden ser separados por su afinidad al sesgo y si, en general, los inversionistas presentan el sesgo en sus decisiones.

Los resultados de utilizar simplificaciones heurísticas para inversionistas implican que estos puedan exagerar su optimismo al haber tomado decisiones correctas o ser exageradamente pesimistas con respecto a pérdidas o malas decisiones realizadas.

Por lo tanto, se realizó una pregunta ${ }^{9}$ para observar si los inversionistas consideraban el comportamiento pasado de una acción antes de invertir en ella. El resultado de esta pregunta fue que el $70 \%$ de los inversionistas jóvenes y el $43.2 \%$ de los inversionistas experimentados siempre analizaban el comportamiento pasado de una acción antes de invertir en ella.

Por otro lado, se considera que un inversionista está sujeto al sesgo de representatividad cuando piensa que pueda predecir el valor futuro de una acción basado exclusivamente en su comportamiento pasado. En la pregunta 8 se hizo está misma pregunta, los resultados fueron sorprendentes ya que el $9.5 \%$ de los inversionistas

\footnotetext{
${ }^{9}$ Pregunta 5, Anexo I.
} 
considera que sí es posible encontrar el valor futuro de una acción mediante un análisis detallado de su comportamiento pasado y el $63.1 \%$ de los inversionistas consideran que es posible en algunas ocasiones.

Para comprobar si los inversionistas en la presente investigación estaban o no sujetos de manera significativa al sesgo se realizaron dos preguntas ${ }^{10}$, ambas corresponden a una escala de Likert de 3 puntos, las cuales fueron combinadas de la forma previamente explicada para analizar el sesgo.

Tabla 3.24

Representatividad - tabla de contingencia

\begin{tabular}{|c|c|c|c|c|c|c|}
\hline & & VariableDicotomica * Representat & dad Crosst: & ibulation & & \\
\hline & 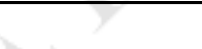 & 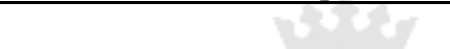 & & Represe & atividad & \\
\hline & & & Siempre & $\begin{array}{c}\text { Algunas } \\
\text { Veces }\end{array}$ & Nunca & Total \\
\hline & Jóven & Count & 20 & 19 & 1 & \\
\hline Variable & Joven & $\%$ dentro del tipo de inversionista & $50.0 \%$ & $47.5 \%$ & $2.5 \%$ & $100.0 \%$ \\
\hline Dicotomica & & Count & 15 & 21 & 8 & 44 \\
\hline & Experimentado & $\%$ dentro del tipo de inversionista & $34.1 \%$ & $47.7 \%$ & $18.2 \%$ & $100.0 \%$ \\
\hline & Tot & Count & 35 & 40 & 9 & 84 \\
\hline & otal & $\%$ dentro del tipo de inversionista & $41.7 \%$ & $47.6 \%$ & $10.7 \%$ & $100.0 \%$ \\
\hline
\end{tabular}

Fuente: Data recopilada y procesada en SPSS.

De la misma manera que en el análisis anterior podemos observar que el 50\% de los inversionistas jóvenes y el $34.1 \%$ de los experimentados son afectados por el sesgo conductual de manera significativa y solo un $10.7 \%$ de los inversionistas totales no son afectados por el sesgo de representatividad (siendo la mayoría inversionistas experimentados y muy pocos jóvenes). Estos porcentajes son significativamente diferentes y podemos observar que el sesgo afecta en mayor medida a los inversionistas jóvenes frente a los experimentados.

Para comprobar estos resultados se utilizó la prueba de Chi-cuadrado de la misma forma que en el sesgo anterior, sin embargo, el número de casos recomendados por el SPSS no se cumple por lo que los resultados no pueden ser presentados con significancia (el test rechazaba $\mathrm{H} 0$ de manera que los inversionistas jóvenes son más afectados que los inversionistas experimentados).

${ }^{10}$ Pregunta 5 y 8 , Anexo I. 
Tabla 3.25

Representatividad - puntajes ponderados

\begin{tabular}{|c|c|c|c|c|}
\hline $\begin{array}{ll}\text { Tipo } & \text { de } \\
\text { Inversionista }\end{array}$ & $\begin{array}{l}\text { Puntaje } \\
\text { Ponderado }\end{array}$ & Promedio & $\begin{array}{l}\text { Puntaje } \\
\text { referencia }\end{array}$ & Resultado \\
\hline Jóven & 99 & 16.5 & 13.3 & $\begin{array}{l}\text { Presencia } \\
\text { Sesgo }\end{array}$ \\
\hline Experimentado & 95 & 15.8 & 14.7 & $\begin{array}{l}\text { Presencia } \\
\text { Sesgo }\end{array}$ \\
\hline
\end{tabular}

Fuente: Data recopilada y procesada en MS Excel.

Luego se evaluó mediante el método de puntajes ponderados si los inversionistas presentaban el sesgo en mayor proporción a una muestra de referencia con todos los inversionistas neutrales al riesgo. Los resultados muestran tanto para los inversionistas jóvenes como para los experimentados son afectados en mayor medida que la muestra de referencia, además se observa que el puntaje promedio de los inversionistas jóvenes es significativamente mayor al de los inversionistas experimentados, brindando mayor evidencia de que este grupo es más afectado que el segundo por el sesgo conductual.

Para resumir los resultados indican que los inversionistas entrevistados son altamente susceptibles a presentar el sesgo de representatividad al tomar decisiones de inversión, siendo los inversionistas jóvenes el grupo más propenso a ser afectado por dicho sesgo. Esto puede estar llevándolos a tomar decisiones de inversión erradas subestimando compañías que tengan características similares malas inversiones realizadas en el pasado y sobrestimando el valor de compañías que sean similares a buenas inversiones pasadas.

\subsubsection{Efecto manada}

Si un inversionista basa la mayor parte de sus decisiones en los "sentimientos" del mercado o en las decisiones tomadas por la mayoría en lugar de utilizar su propio criterio puede decirse efectivamente que está siendo afectado por el sesgo conductual Efecto Manada.

Ya sea debido a que considere que la mayoría de las personas toman la decisión correcta o porque tenga miedo de quedar en ridículo si se equivoca, el efecto manada daña los resultados del inversionista ya que al tomar las mismas decisiones que el resto es imposible obtener ganancias anormales. El grave problema del efecto manada se 
genera cuando hay corrientes negativas, como el caso de las "corridas o rally" (cuando gran parte de los inversionistas entran en pánico debido a alguna noticia o suceso y venden en "manada" toda su posición de una acción y de esta manera destruyen el precio el precio de esta) por ejemplo. Esto puede llevar a los inversionistas a incurrir en pérdidas extraordinarias, en especial para inversionistas privados ya que estos son más propensos a mantener acciones a la baja debido a la incerteza o por imitar lo que el resto de los inversionistas está haciendo.

Para la presente investigación se preguntó ${ }^{11}$ a los inversionistas en que juicio o criterio daban mayor importancia al realizar inversiones, a continuación, se muestran los resultados:

El 53.6\% del total de inversionistas confían más en su propio criterio que en otras fuentes, el $60 \%$ de los inversionistas jóvenes, frente a un $47.7 \%$ de los inversionistas experimentados.

El 47.7\% de los inversionistas experimentados confían en el criterio de brokers o expertos más que en cualquier otra fuente, mientras que tan solo el $30 \%$ de los inversionistas jóvenes confían más en expertos y brokers. Este resultado puede implicar que los inversionistas jóvenes hacen menor uso de brokers al realizar inversiones.

Solo el $7.1 \%$ del total de inversionistas confían en el juicio de amigos o colegas, el $10 \%$ de los inversionistas jóvenes y el $4.5 \%$ de los inversionistas experimentados.

Tabla 3.26

Efecto manada preliminar - tabla de contingencia II

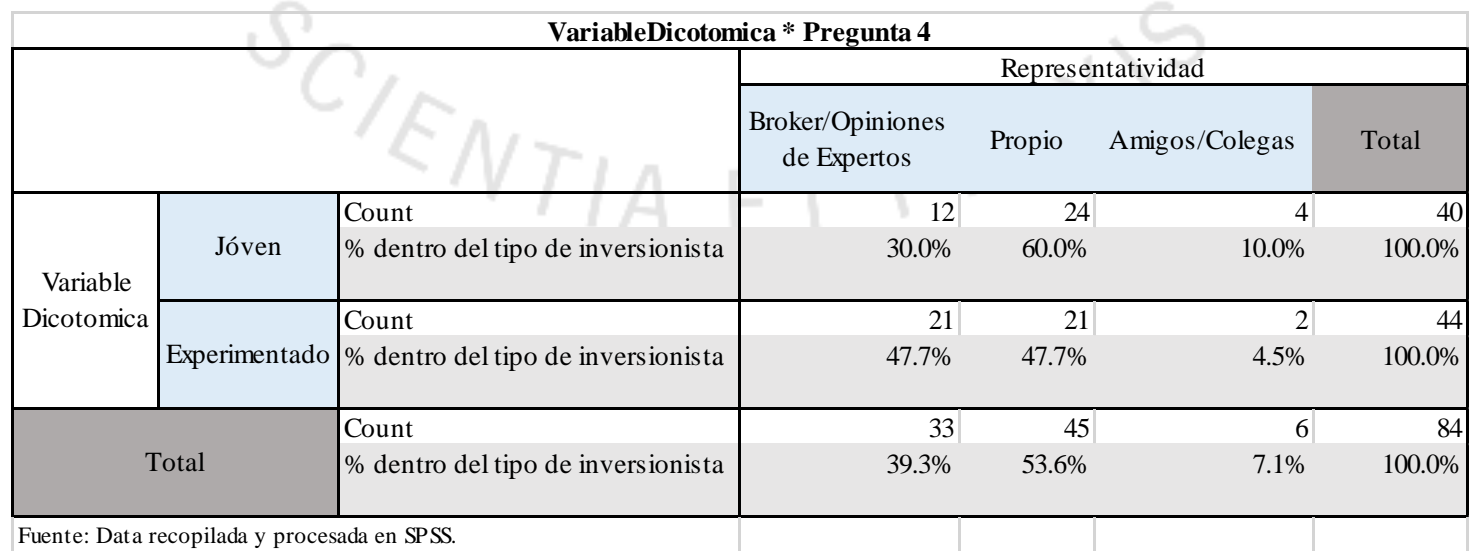

${ }^{11}$ Pregunta 4, Anexo I. 
Para confirmar la significancia de la tabla anterior se realizó un test Chi-cuadrado, sin embargo, para esta pregunta el número de casos recomendados por el SPSS no se cumple por lo que los resultados no pueden ser presentados con significancia.

Idealmente, si se realizan inversiones de largo plazo, los volúmenes diarios de compra-venta de una acción no deberían tener mucho peso en las decisiones de los inversionistas. Volúmenes altos usualmente representan el trabajo de traders o en algunos casos especuladores. Para ver como reaccionaban los inversionistas peruanos se realizó una pregunta ${ }^{12}$, los resultados son presentados en la tabla 3.27

Tabla 3.27

Efecto manada preliminar - tabla de contingencia II

\begin{tabular}{|c|c|c|c|c|c|c|}
\hline & 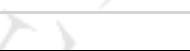 & VariableDicotomica * & Pregunta 6 & & & \\
\hline & & & & Efecto Ma & ada & \\
\hline & & & Siempre & Algunas veces & Nunca & Total \\
\hline & Jóx & Count & 27 & 8 & 5 & 40 \\
\hline Variable & Joven & $\%$ dentro del tipo de inversionista & $67.5 \%$ & $20.0 \%$ & $12.5 \%$ & $100.0 \%$ \\
\hline Dicotomica & & Count & 25 & 8 & 11 & 44 \\
\hline & Experimentado & $\%$ dentro del tipo de inversionista & $56.8 \%$ & $18.2 \%$ & $25.0 \%$ & $100.0 \%$ \\
\hline & Cotal & Count & 52 & 16 & 16 & 84 \\
\hline & otal & $\%$ dentro del tipo de inversionista & $61.9 \%$ & $19.0 \%$ & $19.0 \%$ & $100.0 \%$ \\
\hline
\end{tabular}

Fuente: Data recopilada y procesada en SPSS.

Para el caso peruano el $61.9 \%$ de los inversionistas totales aceptaron siempre observar el volumen de compra de una acción antes de realizar decisiones, $67.5 \%$ de los inversionistas jóvenes y el $56.8 \%$ de los inversionistas experimentados.

A pesar de que es un indicador de efecto manada la pregunta anterior por sí sola no puede ser considerada como una prueba concreta de la presencia del efecto manada en los inversionistas de la muestra por lo tanto se realizó una pregunta ${ }^{13}$ adicional para ver cómo reaccionarían los inversionistas ante una "fiebre de compras", los resultados se muestran en la tabla 3.28 .

\footnotetext{
${ }^{12}$ Pregunta 6, anexo I.

${ }^{13}$ Pregunta 7, anexo I
} 
Tabla 3.28

Efecto manada preliminar - tabla de contingencia III

\begin{tabular}{|c|c|c|c|c|c|c|}
\hline \multicolumn{7}{|c|}{ VariableDicotomica * Pregunta 7} \\
\hline & & & \multicolumn{4}{|c|}{ Efecto Manada } \\
\hline & & & Positivamente & Sin efecto & Negativamente & Total \\
\hline \multirow{4}{*}{$\begin{array}{c}\text { Variable } \\
\text { Dicotomica }\end{array}$} & \multirow{2}{*}{ Jóven } & Count & 24 & 14 & 2 & 40 \\
\hline & & $\%$ dentro del tipo de inversionista & $60.0 \%$ & $35.0 \%$ & $5.0 \%$ & $100.0 \%$ \\
\hline & \multirow{2}{*}{ Experimentado } & Count & 20 & 21 & 3 & 44 \\
\hline & & $\%$ dentro del tipo de inversionista & $45.5 \%$ & $47.7 \%$ & $6.8 \%$ & $100.0 \%$ \\
\hline \multirow{2}{*}{\multicolumn{2}{|c|}{ Total }} & Count & 44 & 35 & 5 & 84 \\
\hline & & $\%$ dentro del tipo de inversionista & $52.4 \%$ & $41.7 \%$ & $6.0 \%$ & $100.0 \%$ \\
\hline
\end{tabular}

En la tabla se puede apreciar que el $52.4 \%$ de los inversionistas reaccionarían positivamente a la situación planteada y esto da una gran señal de la presencia del efecto manada. Es importante resaltar este sesgo parece afectar en mayor medida a los inversionistas jóvenes ya que el $60 \%$ se vería influenciado por la fiebre de compras frente a solo el $45.5 \%$ de los inversionistas experimentados.

Para comprobar la presencia del sesgo las dos últimas preguntas fueron combinadas y clasificadas como ha sido previamente explicado para crear una escala de Likert de 3 puntos, los resultados se observan en la tabla 3.29

Tabla 3.29

Efecto manada - tabla de contingencia

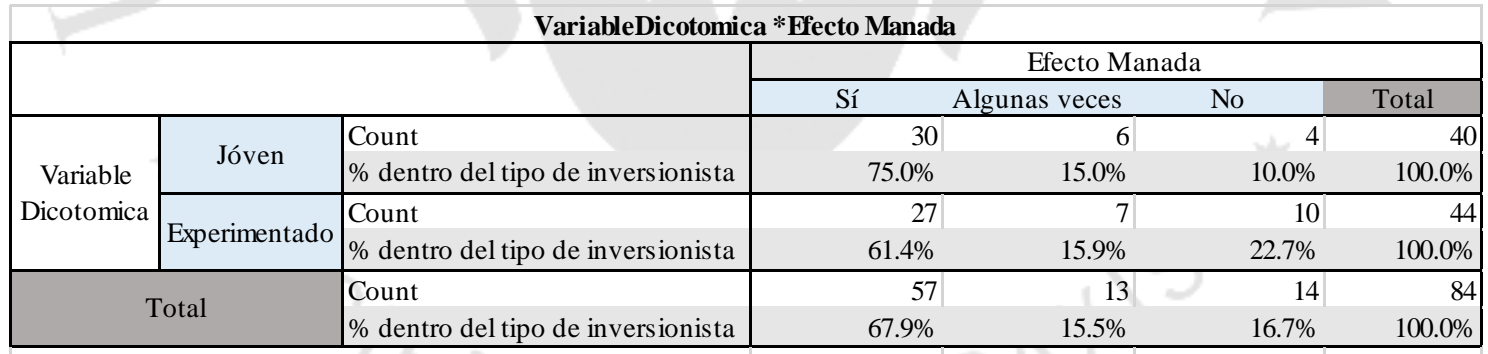

Fuente: Data recopilada y procesada en SPSS.

La tabla 3.31 presenta evidencia que el $67.9 \%$ de los inversionistas entrevistados muestran una conducta afectada por el sesgo conductual efecto manada. Los inversionistas jóvenes (75\%) parecen mostrar una presencia del sesgo en mayor proporción a los inversionistas experimentados. Es importante resaltar que el $22.7 \%$ de los inversionistas experimentados no muestran indicios de estar afectados por dicho sesgo, solo el $10 \%$ de los inversionistas jóvenes tienen el mismo comportamiento. 
Se realizó la prueba de puntajes ponderados para confirmar la suposición de que los inversionistas de la muestra son afectados por el efecto manada, los resultados se presentan en la tabla 3.30

Tabla 3.30

Efecto manada - puntajes ponderados

\begin{tabular}{|c|c|c|c|c|}
\hline $\begin{array}{ll}\text { Tipo } & \text { de } \\
\text { Inversionista } & \end{array}$ & $\begin{array}{l}\text { Puntaje } \\
\text { Ponderado }\end{array}$ & Promedio & $\begin{array}{l}\text { Puntaje de } \\
\text { referencia }\end{array}$ & Resultado \\
\hline Jóven & 106 & 17.7 & 13.3 & Presencia del Sesgo \\
\hline Experimentado & 105 & 17.5 & 14.7 & Presencia del Sesgo \\
\hline
\end{tabular}

Fuente: Data recopilada y procesada en MS Excel.

En ambos grupos de inversionistas el puntaje promedio es superior al puntaje de referencia, lo que indica la presencia del sesgo. Es importante observar que el puntaje obtenido por los inversionistas jóvenes es muy superior a su puntaje de referencia lo cual presenta evidencia de que los inversionistas jóvenes son más afectados por el sesgo que los experimentados.

Para comprobar estadísticamente la hipótesis de que los inversionistas jóvenes están más afectados por el sesgo se realizó una prueba Chi-cuadrado con las siguientes hipótesis.

- H0: Ambos grupos de inversionistas son igualmente afectados el sesgo.

- H1: Los inversionistas jóvenes son más propensos a presentar el sesgo frente a los inversionistas experimentados.

Los resultados se muestran en la tabla 3.31 , el p-valor de 0.270 no permite rechazar la hipótesis nula, por lo tanto, no se puede afirmar estadísticamente que alguno de los dos grupos de inversionistas sea más afectado por el Efecto Manada que el otro. Los resultados son consistentes con lo reportado por el análisis discriminante ya que tampoco se pudo mediante dicho análisis separar a los inversionistas en dos grupos satisfactoriamente. 
Tabla 3.31

Efecto manada - test chi-cuadrado

\begin{tabular}{|l|r|r|c|}
\multicolumn{1}{c}{ Chi-Square Tests } \\
\hline & Value & df & Asymp. Sig. (2-sided) \\
\hline Pearson Chi-Square & $2.622^{\mathrm{a}}$ & 2 & .270 \\
Likelihood Ratio & 2.701 & 2 & .259 \\
N of Valid Cases & 84 & & \\
\hline
\end{tabular}

a. 0 cells $(0.0 \%)$ have expected count less than 5 . The minimum

Fuente: Data recopilada y procesada en SPSS.

\subsubsection{Anclaje}

El anclaje en la bolsa de valores se puede presentar cuando los inversionistas se "anclan" a información o precios en el momento de tomar decisiones. En muchas ocasiones el hecho de fijar un precio para una acción con mucho tiempo de anticipación (tanto para comprar como para vender) basado en el comportamiento pasado de la acción puede llevar a los inversionistas a entrar al mercado en un mal momento o vender acciones con alto potencial con mucha anticipación. Los resultados de fijarse a un precio determinado pueden ocasionar graves problemas o pérdida de oportunidades ya que muchas veces dichos precios no pueden ser alcanzados nuevamente.

Se consultó ${ }^{14}$ por lo tanto a los inversionistas si habitualmente fijaban un precio de compra o venta para ciertas acciones antes de la apertura de la bolsa, el $38.1 \%$ de los inversionistas respondieron positivamente mientras que un $36.9 \%$ lo hace en ocasiones. Ya que el $75 \%$ de los inversionistas respondieron que al menos en ocasiones fijan precios se puede decir con seguridad que la mayor parte de los inversionistas tienen un rango de precios para las acciones en mente antes de observar o analizar los resultados que se presentan en el día.

También se realizó una pregunta ${ }^{15}$ para evaluar si los inversionistas utilizan o no los llamados "stop loss" en sus intercambios, estas órdenes son evidencia de que los inversionistas tienen estrategias de salida si sus inversiones empiezan a deteriorarse.

\footnotetext{
${ }^{14}$ Pregunta 15 , anexo I

${ }^{15}$ Pregunta 16, anexo I
} 
El 27.5\% de los inversionistas jóvenes y el $13.6 \%$ de los inversionistas experimentados utilizan "stop loss" en sus intercambios, en total tan solo el $20.2 \%$ de los inversionistas dicen siempre utilizarlos.

La última pregunta ${ }^{16}$ relacionada a este sesgo corresponde a una situación hipotética donde se les pregunta a los inversionistas si comprarían una acción que tiene un valor $80 \%$ menor a su precio ancla. El $34.5 \%$ de los inversionistas respondieron afirmativamente mientras que un $15.5 \%$ dijeron que no la comprarían.

Para comprobar si los inversionistas están o no afectados por el sesgo las tres preguntas fueron combinadas y reclasificadas para crear una sola variable "Anclaje".

Los resultados son presentados en la tabla 3.32, donde se observa que tan solo el $16.7 \%$ de los inversionistas son siempre afectados por dicho sesgo (en las preguntas realizadas), y el $25 \%$ no se ha visto afectado por el sesgo.

Tabla 3.32

Anclaje - tabla de contingencia

\begin{tabular}{|c|c|c|c|c|c|c|}
\hline \multicolumn{7}{|c|}{ VariableDicotomica * Anclaje Crosstabulation } \\
\hline & & & & \multicolumn{2}{|c|}{ Anclaje } & $\square$ \\
\hline & & & Afectados & $\begin{array}{c}\text { Algunas } \\
\text { Veces }\end{array}$ & $\begin{array}{c}\text { No } \\
\text { afectados }\end{array}$ & Total \\
\hline \multirow{4}{*}{$\begin{array}{c}\text { Variable } \\
\text { Dicotomica }\end{array}$} & \multirow[b]{2}{*}{ Jóven } & Count & 7 & 21 & 12 & 40 \\
\hline & & $\%$ dentro del tipo de inversionista & $17.5 \%$ & $52.5 \%$ & $30.0 \%$ & $100.0 \%$ \\
\hline & \multirow[b]{2}{*}{ Experimentado } & Count & 7 & 28 & 9 & 44 \\
\hline & & $\%$ dentro del tipo de inversionista & $15.9 \%$ & $63.6 \%$ & $20.5 \%$ & $100.0 \%$ \\
\hline \multirow{2}{*}{\multicolumn{2}{|c|}{ Total }} & Count & 14 & 49 & 21 & 84 \\
\hline & & $\%$ dentro del tipo de inversionista & $16.7 \%$ & $58.3 \%$ & $25.0 \%$ & $100.0 \%$ \\
\hline
\end{tabular}

Fuente: Data recopilada y procesada en SPSS.

Para comprobar si ambos grupos son afectados de manera diferente por el sesgo se realizó una prueba Chi-cuadrado.

- H0: Ambos grupos de inversionistas son afectados de la misma forma por el anclaje.

\footnotetext{
${ }^{16}$ Pregunta 19, anexo I.
} 
- H1: Los inversionistas jóvenes son afectados en mayor medida por el anclaje que los experimentados.

Tabla 3.33

Anclaje - test chi-cuadrado

Chi-Square Tests

\begin{tabular}{|l|r|r|c|}
\hline & Value & df & Asymp. Sig. (2-sided) \\
\hline Pearson Chi-Square & $1.241 \mathrm{a}$ & 2 & .538 \\
Likelihood Ratio & 1.243 & 2 & .537 \\
N of Valid Cases & 84 & & \\
\hline
\end{tabular}

a. 0 cells $(0.0 \%)$ have expected count less than 5 . The minimum

Fuente: Data recopilada y procesada en SPSS.

Como podemos observar en la tabla 3.33 , el $\mathrm{p}$-valor de 0.538 no permite rechazar la hipótesis nula de manera que no se puede comprobar que el sesgo conductual anclaje afecte de manera diferente a los inversionistas jóvenes en comparación con los experimentados.

Por último, se realizó un análisis por puntajes ponderados para comprobar si los inversionistas estarían más afectados por dicho sesgo en comparación a una muestra neutral de referencia.

Tabla 3.34

Anclaje - Puntajes ponderados

\begin{tabular}{lrrrr}
\hline Tipo de Inversionista & Puntaje Ponderado & Promedio & Puntaje de referencia & Resultado \\
\hline Jóven & 75 & 12.5 & 13.3 & Ausencia del Sesgo \\
Experimentado & 86 & 14.3 & 14.7 Ausencia del Sesgo \\
\cline { 1 - 2 } Fuente: Data recopilada y procesada en MS Excel. & & &
\end{tabular}

Debido a que las puntuaciones promedio son inferiores a los puntajes de referencia podemos concluir que los inversionistas de la muestra (tanto jóvenes como experimentados) no presentan diferencias en el sesgo conductual Anclaje, de manera significativa.

\subsubsection{Disonancia cognitiva}

La disonancia cognitiva es un sesgo conductual, que ocurre cuando los inversionistas cambian sus creencias y opiniones de manera que sean consistentes con sus decisiones pasadas (Subash, 2012). Inconscientemente la mente humana tiende a protegerse a sí 
mismo eliminado o tratando de olvidar errores pasados, esto sucede en casi todos los aspectos de la vida cotidiana y las decisiones de inversión no son la excepción.

En sentido estricto las personas afectadas por este sesgo conductual evitan o minimizan nueva información que entra en contradicción con creencias o conceptos pasados. De esta manera los inversionistas afectados por este sesgo tratarían de evitar entrar en contacto o simplemente ignorarían información que pueda dañar sus decisiones pasadas de inversión.

Se les preguntó ${ }^{17}$ a los inversionistas si consideraban que su mente trataba de justificar errores cometidos en el pasado, el $22.6 \%$ de los inversionistas respondió afirmativamente, lo interesante en este caso es observar que el $42.9 \%$ de los inversionistas admitió que en ocasiones su mente trataba de justificar sus errores, lo cual demuestra que una gran parte de la muestre de inversionistas podría verse afectada por este sesgo.

En otra pregunta se creó una situación hipotética en la cual se le presentaba al inversionista nueva información que entraba en directa contradicción con decisiones u opiniones pre-existentes, los resultados indican que solo el $11.9 \%$ de los inversionistas aceptaría inmediatamente dicha información, mientras que el $26.2 \%$ admitió que no lo haría, es importante resaltar que la mayor parte de los inversionistas (61.9\%) no descartaría la información, pero tampoco reaccionaría inmediatamente a ella.

Se combinaron las dos preguntas para crear una sola variable, es importante resaltar que en este caso la segunda pregunta fue recodificada de manera inversa a lo usual en el estudio. Las respuestas positivas tuvieron un puntaje de 1 mientras que las respuestas negativas fueron puntuadas con 3 ya que en este caso las respuestas negativas implican la presencia del sesgo.

\footnotetext{
${ }^{17}$ Pregunta 20, anexo I.
} 
Tabla 3.35

Disonancia cognitiva - tabla de contingencia

\begin{tabular}{|c|c|c|c|c|c|c|}
\hline \multicolumn{7}{|c|}{ VariableDicotomica *Disonancia Cognitiva } \\
\hline & & & \multicolumn{4}{|c|}{ Disonancia Cognitiva } \\
\hline & & & Sí & Neutro & No & Total \\
\hline \multirow{4}{*}{$\begin{array}{c}\text { Variable } \\
\text { Dicotomica }\end{array}$} & \multirow{2}{*}{ Jóven } & Count & 12 & 19 & 9 & 40 \\
\hline & & $\%$ dentro del tipo de inversionista & $30.0 \%$ & $47.5 \%$ & $22.5 \%$ & $100.0 \%$ \\
\hline & \multirow{2}{*}{ Experimentado } & Count & 10 & 22 & 12 & 44 \\
\hline & & $\%$ dentro del tipo de inversionista & $22.7 \%$ & $50.0 \%$ & $27.3 \%$ & $100.0 \%$ \\
\hline \multirow{2}{*}{\multicolumn{2}{|c|}{ Total }} & Count & 22 & 41 & 21 & 84 \\
\hline & & $\%$ dentro del tipo de inversionista & $26.2 \%$ & $48.8 \%$ & $25.0 \%$ & $100.0 \%$ \\
\hline
\end{tabular}

Fuente: Data recopilada y procesada en SPSS.

Los resultados de la tabla muestran que el $26.2 \%$ de la muestra se ve afectada por el sesgo, el $48.8 \%$ es neutro frente al sesgo (no puede ser considerado como afectado o no afectado por el sesgo) y el $25 \%$ no es afectado.

Para continuar con el análisis se prosiguió con el método de puntajes ponderados. En este caso los resultados son opuestos, para el grupo de inversionistas experimentados el puntaje promedio es inferior al de referencia indicando la ausencia del sesgo, mientras que para los inversionistas jóvenes se prueba la presencia del sesgo. Es importante resaltar que en el caso de los inversionistas jóvenes el puntaje promedio es mayor al puntaje de referencia por muy poco, casi estando al mismo nivel que una muestra completamente neutral al sesgo.

Tabla 3.36

Disonancia cognitiva - puntajes ponderados

\begin{tabular}{lrrrr}
\hline Tipo de Inversionista & Puntaje Ponderado & Promedio & Puntaje de referencia & \multicolumn{1}{c}{ Resultado } \\
\hline Jóven & 83 & 13.8 & 13.3 Presencia del Sesgo \\
Experimentado & 86 & 14.3 & 14.7 Ausencia del Sesgo \\
\hline Fuente: Data recopilada y procesada en MS Excel. & & &
\end{tabular}

Para comprobar que el sesgo conductual de disonancia cognitiva afecta de manera diferente a ambos grupos de inversionistas se realizó una prueba Chi-cuadrado.

- H0: Ambos grupos de inversionistas son afectados de la misma forma por Disonancia Cognitiva.

- H1: Los inversionistas jóvenes son afectados en mayor medida por la disonancia cognitiva frente a los experimentados, 
Tabla 3.37

Disonancia cognitiva - test chi-cuadrado

\begin{tabular}{|l|r|r|c|}
\multicolumn{1}{c}{ Chi-Square Tests } \\
\hline & Value & df & Asymp. Sig. (2-sided) \\
\hline Pearson Chi-Square & $.641 \mathrm{a}$ & 2 & .726 \\
Likelihood Ratio & 0.641 & 2 & .726 \\
N of Valid Cases & 84 & & \\
\hline
\end{tabular}

a. 0 cells $(0.0 \%)$ have expected count less than 5 . The minimum

expected count is 10 .

Fuente: Data recopilada y procesada en SPSS.

El p-valor de 0.726 no permite rechazar la hipótesis nula por lo tanto no puede afirmarse que los inversionistas jóvenes son más afectados que los inversionistas experimentados por este sesgo, los resultados son similares a los encontrados por el análisis discriminante donde este sesgo no es representativo para separar la muestra.

\subsubsection{Temor al arrepentimiento}

En inversiones el temor al arrepentimiento se presenta cuando las personas evitan tomar decisiones decisivas ya que temen tomar decisiones erróneas. Esto ocasiona que el inversionista evite vender acciones que representaron una mala inversión o se muestre reacio a ingresar al mercado cuando este le ha ocasionado pérdidas recientes. Se le preguntó a los inversionistas si habían mantenido acciones a la baja por mucho tiempo o viceversa (vender una acción al alza en muy poco tiempo), el 17.9\% de los inversionistas admitió que casi siempre padecían del mismo problema e interesantemente el $66.7 \%$ admitió que les sucedía algunas veces. También se hizo una pregunta para observar si habitualmente los inversionistas frenaban sus inversiones ante la expectativa de obtener buenas noticias, el $15.5 \%$ de los inversionistas admitieron que casi siempre esperaban por buenas noticias antes de realizar inversiones y un $71.4 \%$ de estos admitieron haberlo hecho en ocasiones. Ambas preguntas fueron recodificadas para crear una tabla de contingencia y poder analizar el sesgo en conjunto. Los resultados se presentan en la tabla 3.38 donde se observa que el $17.9 \%$ de los inversionistas de la muestra son afectados por el sesgo y un $63.1 \%$ de estos podrían estar siendo afectos al menos en ocasiones. 
Tabla 3.38

Temor al arrepentimiento - tabla de contingencia

\begin{tabular}{|c|c|c|c|c|c|c|}
\hline \multicolumn{7}{|c|}{ VariableDicotomica * Temoralarrepentimiento Crosstabulation } \\
\hline & & & \multicolumn{4}{|c|}{ Temor al arrepentimiento } \\
\hline & & & Siempre & Algunas veces & Nunca & Total \\
\hline \multirow{4}{*}{$\begin{array}{c}\text { Variable } \\
\text { Dicotomica }\end{array}$} & \multirow{2}{*}{ Jóven } & Count & 9 & 26 & 5 & 40 \\
\hline & & $\%$ dentro del tipo de inversionista & $22.5 \%$ & $65.0 \%$ & $12.5 \%$ & $100.0 \%$ \\
\hline & \multirow{2}{*}{ Experimentado } & Count & 6 & 27 & 11 & 44 \\
\hline & & $\%$ dentro del tipo de inversionista & $13.6 \%$ & $61.4 \%$ & $25.0 \%$ & $100.0 \%$ \\
\hline \multirow{2}{*}{\multicolumn{2}{|c|}{ Total }} & Count & 15 & 53 & 16 & 84 \\
\hline & & $\%$ dentro del tipo de inversionista & $17.9 \%$ & $63.1 \%$ & $19.0 \%$ & $100.0 \%$ \\
\hline
\end{tabular}

Fuente: Data recopilada y procesada en SPSS

Para probar si existe una diferencia estadísticamente significativa en el efecto del sesgo en ambos grupos de inversionistas se realizó una prueba Chi-cuadrado.

Se probaron las hipótesis.

- H0: Ambos grupos de inversionistas son afectados de la misma manera por el sesgo.

- H1: Los inversionistas jóvenes son más propensos a ser afectados por el sesgo frente a los inversionistas experimentados.

Tabla 3.39

Temor al arrepentimiento - test chi-cuadrado

Chi-Square Tests

\begin{tabular}{|l|r|r|c|}
\hline \multicolumn{1}{|c|}{} & Value & df & Asymp. Sig. (2-sided) \\
\hline Pears on Chi-Square & $2.684 \mathrm{a}$ & 2 & .261 \\
Likelihood Ratio & 2.738 & 2 & .254 \\
N of Valid Cases & 84 & & \\
\hline
\end{tabular}

a. 0 cells $(0.0 \%)$ have expected count less than 5 . The minimum expected count is 7.14

Fuente: Data recopilada y procesada en SPSS

Debido al valor del p-valor, estadísticamente no se puede rechazar la hipótesis nula.

Finalmente se procedió a realizar la prueba de puntajes ponderados, los resultados han sido presentados en la tabla 3.40. 
Tabla 3.40

Temor al arrepentimiento - puntajes ponderados

\begin{tabular}{lrrrr}
\hline Tipo de Inversionista & Puntaje Ponderado & Promedio & Puntaje de referencia & \multicolumn{1}{c}{ Resultado } \\
\hline Jóven & 84 & 14.0 & 13.3 Presencia del Sesgo \\
Experimentado & 83 & 13.8 & 14.7 Ausencia del Sesgo \\
\hline Fuente: Data recopilada y procesada en MS Excel. & & & \\
\hline
\end{tabular}

A pesar de los resultados encontrados por la prueba Chi-cuadrado se puede observar que el puntaje ponderado promedio de los inversionistas jóvenes es superior al puntaje de referencia, lo cual indicaría la presencia del sesgo. Lo mismo no puede decirse de los inversionistas experimentados ya que la prueba permite descargar la presencia del sesgo. Los resultados no son absolutos y la presencia del sesgo solo podría validarse ligeramente en los inversionistas jóvenes.

\subsubsection{Falacia del jugador}

Como ya ha sido explicada, la falacia del jugador en el mercado de valores sucede cuando los inversionistas tratan de predecir incorrectamente cambios en las tendencias de mercado, es probable que inversionistas afectados por el sesgo se sientan en capacidad de predecir cambios de tendencia o resultados futuros, lo cual en la realidad no es posible.

Uno de los ejemplos más comunes de falacia del jugador es la predicción del resultado de un simple lanzamiento de moneda, por lo tanto, se realizó dicha pregunta ${ }^{18}$ en la encuesta.

Sorprendentemente solo el $58.3 \%$ de los encuestados permanecieron neutros al resultado (demostrando así no caer en el sesgo) mientras que el 41.7\% restante eligió una de las dos caras de la moneda. Por lo tanto, se puede asumir que para este caso el $41.7 \%$ de los encuestados han estado sujetos al sesgo ya que no han considerado el hecho de que cada lanzamiento de moneda es un evento independiente y la probabilidad del resultado no puede de ninguna manera ser condicionada por los lanzamientos anteriores.

${ }^{18}$ Pregunta 26, anexo I. 
Tabla 3.41

Falacia del jugador - tabla de contingencia I

\begin{tabular}{|c|c|c|c|c|c|c|}
\hline \multicolumn{7}{|c|}{ VariableDicotomica * 26 Crosstabulation } \\
\hline & & & \multicolumn{4}{|c|}{ Falacia del Jugador } \\
\hline & & & Cara & Sello & Sin preferencia & Total \\
\hline \multirow{4}{*}{$\begin{array}{c}\text { Variable } \\
\text { Dicotomica }\end{array}$} & \multirow{2}{*}{ Jóven } & Count & 17 & 2 & 21 & 40 \\
\hline & & $\%$ dentro del tipo de inversionista & $42.5 \%$ & $5.0 \%$ & $52.5 \%$ & $100.0 \%$ \\
\hline & \multirow{2}{*}{ Experimentado } & Count & 15 & 1 & 28 & 44 \\
\hline & & $\%$ dentro del tipo de inversionista & $34.1 \%$ & $2.3 \%$ & $63.6 \%$ & $100.0 \%$ \\
\hline \multirow{2}{*}{\multicolumn{2}{|c|}{ Total }} & Count & 32 & 3 & 49 & 84 \\
\hline & & $\%$ dentro del tipo de inversionista & $38.1 \%$ & $3.6 \%$ & $58.3 \%$ & $100.0 \%$ \\
\hline
\end{tabular}

Ya que no se puede considerar solo con esta simple pregunta que los inversionistas son afectados por el sesgo conductual, se incluyó una segunda pregunta ${ }^{19}$ en el análisis para ver que pensaban los inversionistas acerca de su habilidad de predecir cambios de tendencia en la BVL. En la tabla 3.41 se observa que solamente el $4.8 \%$ del total de inversionistas se consideraban en grado de poder anticipar siempre o casi siempre cambios de tendencia en el mercado de acciones, lo cual es un resultado que no indica la presencia del sesgo. Sin embargo, se observa que el $78.6 \%$ de los inversionistas cree ser capaz de poder predecir los cambios en ocasiones. Estos resultados y los obtenidos en la tabla 3.41 son bastante contradictorios, hay que señalar que la pregunta del lanzamiento de la moneda era más sutil, aunque es un tema habitual en la mayor parte de libros y clases de estadística básica.

Tabla 3.42

Falacia del jugador - tabla de contingencia II

\begin{tabular}{|c|c|c|c|c|c|c|}
\hline \multicolumn{7}{|c|}{ VariableDicotomica *Falacia del Jugador Crosstabulation } \\
\hline & & & \multicolumn{4}{|c|}{ Falacia del Jugador } \\
\hline & & & Sí & Algunas veces & No & Total \\
\hline \multirow{4}{*}{$\begin{array}{c}\text { Variable } \\
\text { Dicotomica }\end{array}$} & \multirow{2}{*}{ Jóven } & Count & 2 & 32 & 6 & 40 \\
\hline & & $\%$ dentro del tipo de inversionista & $5.0 \%$ & $80.0 \%$ & $15.0 \%$ & $100.0 \%$ \\
\hline & \multirow{2}{*}{ Experimentado } & \begin{tabular}{|l|l} 
Count \\
\end{tabular} & 2 & 34 & 8 & 44 \\
\hline & & $\%$ dentro del tipo de inversionista & $4.5 \%$ & $77.3 \%$ & $18.2 \%$ & $100.0 \%$ \\
\hline \multirow{2}{*}{\multicolumn{2}{|c|}{ Total }} & Count & 4 & 66 & 14 & 84 \\
\hline & & $\%$ dentro del tipo de inversionista & $4.8 \%$ & $78.6 \%$ & $16.7 \%$ & $100.0 \%$ \\
\hline
\end{tabular}

Fuente: Data recopilada y procesada en SPSS

\footnotetext{
${ }^{19}$ Pregunta 25, anexo I.
} 
Debido a que los conteos en las celdas no eran suficientes los resultados no pudieron ser validados con una prueba de Chi-cuadrado, sin embargo, se realizó la prueba de puntajes ponderados, los resultados se observan en la tabla 3.45

Tabla 3.43

Falacia del jugador - puntajes ponderados

\begin{tabular}{|c|c|c|c|c|}
\hline Tipo de Inversionista & Puntaje Ponderado & Promedio & Puntaje de referencia & Resultado \\
\hline Jóven & 76 & 12.7 & 13.3 & Ausencia del Sesgo \\
\hline Experimentado & 82 & 13.7 & 14.7 & Ausencia del Sesgo \\
\hline Fuente: Data recopilada y & ocesada en MS Excel. & 6 & t & \\
\hline
\end{tabular}

La prueba de puntajes ponderados por su parte también rechaza la presencia del sesgo en ambos grupos de inversionistas, siendo este el primer sesgo que no se presenta en conjunto alguno de los dos grupos.

\subsubsection{Contabilidad mental}

Es usual que las personas y los inversionistas separen sus ingresos en diferentes cuentas por una infinidad de razones. Pero en ciertas ocasiones este comportamiento se lleva al extremo ya que los inversionistas tienden a realizar inversiones de manera diferente para las diferentes "cuentas" de dinero. Si los inversionistas separan un porcentaje para invertir en la bolsa sabiendo que no lo necesitan y que perderlo no les traerá grandes consecuencias se está cayendo en este sesgo conductual. El inversionista puede verse tentado a invertir este dinero "no vital" de una forma completamente diferente y mucho más arriesgada a lo que haría si el dinero fuera necesario.

La tabla 3.44 muestra los resultados, solo el $45.2 \%$ de los inversionistas admitió siempre separar parte de sus ingresos normales para invertir en la BVL, lo que es interesante notar es que más de la mitad de los inversionistas jóvenes (52.5\%) separa parte de sus ingresos para la BVL mientras que solo el 38.6\% de los inversionistas experimentados hace lo mismo. 
Tabla 3.44

Contabilidad mental - tabla de contingencia

\begin{tabular}{|c|c|c|c|c|c|c|}
\hline \multicolumn{7}{|c|}{ VariableDicotomica *Falacia del Jugador Crosstabulation } \\
\hline & & & \multicolumn{4}{|c|}{ Contabilidad Mental } \\
\hline & & & Siempre & Algunas veces & Nunca & Total \\
\hline \multirow{4}{*}{$\begin{array}{c}\text { Variable } \\
\text { Dicotomica }\end{array}$} & \multirow{2}{*}{ Jóven } & Count & 21 & 32 & 6 & 40 \\
\hline & & $\%$ dentro del tipo de inversionista & $52.5 \%$ & $80.0 \%$ & $15.0 \%$ & $100.0 \%$ \\
\hline & \multirow{2}{*}{ Experimentado } & Count & 17 & 34 & 8 & 44 \\
\hline & & $\%$ dentro del tipo de inversionista & $38.6 \%$ & $77.3 \%$ & $18.2 \%$ & $100.0 \%$ \\
\hline \multirow{2}{*}{\multicolumn{2}{|c|}{ Total }} & Count & 38 & 66 & 14 & 84 \\
\hline & & $\%$ dentro del tipo de inversionista & $45.2 \%$ & $78.6 \%$ & $16.7 \%$ & $100.0 \%$ \\
\hline
\end{tabular}

Fuente: Data recopilada y procesada en SPSS

La variable contabilidad mental fue para el análisis discriminante una de las variables más importantes para separar ambas muestras, este resultado es apoyado por los resultados obtenidos de la prueba Chi-cuadrado mostrada en la tabla 3.45

Tabla 3.45

Contabilidad mental - test chi-cuadrado

Chi-Square Tests

\begin{tabular}{|l|r|r|c|}
\hline \multicolumn{1}{|c|}{} & Value & df & Asymp. Sig. (2-sided) \\
\hline Pearson Chi-Square & $7.515 \mathrm{a}$ & 2 & .023 \\
Likelihood Ratio & 8.281 & 2 & .016 \\
N of Valid Cases & 84 & & \\
\hline
\end{tabular}

a. 0 cells $(0.0 \%)$ have expected count less than 5 . The minimum

expected count is 6.67 .

Fuente: Data recopilada y procesada en SPSS.

Se probaron las siguientes hipótesis,

- H0: Ambos grupos de inversionistas son igualmente afectados por el sesgo.

- H1: Los inversionistas jóvenes son más afectados por el sesgo que los inversionistas experimentados.

El p-valor de 0.023 nos permite rechazar la hipótesis nula de manera que se comprueba estadísticamente que los inversionistas jóvenes son afectados en mayor medida por el sesgo discutido anteriormente.

Para comprobar ulteriormente los resultados se realizó la prueba de puntajes ponderados, los resultados de la tabla 3.44 comprobaron que ambos grupos de inversionistas son más afectados por los sesgos conductuales en comparación a una 
muestra completamente neutra. Esto implica que no solo los inversionistas jóvenes son más afectados por este sesgo en promedio.

Tabla 3.46

Contabilidad mental - puntajes ponderados

\begin{tabular}{lrrrr}
\hline Tipo de Inversionista & Puntaje Ponderado & Promedio & Puntaje de referencia & Resultado \\
\hline Jóven & 133 & 22.2 & 13.3 Presencia del sesgo \\
\hline Experimentado & 127 & 21.2 & 14.7 Presencia del sesgo \\
\hline Fuente: Data recopilada y procesada en MS Excel. & & &
\end{tabular}

\subsubsection{Retrospectiva}

Es habitual para el ser humano reflexionar sobre situaciones y decisiones pasadas. La mente humana y los procesos cognitivos son elementos altamente complejos, pero existen ciertas características en nuestro modo de pensar que nos hacen más propensos a caer en lógicas irracionales, el sesgo retrospectivo es una de estas.

Es un error común para nuestra mente creerse en capacidad de saber el resultado de una determinada acción o decisión una vez que el evento ya ha pasado. Para probar si este sesgo afecta de manera significativa a los inversionistas peruanos se realizaron dos preguntas relacionadas.

En la primera se preguntó ${ }^{20}$ si fue posible predecir el colapso financiero de la bolsa de valores de Wall-Street al inicio de la crisis financiera, el $13.1 \%$ de los inversionistas dijo pensar que realizar la predicción era muy sencillo mientras que el $20.2 \%$ consideró que habría sido sencillo. Esta es una clara señal de la presencia del sesgo retrospectivo.

En un inicio las razones de la crisis de Wall-Street y las consecuencias que esta iba a tener eran inimaginables para la gran mayoría, además un gran número de expertos vivía en esos momentos de decisiones de inversión y análisis del comportamiento de la bolsa y ellos tampoco pudieron predecirlo.

${ }^{20}$ Pregunta 9, anexo I. 
Tabla 3.47

Retrospectivo - tabla de contingencia I

\begin{tabular}{|c|c|c|c|c|c|c|}
\hline \multicolumn{7}{|c|}{ VariableDicotomica $* 9$ Crosstabulation } \\
\hline & & & \multicolumn{4}{|c|}{ Retrospectivo } \\
\hline & & & Muy Sencillo & Sencillo & Difícil & Total \\
\hline \multirow{4}{*}{$\begin{array}{c}\text { Variable } \\
\text { Dicotomica }\end{array}$} & \multirow{2}{*}{ Jóven } & Count & 4 & 9 & 27 & 40 \\
\hline & & $\%$ dentro del tipo de inversionista & $10.0 \%$ & $22.5 \%$ & $67.5 \%$ & $100.0 \%$ \\
\hline & \multirow{2}{*}{ Experimentado } & Count & 7 & 8 & 29 & 44 \\
\hline & & $\%$ dentro del tipo de inversionista & $15.9 \%$ & $18.2 \%$ & $65.9 \%$ & $100.0 \%$ \\
\hline \multirow{2}{*}{\multicolumn{2}{|c|}{ Total }} & \begin{tabular}{|l|l} 
Count \\
\end{tabular} & 11 & 17 & 56 & 84 \\
\hline & & $\%$ dentro del tipo de inversionista & $13.1 \%$ & $20.2 \%$ & $66.7 \%$ & $100.0 \%$ \\
\hline
\end{tabular}

Fuente: Data recopilada y procesada en SPSS.

La segunda pregunta realizada fue similar, se consultó a los inversionistas que tan fácil habría sido convencerlos de que se acercaba una crisis financiera entre 2006 y 2007 , se le dio un rango de respuestas en una escala de 1 a 5 . Las respuestas fueron recodificadas de la siguiente manera 1-2 (no convencido), 3 (tal vez) y de 4-5 (fácilmente convencido), las respuestas se muestran en la tabla 3.49

Tabla 3.48

Retrospectivo - tabla de contingencia II

\begin{tabular}{|c|c|c|c|c|c|c|}
\hline \multicolumn{2}{|l|}{2} & \multicolumn{4}{|c|}{ VariableDicotomica *RetrospectivoCrosstabulation } & \multirow{2}{*}{+} \\
\hline & & & \multicolumn{3}{|c|}{ Retrospectivo } & \\
\hline & & & $\begin{array}{c}\text { Fácilmente } \\
\text { Convencido }\end{array}$ & Talvez & $\begin{array}{c}\text { No } \\
\text { convencido }\end{array}$ & Total \\
\hline \multirow{4}{*}{$\begin{array}{c}\text { Variable } \\
\text { Dicotomica }\end{array}$} & \multirow{2}{*}{ Jóven } & Count & 12 & 18 & 10 & 40 \\
\hline & & $\%$ dentro del tipo de inversionista & $30.0 \%$ & $45.0 \%$ & $25.0 \%$ & $100.0 \%$ \\
\hline & \multirow{2}{*}{ Experimentado } & Count & 18 & 11 & 15 & 44 \\
\hline & & $\%$ dentro del tipo de inversionista & $40.9 \%$ & $25.0 \%$ & $34.1 \%$ & $100.0 \%$ \\
\hline \multirow{2}{*}{\multicolumn{2}{|c|}{ Total }} & Count & 30 & 29 & 25 & 84 \\
\hline & & $\%$ dentro del tipo de inversionista & $35.7 \%$ & $34.5 \%$ & $29.8 \%$ & $100.0 \%$ \\
\hline
\end{tabular}

Fuente: Data recopilada y procesada en SPSS.

Un $35.7 \%$ de los encuestados respondió que habría sido fácil o muy fácil convencerlos de que se aproximaba una crisis y solo el $29.8 \%$ admitió que habría sido muy difícil convencerlos.

La prueba de puntajes ponderados en la tabla 3.49 permitió aclarar el efecto, observando que con respecto a una muestra neutral de referencia los inversionistas encuestados se ven afectados por el sesgo retrospectivo, tanto para los jóvenes como para los experimentados. 
Tabla 3.49

Retrospectivo - puntajes ponderados

\begin{tabular}{lrrrr}
\hline Tipo de Inversionista & Puntaje Ponderado & Promedio & Puntaje de referencia & Resultado \\
\hline Jóven & 82 & 13.7 & 13.3 Presencia del sesgo \\
Experimentado & 91 & 15.2 & 14.7 Presencia del ses go \\
\hline
\end{tabular}

Fuente: Data recopilada y procesada en MS Excel. 


\section{CAPÍTULO IV: RESUMEN DE RESULTADOS}

Esta tesis ha sido diseñada para analizar la presencia y los efectos de nueve sesgos conductuales en los procesos de decisión de inversionistas peruanos en el periodo 20102015. Se realizaron 30 preguntas a una muestra de 84 inversionistas que participaron en la bolsa de valores de Lima. y los resultados fueron analizados principalmente mediante el software estadístico IBM SPSS. Se obtuvieron de la muestra principal dos sub muestras definidas a priori en función a los años de experiencia de los inversionistas, se codificaron 10 variables en SPSS una dicotómica (años de experiencia) y el resto corresponden a los 9 sesgos conductuales. Estas variables fueron creadas utilizando técnicas de escalamiento como Likert 3 y Likert 5.

Se descartó la posibilidad de la presencia de multicolinealidad en la muestra y posteriormente se aplicó el análisis discriminante para observar si el comportamiento de los inversionistas en función de los sesgos era significativamente diferente entre ambos grupos. Posteriormente se realizó un análisis individual a cada sesgo para comprobar si la muestra mostraba presencia de dichos sesgos y si estos afectaban de manera estadísticamente diferente a ambos grupos. Las pruebas realizadas y las hipótesis fueron analizadas con pruebas Chi-cuadrado en SPSS.

Los resultados del análisis discriminante se presentan en la tabla 4.1, mientras que en las tablas 4.2 y 4.3 se observan, respectivamente, el resumen de resultados de las pruebas de puntajes ponderados y Chi-cuadrado. 
Tabla 4.1

Análisis discriminante - resumen de resultados

Análisis Discriminante
\begin{tabular}{|l|l|}
\hline Sesgos Conductuales & ¿Un grupo de inversionista es mas afectado que otro? \\
\hline Exceso de Confianza & No \\
Representatividad & Sí \\
Efecto Manada & No \\
Anclaje & No \\
Disonancia Cognitiva & No \\
Temor al arrepentimiento & No \\
Falacia del Jugador & No \\
Contabilidad Mental & Sí \\
Retrospectiva & No \\
\hline Fuente: Data recopilada y procesada en SPSS. &
\end{tabular}

Como podemos observar el análisis discriminante establece que para 7 de los 9 sesgos conductuales no se puede afirmar que los inversionistas jóvenes estén siendo más afectados que los inversionistas experimentados. Esto presenta evidencia de que no sería correcto separar en dos grupos que se comportan diferente en función a los años de experiencia.

Sin embargo, el análisis discriminante asignó correctamente el $67.9 \%$ de los casos de manera que establece un alto grado de predicción en base a las variables especificadas. A pesar de que no existe una diferencia estadísticamente aceptable para afirmar que ambos grupos son afectados de manera diferente por los sesgos sí se puede afirmar que en su mayoría la muestra de inversionistas jóvenes fue más propensa a caer en comportamientos irracionales al momento de realizar inversiones.

Cuando se preguntó a los inversionistas acerca de las pérdidas incurridas en el periodo 2013-2014 el 83\% de los inversionistas jóvenes admitió haber experimentado pérdidas y el $75 \%$ de los inversionistas experimentados también. El objetivo de esta prueba era saber si algún grupo de inversionistas era más afectado que el otro por las pérdidas y los resultados demostraron que los inversionistas jóvenes y los experimentados eran afectados de la misma manera en el periodo analizado es decir los años de experiencia no habían mitigado el impacto de las pérdidas.

En la tabla 4.1 se comprueba la presencia de 5 de los 9 sesgos en la muestra de inversionistas y 7 de 9 sesgos para la sub muestra de inversionistas jóvenes. Relacionando esta información con los resultados presentados por los inversionistas explicados 
anteriormente podría inferirse que las pérdidas en las que incurrieron los inversionistas podrían estar ligadas directamente a los sesgos conductuales que estos presentan. Comparativamente parece presentarse una relación ya que los inversionistas jóvenes son influenciados por $77.7 \%$ de los sesgos y presentan el mayor porcentaje de pérdidas (83\%) mientras que los inversionistas experimentados son afectados solo por el $55.5 \%$ de los sesgos y el nivel de pérdidas que presentaron fue menor (75\%).

\section{Tabla 4.2}

Método de puntajes ponderados - resumen de resultados

Resultados: Método de Puntajes Ponderados

\begin{tabular}{|l|l|}
\hline Sesgos Conductuales & ¿Presencia del sesgo? \\
\hline Exceso de Confianza & Sí \\
Representatividad & Sí \\
Efecto Manada & Sí \\
Anclaje & No \\
Disonancia Cognitiva & Presencia en jóvenes \\
Temor al arrepentimiento & Presencia en jóvenes \\
Falacia del Jugador & No \\
Contabilidad Mental & Sí \\
Retrospectiva & Sí \\
\hline
\end{tabular}

Fuente: Data recopilada y procesada en SPSS.

Tabla 4.3

Pruebas chi-cuadrado - resumen tablas de contingencia

Pruebas Chi-cuadrado

\begin{tabular}{|l|l|}
\hline Sesgos Conductuales & ¿Un grupo de inversionistas más sesgado que otro? \\
\hline Exceso de Confianza & Sí \\
Representatividad & Resultado Inconcluso \\
Efecto Manada & No \\
Anclaje & No \\
Disonancia Cognitiva & No \\
Temor al arrepentimiento & No \\
Falacia del Jugador & Resultado Inconcluso \\
Contabilidad Mental & Sí \\
Retrospectiva & Resultado Inconcluso \\
\hline
\end{tabular}

Fuente: Data recopilada y procesada en SPSS.

El resultado de las pruebas Chi-cuadrado a las tablas de contingencia muestra que solo se puede considerar que el grupo de inversionistas jóvenes se encuentra más sesgado que el de inversionistas experimentados para las variables Contabilidad y Exceso de confianza, debido al tamaño de la muestra y los resultados la prueba ha sido inconcluyente para 3 sesgos conductuales y ha sido rechazada para otros 4 . 


\subsection{Efectos claves y consecuencias}

Los efectos y consecuencias de los sesgos conductuales previamente presentados se resumen en la siguiente tabla.

Tabla 4.4

\section{Efectos y consecuencias - resumen}

\begin{tabular}{|c|c|c|}
\hline Sesgo conductual & Efectos clave en el inversionista & Consecuencias \\
\hline Exceso de Confianza & $\begin{array}{l}\text { Demasiados intercambios, toma de } \\
\text { demasiado riesgo y poca o nula } \\
\text { diversificación }\end{array}$ & $\begin{array}{l}\text { Pagos excesivos a brokers e impuestos, } \\
\text { mayor probabilidad de altas pérdidas }\end{array}$ \\
\hline Representatividad & $\begin{array}{l}\text { Tendencia a asociar nuevos eventos a otros } \\
\text { pasados y realizar inversiones basadas } \\
\text { exclusivamente en la similitud }\end{array}$ & $\begin{array}{l}\text { Compra de acciones sobre valoradas, evitar } \\
\text { acciones desconocidas a pesar de anális is } \\
\text { favorable }\end{array}$ \\
\hline Efecto Manada & $\begin{array}{l}\text { Falta de individualismo en la toma de } \\
\text { decisiones }\end{array}$ & $\begin{array}{l}\text { Burbujas y exceso de precio en accione, } \\
\text { también pánicos y caídas. }\end{array}$ \\
\hline Anclaje & $\begin{array}{l}\text { Tendencia a considerar como apropiados } \\
\text { niveles de precio irrelevantes en el proceso } \\
\text { de toma de decisiones }\end{array}$ & $\begin{array}{l}\text { Pérdida de oportunidades de inversión, mal } \\
\text { momento de entrada o salida del mercado }\end{array}$ \\
\hline Disonancia Cognitiva & $\begin{array}{l}\text { Ignorar nueva información que contradice } \\
\text { creencias o decisiones pasadas }\end{array}$ & $\begin{array}{l}\text { Reduce la habilidad para tomar decisiones } \\
\text { racionales y realizar buenas inversiones }\end{array}$ \\
\hline Temor al arrepentimiento & $\begin{array}{l}\text { Vender acciones que están generando } \\
\text { ganancias muy pronto y aferrarse } \\
\text { demasiado a acciones que están generando } \\
\text { pérdidas }\end{array}$ & Menores retornos \\
\hline Falacia del Jugador & $\begin{array}{l}\text { Tomar demasiado riesgo luego de haber } \\
\text { tenido suerte en ciertas inversiones }\end{array}$ & $\begin{array}{l}\text { Aumento de la probabilidad de altas } \\
\text { pérdidas }\end{array}$ \\
\hline Contabilidad Mental & Diversificación baja o nula & $\begin{array}{l}\text { Efectos irracionales y negativos en la } \\
\text { rentabilidad }\end{array}$ \\
\hline Retrospectiva & $\begin{array}{l}\text { Tendencia a sentir que un evento pasado } \\
\text { era obvio cuando en realidad no lo era. }\end{array}$ & $\begin{array}{l}\text { Exceso de simplificación en los procesos de } \\
\text { toma de decisiones }\end{array}$ \\
\hline
\end{tabular}

Fuente: Subash (Behavioral Finance in Portfolio Investment Decisions: Evidence from India, 2012) elaboración propia. Revisado en octubre 2015

La última pregunta de la encuesta tenía como objetivo captar el grado de conocimiento que tienen los inversionistas con relación a las finanzas conductuales. 
Tabla 4.5

Conocimiento de las finanzas conductuales

\begin{tabular}{|c|c|c|c|c|c|c|c|c|}
\hline \multicolumn{9}{|c|}{ VariableDicotomica * Conocimiento de las Finanzas Conductuales Crosstabulation } \\
\hline & & & \multicolumn{6}{|c|}{ Overconfidence } \\
\hline & & & Nula & Mala & Baja & Promedio & Buena & Total \\
\hline \multirow{4}{*}{$\begin{array}{c}\text { Variable } \\
\text { Dicotomica }\end{array}$} & \multirow[b]{2}{*}{ Jóven } & Count & 8 & 10 & 16 & 5 & 1 & 40 \\
\hline & & $\%$ dentro del tipo de inversionista & $20.0 \%$ & $25.0 \%$ & $40.0 \%$ & $12.5 \%$ & $2.5 \%$ & $100.0 \%$ \\
\hline & \multirow[b]{2}{*}{ Experimentado } & Count & 17 & 11 & 6 & 4 & 4 & 42 \\
\hline & & $\%$ dentro del tipo de inversionista & $40.5 \%$ & $26.2 \%$ & $14.3 \%$ & $9.5 \%$ & $9.5 \%$ & $100.0 \%$ \\
\hline \multirow{2}{*}{\multicolumn{2}{|c|}{ Total }} & Count & 25 & 21 & 22 & 9 & 5 & 82 \\
\hline & & $\%$ dentro del tipo de inversionista & $30.5 \%$ & $25.6 \%$ & $26.8 \%$ & $11.0 \%$ & $6.1 \%$ & $100.0 \%$ \\
\hline
\end{tabular}

Fuente: Data recopilada y procesada en SPSS.

Como se puede observar en la tabla, solo el $11 \%$ de la muestra de inversionistas (9 de un total de 82 que respondieron la pregunta) consideran tener un nivel promedio de conocimiento de las finanzas conductuales, mientras que solo 5 (casi todos inversionistas experimentados) admiten tener una buena o alta experiencia del tema. Aproximadamente el $56 \%$ de la muestra no tenía conocimiento o su conocimiento era malo. El $27 \%$ restante admitió tener un bajo o poco conocimiento del tema. 


\section{CONCLUSIONES}

El objetivo de la presente tesis era el de evaluar concretamente la presencia y consecuencias de los llamados "sesgos conductuales" en una muestra de inversionistas peruanos, identificando los sesgos de mayor incidencia y frecuencia y comparar los resultados obtenidos por los inversionistas en relación a estos. La investigación ha logrado obtener resultados que permiten evaluar correctamente los objetivos trazados, tanto el objetivo principal como ambos objetivos específicos.

A continuación, detallaremos las conclusiones a las que se han llegado a partir de la presente investigación:

- Se ha logrado probar satisfactoriamente la hipótesis principal de presencia de sesgos conductuales en los inversionistas peruanos y la primera hipótesis específica $^{21}$, pero no se ha encontrado evidencia confirmatoria para la segunda hipótesis específica ${ }^{22}$.

- Se ha logrado comprobar la presencia de la mayoría de sesgos (con excepción de Falacia del Jugador y Anclaje) en la muestra analizada, sin embargo, no ha sido posible probar una relación directa concreta entre el impacto de los sesgos y los años de experiencia de los inversionistas.

- Los resultados indican que con excepción de Contabilidad Mental y Exceso de Confianza los sesgos conductuales afectan de manera similares tanto a los inversionistas jóvenes como a los experimentados.

- No se ha encontrado evidencia concluyente que indique que sin lugar a dudas los años de experiencia influyen en la frecuencia e incidencia de los sesgos conductuales en la muestra de inversionistas analizada.

${ }^{21}$ El número de años de experiencia de los inversionistas considerados no reduce la frecuencia y la incidencia de los sesgos conductuales en la toma de decisiones.

${ }^{22}$ Los sesgos conductuales que se presentan con mayor frecuencia son "efecto manada", "exceso de confianza" y anclaje" sesgos que pueden generar burbujas y caídas de precios en el mercado de valores peruano 
- No se ha encontrado evidencia de que exista anclaje en los inversionistas analizados, aunque si se ha probado la presencia de efecto manada y exceso de confianza en la muestra.

Limitaciones: El presente estudio plantea estudiar el comportamiento de los inversionistas mediante un cuestionario. La toma de decisiones de inversión es un proceso complejo y exhaustivo, por lo tanto, es posible que durante el cuestionario el inversionista se encuentre relajado y con la mente fresca, por lo tanto, podría elegir respuestas que lo hagan quedar bien, especialmente en contextos en que se presentan situaciones hipotéticas 


\section{RECOMENDACIONES}

Autores como Pompian, John Logo, Rahul Subash entre otros indican que el conocimiento de las finanzas conductuales puede ayudar a disminuir el impacto que tienen los sesgos conductuales en las decisiones de inversión de inversionistas en todo el mundo.

A continuación, detallaremos las recomendaciones:

- En primer lugar, se recomienda a los inversionistas conocer la teoría de las finanzas conductuales, cuáles son sus principales implicancias y comprender de manera básica los sesgos conductuales en un proceso de 3 pasos.

¿Cuáles son los sesgos conductuales y sus efectos?

¿Cuándo aparecen dichos sesgos y de qué manera se presentan?

¿Cómo evitarlos o mitigarlos?

- En segundo lugar, una vez comprendido en qué consiste y qué implican los sesgos conductuales se recomienda a los inversionistas analizar detalladamente su comportamiento pasado para encontrar la presencia de dichos sesgos en su comportamiento pasado. Una vez que se identifican los comportamientos sesgados el inversionista debe reconocer que tipo de eventos o razonamientos llevaron a estos para, en el futuro, evitar cometer los mismos errores.

- En tercer lugar se recomendaría a la Superintendencia de Mercado de Valores (SMV) realizar presentaciones simples en determinados canales de televisión y noticieros que expliquen brevemente los conceptos básicos de las finanzas conductuales y algunos de los sesgos conductuales más representativos. De esta manera se espera generar mayor consciencia entre los inversionistas acerca de los peligros de estos y el daño que pueden generar a su rentabilidad. También se podrían colgar presentaciones específicas que expliquen, mediante ejemplos simples, en qué consisten dichos sesgos, como identificarlos y evitarlos. 
- El autor Michael Pompian en su libro Behavioral Finance and Wealth Management presenta de manera práctica y didáctica métodos concretos que utilizan las finanzas conductuales para identificar los sesgos en el comportamiento de inversionistas y mitigarlos bajo los principios de moderación y adaptación, también incluye pruebas de personalidad que permiten catalogar a los diferentes inversionistas de acuerdo a las características que presentan y brinda estrategias para construir portafolios eficientes que mitiguen los sesgos conductuales. Finalmente, la última recomendación sería diseñar y dictar cursos similares al propuesto anteriormente, en entidades como la SMV o Universidades e Institutos, estos cursos estarían dirigidos principalmente a traders y brokers.

Estas medidas serían una manera efectiva y práctica de disminuir la presencia de sesgos conductuales en los inversionistas promedio y permitiría disminuir las anomalías de mercado en el comportamiento de la bolsa de valores de Lima. Por otro lado, estas medidas aumentarían incrementar la rentabilidad de brokers, traders e inversionistas mejorando sus retornos.

Se resalta que los resultados obtenidos por la presente investigación aún son válidos a pesar del tiempo transcurrido desde la aplicación de la encuetas porque ni la formación de los inversionistas ni las condiciones del mercado han cambiado radicalmente desde entonces. 


\section{REFERENCIAS}

Aldas Manzano, J. y Uriel Jimenez, E. (2005). Análisis Multivariante Aplicado. Madrid: International Thomson Editores. Recuperado de: http://dspace.ucbscz.edu.bo/dspace/bitstream/123456789/4268/1/4542.pdf

Barber, B. M. y Odean, T. (Febraury de 2001). Boys will be Boys: Gender, Overconfidence and Common Stock Investment. The Quarterly Journal of Economics, págs. 261-292. Recuperado en: https://faculty.haas.berkeley.edu/odean/papers/gender/boyswillbeboys.pdf

Barberis, N. y Thaler, R. (2003). A Survey of Behavioral Finance. Handbook of the Economics of Finance. Elsevier Science. Recuperado de: http://faculty.som.yale.edu/nicholasbarberis/ch18_6.pdf

Behavioral Finance: A new sunrise or a false dawn? (2000). Limerick: University of Limerick. Recuperado de: https://wenku.baidu.com/view/03d9b56baf1ffc4ffe47ace7.html

Belsky, G. y Gilovich, T. (1999). Behavioural Finance. Recuperado de: http://introduction.behaviouralfinance.net/.

Bernstein, P. L. (1998). Against the Gods. Recuperado de: https://www.wiley.com/enus/Against+the+Gods\%3A+The+Remarkable+Story+of+Risk-p9780471295631

Cano, C. y Cardoso, E. (2015). El Impacto de los sesgos conductuales en la toma de decisiones de inversión. Revista Moneda - 162. Recuperado de http://www.bcrp.gob.pe/docs/Publicaciones/Revista-Moneda/moneda162/moneda-162-07.pdf

Capital Market Seasonality: The case of stock returns. (1976). Journal of Financial Economics. Recuperado de: https://www.sciencedirect.com/science/article/pii/0304405X76900283 
De la Fuente F., S. (2011). Análisis Discriminante. Madrid: Universidad Autonoma de Madrid. Recuperado de:

http://www.fuenterrebollo.com/Economicas/ECONOMETRIA/SEGMENTACI ON/DISCRIMINANTE/analisis-discriminante.pdf

De la Garza García, J., Morales Serrano, B. y Gonzáles Cavazos, B. ( 2013). Análisis Estadístico Multivariante: Un enfoque teórico y práctico. México DF: McGrawHill/Interamericana Editores. Recuperado de: https://industrial.utp.edu.co/maestrias/investigacion-operativa/libros-dereferencia/analisis-estadistico-multivariante-un-enfoque-teorico-y-practico.pdf

Fama, E. (1965). Random Walks in Stock Market Prices. Financial Analysts Journal 21. 55 - 59. Recuperado de: https://www.chicagobooth.edu/ /media/34F68FFD9CC04EF1A76901F6C61C0 A76.PDF

From Efficient Markets Theory to Behavioral Finance. (2002). Journal of Economic Perspectives 17. Recuperado de: https://www.aeaweb.org/articles?id=10.1257/089533003321164967

Goffman, E. (1974). Frame Analysis: An essay on the organization of experience. Recuperado de: https://books.google.com.pe/books/about/Frame_analysis.html?id=7oRqAAAA MAAJ\&redir_esc $=\mathrm{y}$

Graham, B. (1949). The Intelligent Investor. Estados Unidos: Harper \& Brothers. Recuperado de: https://www.goodreads.com/book/show/106835.The_Intelligent_Investor

Herd Behavior and Investment. (Junio de 1990). The American Economy Review, págs. 465-479. Recuperado de: https://scholar.harvard.edu/stein/publications/herdbehavior-and-investment

Kahneman, D. y Tversky, A. (1972). Subjective Probability: A judgment of Representativeness. Cognitive Psychology 3, págs. 430 - 454. Recuperado de: https://link.springer.com/chapter/10.1007/978-94-010-2288-0_3 
Kahneman, D. y Tversky, A. (1973). On the psychology of prediction. Psychological Review 80, págs. 237 - 251. Recuperado de:

http://citeseerx.ist.psu.edu/viewdoc/download?doi=10.1.1.395.3759\&rep=rep1\& type $=$ pdf

Kahneman, D. y Tversky, A. (1979). Prospect Theory: An Analysis of Decision under Risk. Econometrica 47, págs. 263 - 291. Recuperado de: http://www.its.caltech.edu/ camerer/Ec101/ProspectTheory.pdf

Krueger, L. W. y Lawrence, N. (2006). Social Work Research Methods. Pearson. Recuperado de: https://www.pearson.com/us/highereducation/program/Kreuger-Social-Work-Research-Methods-with-ResearchNavigator/PGM180802.html

Liao, D. y Valliant, R. (Junio de 2012). Variance inflation factors in the analyisis of complex survey data. Component of Statistics Canada, págs. 53-60. Recuperado de:

https://pdfs.semanticscholar.org/172a/462f01ab8947d7f5621468e35f64d299819 9.pdf

Nofsinger. (2002). Psychological Biases of Investors. Washigton: Washington State University. Recuperado de: https://www.researchgate.net/publication/230720757_Psychological_Biases_of_ Investors

Odean, T. (Octubre del 1998). Are Investors Reluctant to Realize Their Losses?. Journal of Finance Vol. 53 No. 5, págs. 1775-1798. Recuperado de: https://faculty.haas.berkeley.edu/odean/papers\%20current\%20versions/areinvest orsreluctant.pdf

Odean, T. (December de 1998). Volume, Volatility, Price and Profit When All Traders Are Above Average. The Journal of Finance, págs. 1887-1932. Recuperado de: http://faculty.haas.berkeley.edu/odean/papers\%20current\%20versions/vvpp.pdf

Pérez L, C. (2005). Métodos Estadísticos Avanzados con SPSS. Madrid: International Thomson Editores. Recuperado de: https://www.researchgate.net/publication/44727354_Metodos_estadisticos_avan zados_con_SPSS_Cesar_Perez_Lopez 
Pompian, M. M. (2006). Behavioral Finance and Wealth Management: How to build Optimal Portfolios That Account for Investors Biases. New Jersey: John Wileys \& Sons, Inc. Recuperado de: https://epdf.tips/behavioral-finance-and-wealthmanagement-how-to-build-optimal-portfolios-that-ac.html

Ramirez, D. (2007). Heterocedasticidad. Universidad de Los Andes Venezuela. Recuperado de http://webdelprofesor.ula.ve/economia/dramirez/

Schindler, M. (2007). Rumors in Financial Markets: Insights into Behavioral Finance. West Sussex: John Wiley \& Sons Ltd. Recuperado de: https://books.google.com.pe/books?hl=es\&lr=\&id=f9c455Ucx1AC\&oi=fnd\&pg $=$ PR5\&dq=Rumors+in+Financial+Markets:+Insights+into+Behavioral+Finance \&ots=ezek74Tkzm\&sig=Tgcz6kW8XiQSz6Ni2cqwqGHgYt0\#v=onepage \&q= Rumors\%20in\%20Financial\%20Markets\%3A\%20Insights\%20into\%20Behavio ral\%20Finance $\& \mathrm{f}=$ false

Shefrin, H. (2000). Beyond Greed and Fear: Understanding Behavioral Finance and the Psychology of Investing. New York: Oxford University Press. Recuperado de:

https://books.google.com.pe/books?hl=es\&lr=\&id=hX18tBx3VPsC\&oi=fnd\&p $\mathrm{g}=$ PR9\&dq=Beyond+Greed+and+Fear:+Understanding+Behavioral+Finance $+\mathrm{a}$

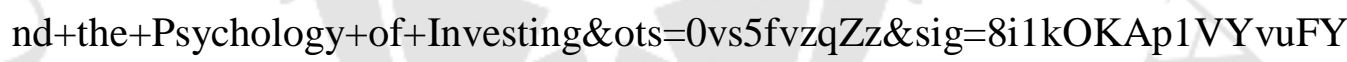
Wo79iFTgvmyU\#v=onepage $\& \mathrm{q}=$ Beyond $\% 20 \mathrm{Greed} \% 20 \mathrm{and} \% 20 \mathrm{Fear} \% 3 \mathrm{~A} \% 20$ Understanding\%20Behavioral\%20Finance\%20and\%20the\%20Psychology\%20o $\mathrm{f} \%$ 20Investing \& $\mathrm{f}=$ false

Shleifer, A. (2000). Finance, Inefficient Markets: An introduction to Behavioral. Oxford University Press. New York. Recuperado de: https://books.google.com.pe/books?hl=es\&lr=\&id=vIP4yluYoIC\&oi=fnd\&pg=PA1808\&dq=Finance, + Inefficient+Markets:+An+introdu ction+to+Behavioral\&ots=P3z1DG9sOm\&sig=yXgoManqigG1kiHEh_i4zGIxG

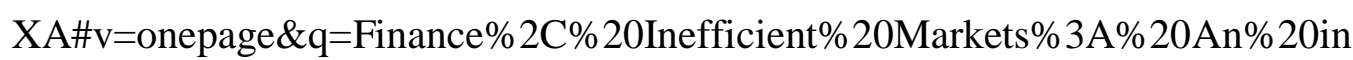
troduction $\% 20$ to $\% 20$ Behavioral $\& \mathrm{f}=$ false

Smith, A. (1759). The Theory of Moral Sentiments. Recuperado de: https://www.earlymoderntexts.com/assets/pdfs/smith1759.pdf 
Subash, R. (2012). Role of Behavioral Finance in Portfolio Investment Decisions: Evidence from India. Prague: Charles University in Prague. Recuperado de: ies.fsv.cuni.cz/default/file/download/id/20803

Subrahmanyam, A. (2007). Behavioral Finance: A Review and Synthesis. European Financial Management 14. Recuperado de: https://www.researchgate.net/publication/46538186_Behavioural_Finance_A_R eview_and_Synthesis

Thaler, R. (1988). Anomalies: The Winner's Curse. Journal of Economic Perspectives. Recuperado de: https://faculty.chicagobooth.edu/richard.thaler/research/pdf/the\%20winner\%27s $\% 20$ curse.pdf

Thaler, R. (2005). Advances in Behavioral Finance, Volume II . Princeton: Princeton University Press. Recuperado de: https://books.google.com.pe/books?hl=es\&lr=\&id=xAE2zfB12BcC\&oi=fnd\&p $\mathrm{g}=\mathrm{PP} 1 \& \mathrm{dq}=$ Advances+in+Behavioral+Finance $\&$ ots=jeTOqbAy9Y\&sig=jZGQ EUBVhR2ALiYst3$\mathrm{yWNI} 25 \mathrm{Yg} \# \mathrm{v}=$ onepage $\& \mathrm{q}=$ Advances $\% 20 \mathrm{in} \% 20 \mathrm{Behaviora} \% 20$ Finance $\& \mathrm{f}=\mathrm{fal}$ se

Thaler, R. H. (December de 1999). Mental Accounting Matters. Journal of Behavioral Decision Making, págs. 183-206. Recuperado de: https://faculty.chicagobooth.edu/richard.thaler/research/pdf/mentalaccounting.p df

Thaler, R. H. (2017). From Cashews to Nudges: The Evolution of Behavioral Economics. Prize Lecture: From Cashews to Nudges: The Evolution of Behavioral Economics. Estocolmo. Recuperado de: https://pubs.aeaweb.org/doi/pdf/10.1257/aer.108.6.1265

Thaler, R. H. y Sunstein, C. R. (2008). Nudge: Improving decisions about health, wealth and happiness. (pág. 283). New haven: Yale University Press. Recuperado de: file://C:/Users/Marin\%20Rodriguez/Downloads/Richard_H._Thaler_Cass_R._ Sunstein_Nudge_Improv..pdf 
Tversky, A. y Kahneman, D. (September de 1974). Judgment under Uncertainty:

Heuristics and Biases. Science, New Series, Vol. 185, No. 4157, págs. 1124-

1131. Recuperado de:

http://psiexp.ss.uci.edu/research/teaching/Tversky_Kahneman_1974.pdf

Tversky, A., y Kahneman, D. (1981). The Framing of Decisions and the Psychology of Choice. Science 211(4481), págs. 453 - 458. Recuperado de:

https://www.uzh.ch/cmsssl/suz/dam/jcr:ffffffff-fad3-547b-ffff-

ffffe54d58af/10.18_kahneman_tversky_81.pdf

Universidad Carlos III de Madrid. (2006). Análisis Multivariante. Madrid: Universidad Carlos III de Madrid. Recuperado de:

http://www.tsc.uc3m.es/ smunoz/Tesis/tesis_smunoz.pdf

Weber, M., y Camerer, C. (1998). Disposition Effect in Securities Trading: an

Experimental Analysis. Journal of Economic Behavior \& Organization, págs.

167-184. Recuperado de:

http://citeseerx.ist.psu.edu/viewdoc/download?doi=10.1.1.594.438\&rep=rep1\&t ype $=$ pdf 


\section{BIBLIOGRAFÍA}

Aldas Manzano, J. y Uriel Jimenez, E. (2005). Análisis Multivariante Aplicado. Madrid: International Thomson Editores. Recuperado de: http://dspace.ucbscz.edu.bo/dspace/bitstream/123456789/4268/1/4542.pdf

Barber, B. M. y Odean, T. (Febraury de 2001). Boys will be Boys: Gender, Overconfidence and Common Stock Investment. The Quarterly Journal of Economics, págs. 261-292. Recuperado en: https://faculty.haas.berkeley.edu/odean/papers/gender/boyswillbeboys.pdf

Barberis, N. y Thaler, R. (2003). A Survey of Behavioral Finance. Handbook of the Economics of Finance. Elsevier Science. Recuperado de: http://faculty.som.yale.edu/nicholasbarberis/ch18_6.pdf

Behavioral Finance: A new sunrise or a false dawn? (2000). Limerick: University of Limerick. Recuperado de: https://wenku.baidu.com/view/03d9b56baf1ffc4ffe47ace7.html

Belsky, G. y Gilovich, T. (1999). Behavioural Finance. Recuperado de: http://introduction.behaviouralfinance.net/.

Bernstein, P. L. (1998). Against the Gods. Recuperado de: https://www.wiley.com/enus/Against+the+Gods\%3A+The+Remarkable+Story+of+Risk-p9780471295631

Cano, C. y Cardoso, E. (2015). El Impacto de los sesgos conductuales en la toma de decisiones de inversión. Revista Moneda - 162. Recuperado de http://www.bcrp.gob.pe/docs/Publicaciones/Revista-Moneda/moneda162/moneda-162-07.pdf

Capital Market Seasonality: The case of stock returns. (1976). Journal of Financial Economics. Recuperado de: https://www.sciencedirect.com/science/article/pii/0304405X76900283 
De la Fuente F., S. (2011). Análisis Discriminante. Madrid: Universidad Autonoma de Madrid. Recuperado de:

http://www.fuenterrebollo.com/Economicas/ECONOMETRIA/SEGMENTACI ON/DISCRIMINANTE/analisis-discriminante.pdf

De la Garza García, J., Morales Serrano, B. y Gonzáles Cavazos, B. ( 2013). Análisis Estadístico Multivariante: Un enfoque teórico y práctico. México DF: McGrawHill/Interamericana Editores. Recuperado de: https://industrial.utp.edu.co/maestrias/investigacion-operativa/libros-dereferencia/analisis-estadistico-multivariante-un-enfoque-teorico-y-practico.pdf

Fama, E. (1965). Random Walks in Stock Market Prices. Financial Analysts Journal 21. 55 - 59. Recuperado de: https://www.chicagobooth.edu/ /media/34F68FFD9CC04EF1A76901F6C61C0 A76.PDF

From Efficient Markets Theory to Behavioral Finance. (2002). Journal of Economic Perspectives 17. Recuperado de: https://www.aeaweb.org/articles?id=10.1257/089533003321164967

Goffman, E. (1974). Frame Analysis: An essay on the organization of experience. Recuperado de: https://books.google.com.pe/books/about/Frame_analysis.html?id=7oRqAAAA MAAJ\&redir_esc $=\mathrm{y}$

Graham, B. (1949). The Intelligent Investor. Estados Unidos: Harper \& Brothers. Recuperado de: https://www.goodreads.com/book/show/106835.The_Intelligent_Investor

Herd Behavior and Investment. (Junio de 1990). The American Economy Review, págs. 465-479. Recuperado de: https://scholar.harvard.edu/stein/publications/herdbehavior-and-investment

Kahneman, D. y Tversky, A. (1972). Subjective Probability: A judgment of Representativeness. Cognitive Psychology 3, págs. 430 - 454. Recuperado de: https://link.springer.com/chapter/10.1007/978-94-010-2288-0_3 
Kahneman, D. y Tversky, A. (1973). On the psychology of prediction. Psychological Review 80, págs. 237 - 251. Recuperado de:

http://citeseerx.ist.psu.edu/viewdoc/download?doi=10.1.1.395.3759\&rep=rep1\& type $=$ pdf

Kahneman, D. y Tversky, A. (1979). Prospect Theory: An Analysis of Decision under Risk. Econometrica 47, págs. 263 - 291. Recuperado de: http://www.its.caltech.edu/ camerer/Ec101/ProspectTheory.pdf

Krueger, L. W. y Lawrence, N. (2006). Social Work Research Methods. Pearson. Recuperado de: https://www.pearson.com/us/highereducation/program/Kreuger-Social-Work-Research-Methods-with-ResearchNavigator/PGM180802.html

Liao, D. y Valliant, R. (Junio de 2012). Variance inflation factors in the analyisis of complex survey data. Component of Statistics Canada, págs. 53-60. Recuperado de:

https://pdfs.semanticscholar.org/172a/462f01ab8947d7f5621468e35f64d299819 9.pdf

Nofsinger. (2002). Psychological Biases of Investors. Washigton: Washington State University. Recuperado de: https://www.researchgate.net/publication/230720757_Psychological_Biases_of_ Investors

Odean, T. (Octubre del 1998). Are Investors Reluctant to Realize Their Losses?. Journal of Finance Vol. 53 No. 5, págs. 1775-1798. Recuperado de: https://faculty.haas.berkeley.edu/odean/papers\%20current\%20versions/areinvest orsreluctant.pdf

Odean, T. (December de 1998). Volume, Volatility, Price and Profit When All Traders Are Above Average. The Journal of Finance, págs. 1887-1932. Recuperado de: http://faculty.haas.berkeley.edu/odean/papers\%20current\%20versions/vvpp.pdf

Pérez L, C. (2005). Métodos Estadísticos Avanzados con SPSS. Madrid: International Thomson Editores. Recuperado de: https://www.researchgate.net/publication/44727354_Metodos_estadisticos_avan zados_con_SPSS_Cesar_Perez_Lopez 
Pompian, M. M. (2006). Behavioral Finance and Wealth Management: How to build Optimal Portfolios That Account for Investors Biases. New Jersey: John Wileys \& Sons, Inc. Recuperado de: https://epdf.tips/behavioral-finance-and-wealthmanagement-how-to-build-optimal-portfolios-that-ac.html

Ramirez, D. (2007). Heterocedasticidad. Universidad de Los Andes Venezuela. Recuperado de http://webdelprofesor.ula.ve/economia/dramirez/

Schindler, M. (2007). Rumors in Financial Markets: Insights into Behavioral Finance. West Sussex: John Wiley \& Sons Ltd. Recuperado de: https://books.google.com.pe/books?hl=es\&lr=\&id=f9c455Ucx1AC\&oi=fnd\&pg $=$ PR5\&dq=Rumors+in+Financial+Markets:+Insights+into+Behavioral+Finance \&ots=ezek74Tkzm\&sig=Tgcz6kW8XiQSz6Ni2cqwqGHgYt0\#v=onepage \&q= Rumors\%20in\%20Financial\%20Markets\%3A\%20Insights\%20into\%20Behavio ral\%20Finance $\& \mathrm{f}=$ false

Shefrin, H. (2000). Beyond Greed and Fear: Understanding Behavioral Finance and the Psychology of Investing. New York: Oxford University Press. Recuperado de:

https://books.google.com.pe/books?hl=es\&lr=\&id=hX18tBx3VPsC\&oi=fnd\&p $\mathrm{g}=\mathrm{PR} 9 \& \mathrm{dq}=$ Beyond+Greed+and+Fear:+Understanding+Behavioral+Finance $+\mathrm{a}$

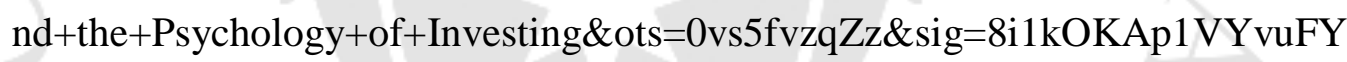
Wo79iFTgvmyU\#v=onepage \&q=Beyond\%20Greed $\% 20$ and $\% 20$ Fear\%3A $\% 20$ Understanding\%20Behavioral\%20Finance\%20and\%20the\%20Psychology\%20o $\mathrm{f} \%$ 20Investing \& $\mathrm{f}=$ false

Shleifer, A. (2000). Finance, Inefficient Markets: An introduction to Behavioral. Oxford University Press. New York. Recuperado de: https://books.google.com.pe/books?hl=es\&lr=\&id=vIP4yluYoIC\&oi=fnd\&pg=PA1808\&dq=Finance, + Inefficient+Markets:+An+introdu ction+to+Behavioral\&ots=P3z1DG9sOm\&sig=yXgoManqigG1kiHEh_i4zGIxG

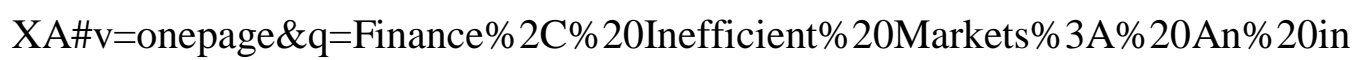
troduction $\% 20$ to $\% 20$ Behavioral $\& \mathrm{f}=$ false

Smith, A. (1759). The Theory of Moral Sentiments. Recuperado de: https://www.earlymoderntexts.com/assets/pdfs/smith1759.pdf 
Subash, R. (2012). Role of Behavioral Finance in Portfolio Investment Decisions: Evidence from India. Prague: Charles University in Prague. Recuperado de: ies.fsv.cuni.cz/default/file/download/id/20803

Subrahmanyam, A. (2007). Behavioral Finance: A Review and Synthesis. European Financial Management 14. Recuperado de: https://www.researchgate.net/publication/46538186_Behavioural_Finance_A_R eview_and_Synthesis

Thaler, R. (1988). Anomalies: The Winner's Curse. Journal of Economic Perspectives. Recuperado de: https://faculty.chicagobooth.edu/richard.thaler/research/pdf/the\%20winner\%27s $\% 20$ curse.pdf

Thaler, R. (2005). Advances in Behavioral Finance, Volume II . Princeton: Princeton University Press. Recuperado de: https://books.google.com.pe/books?hl=es\&lr=\&id=xAE2zfB12BcC\&oi=fnd\&p $\mathrm{g}=\mathrm{PP} 1 \& \mathrm{dq}=$ Advances+in+Behavioral+Finance $\&$ ots=jeTOqbAy9Y\&sig=jZGQ EUBVhR2ALiYst3-

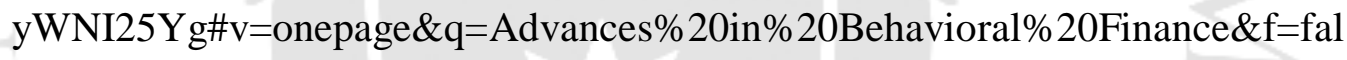
se

Thaler, R. H. (December de 1999). Mental Accounting Matters. Journal of Behavioral Decision Making, págs. 183-206. Recuperado de: https://faculty.chicagobooth.edu/richard.thaler/research/pdf/mentalaccounting.p df

Thaler, R. H. (2017). From Cashews to Nudges: The Evolution of Behavioral Economics. Prize Lecture: From Cashews to Nudges: The Evolution of Behavioral Economics. Estocolmo. Recuperado de: https://pubs.aeaweb.org/doi/pdf/10.1257/aer.108.6.1265

Thaler, R. H. y Sunstein, C. R. (2008). Nudge: Improving decisions about health, wealth and happiness. (pág. 283). New haven: Yale University Press. Recuperado de: file://C:/Users/Marin\%20Rodriguez/Downloads/Richard_H._Thaler_Cass_R._ Sunstein_Nudge_Improv..pdf 
Tversky, A. y Kahneman, D. (September de 1974). Judgment under Uncertainty:

Heuristics and Biases. Science, New Series, Vol. 185, No. 4157, págs. 1124-

1131. Recuperado de:

http://psiexp.ss.uci.edu/research/teaching/Tversky_Kahneman_1974.pdf

Tversky, A., y Kahneman, D. (1981). The Framing of Decisions and the Psychology of Choice. Science 211(4481), págs. 453 - 458. Recuperado de:

https://www.uzh.ch/cmsssl/suz/dam/jcr:ffffffff-fad3-547b-ffff-

ffffe54d58af/10.18_kahneman_tversky_81.pdf

Universidad Carlos III de Madrid. (2006). Análisis Multivariante. Madrid: Universidad Carlos III de Madrid. Recuperado de:

http://www.tsc.uc3m.es/ smunoz/Tesis/tesis_smunoz.pdf

Weber, M., y Camerer, C. (1998). Disposition Effect in Securities Trading: an

Experimental Analysis. Journal of Economic Behavior \& Organization, págs.

167-184. Recuperado de:

http://citeseerx.ist.psu.edu/viewdoc/download?doi=10.1.1.594.438\&rep=rep1\&t ype $=$ pdf 


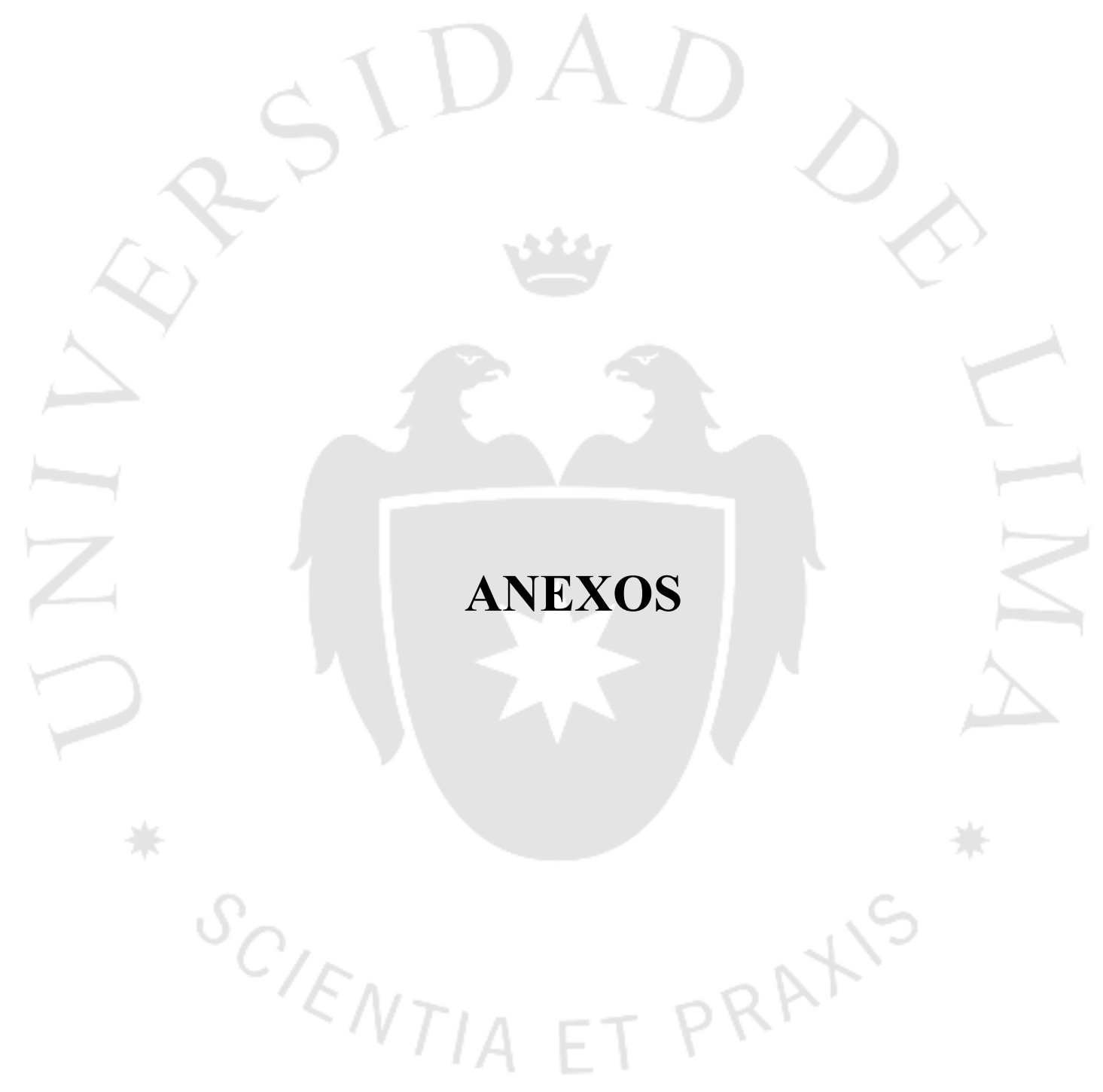




\section{Anexo 1: Encuesta}

¿Cuál es su edad?

Tu respuesta

¿Cuánto tiempo viene realizando operaciones en la bolsa de valores de Lima?

Tu respuesta

¿En cuánta pérdida incurrió su portafolio en el periodo 2013-2014?

$>50 \%$

$30-50 \%$

$10-30 \%$

$<10 \%$

No tuvo pérdidas

Al realizar inversiones, ¿a qué juicio o criterio de análisis usted otorga mayor confianza?

Propio

Broker/Opiniones de Expertos

Amigos/Colegas

¿Usted considera el comportamiento histórico de una acción antes de invertir en ella?

Casi siempre

Algunas veces

Casi nunca 
¿El volumen de transacciones de una acción afecta su decisión de inversión?

Sí

$\bigcirc$ Algunas veces

$\bigcirc$ No

Sus colegas y competidores inician inesperadamente la compra de acciones de una empresa de la que usted tiene poco conocimiento ¿Como afectaría esta actitud hacia su evaluación de las acciones de dicha compañía?

Positivamente

Negativamente

$\bigcirc$ Sin efecto

¿Usted cree que es posible encontrar el valor futuro de una acción a través de un análisis detallado de su evolución histórica?

Casi siempre

Algunas veces

Casi nunca

¿Usted considera que fue posible predecir el colapso de la bolsa de Wall-Street en el inicio de la crisis financiera global del año 2007-2008?

Muy sencillo

Sencillo

Difícil 
¿Como considera usted que sera el desempeño de sus inversiones en comparación al indice de la BVL?
Mejor desempeño
A la par
$\bigcirc$ Peor desempeño

¿Usted considera que es capaz de predecir los precios futuros de las acciones mejor que otros?
Casi siempre
Algunas veces
$\bigcirc$ Casi nunca

En una escala de 1 a 7 (1, bajo riesgo y 7 alto riesgo), ¿Cuál es el nivel de riesgo que usted asume?

\section{Tu respuesta}

¿Usted invertiría en una acción si la evaluación que usted atribuye es diferente a la de algún experto muy conocido cuya evaluación se publicó en una revista de finanzas o en un medio reconocido?

Definitivamente

$\bigcirc$ Tal vez

Nunca 
¿Con que frecuencia sus decisiones de inversión son acertadas?

$>>80 \%$

$50-80 \%$

$\bigcirc<50 \%$

¿Usted realiza órdenes de compra/venta con un precio objetivo antes de que abra la bolsa?

$\bigcirc$ si

No

Algunas veces

En caso de haber elegido sí en la pregunta anterior, ¿cuál de los siguientes criterios usted consideraría para fijar el precio objetivo?

El Max/Min de las últimas 52 semanas

Price/Earnings Ratio (PER)

Precio promedio en el pasado reciente

Precio de emisión

Consejo del broker

Precio de análisis fundamental

Otros

¿Usted utiliza "stop loss" en sus intercambios?

Casi siempre

$\bigcirc$ Algunas veces

$\bigcirc$ Casi nunca 
Entre el PER y el valor intrínseco de una acción, ¿cuál de los dos tiene mayor peso en su decisión de inversión?

PER Ratio

Valor intrínseco

Igual Peso

¿Como reaccionó al periodo de caída de la bolsa peruana entre 2013 y $2015 ?$

Venta de acciones

Compra de acciones a menores precios

Mantener sus acciones

Considere la siguiente situación: El precio de una acción Blue Chip es S/ 500. Este cae a S/ 100 como resultado de una crisis. Los analistas son neutrales y dan señales para mantener la acción. ¿Usted compraría la acción a su nuevo precio (S/100), considerando el alto precio en su pasado cercano?

sí

Es posible

$\bigcirc$ No

¿Usted considera que su subconsciente trata de justificar errores cometidos al realizar decisiones de inversión?

Sí

Algunas veces

$\bigcirc$ No 
Si escuchara la opinión de un famoso analista y esta entra en contradicción con su opinión acerca de una acción, ¿cambiaría su opinión inmediatamente?

sí

Algunas veces

No

¿Qué haría usted si es criticado por invertir en una acción que esta "a la baja" o por vender una acción que se encuentra "en alza"?

Justificar la decisión

Decepcionarse

Reconsiderar la decisión

¿Usted ha mantenido una acción "a la baja" por mucho tiempo esperando un repunte, o ha vendido una acción "en alza" y luego ha sentido que pudo haber esperado un mayor aumento?

Casi siempre

Algunas veces

Casi nunca

¿En algún momento usted no realizó una decisión de inversión debido a que se encontraba esperando nueva información (favorable) concerniente a dicha acción?

Casi siempre

Algunas veces

Casi nunca 
¿Usted es capaz de anticipar el cambio entre buenos y malos retornos de mercado?

Casi siempre

Algunas veces

Casi nunca

Suponga que se lanza una moneda tres veces, y cada vez cae en "Sello". ¿Que pensaría usted del resultado del siguiente lanzamiento de la moneda?

Cara

Sello

Sin preferencia

¿Usted ahorra parte de sus ingresos personales para invertir en la bolsa de valores?

$\bigcirc$ si

Algunas veces

No

Si usted gana una lotería de S/ 10.000.000 (10 Millones), ¿en qué tipo de acciones consideraría invertir?

Precio mayor o igual a $S / 100$

Precio entre $S / 50$ y $S / 99$

Precio menor o igual a $\mathrm{S} / 50$ 
Si usted estuviera entre el 2006 y el 2007, y alguien le dijera que una crisis financiera estaba apunto de explotar en los siguientes años, ¿Usted quedaría convencido? ¿En que rango?
1
2
3
4
5
No
convencido

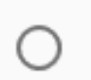
O
O
$\bigcirc$
$\bigcirc \quad \begin{gathered}\text { Muy } \\ \text { convencido }\end{gathered}$

En una escala del 1 al 5 , ¿con cuánto calificaría su conocimiento relativo al nuevo campo de estudios relativo a la toma de decisiones financieras llamado "Behavioral Finance" o "Finanzas Conductuales"?

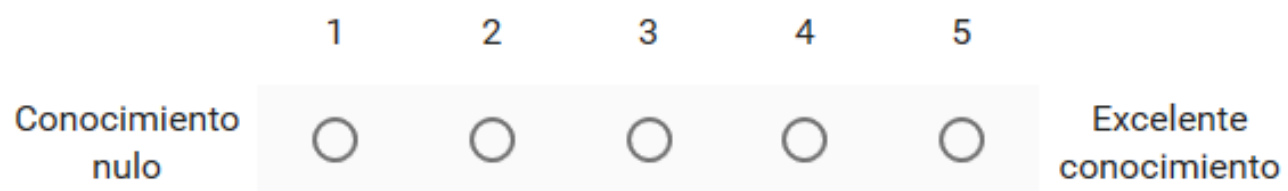

Alguna sugerencia (en caso de tenerla)

\section{Tu respuesta}

